\title{
Characterization of the effects of estrogen on the murine heart under pathophysiologic conditions
}

Citation for published version (APA):

Babiker, F. A. (2004). Characterization of the effects of estrogen on the murine heart under pathophysiologic conditions. [Doctoral Thesis, Maastricht University]. Universiteit Maastricht. https://doi.org/10.26481/dis.20041125fb

Document status and date:

Published: 01/01/2004

DOI:

$10.26481 /$ dis.20041125fb

Document Version:

Publisher's PDF, also known as Version of record

\section{Please check the document version of this publication:}

- A submitted manuscript is the version of the article upon submission and before peer-review. There can be important differences between the submitted version and the official published version of record.

People interested in the research are advised to contact the author for the final version of the publication, or visit the DOI to the publisher's website.

- The final author version and the galley proof are versions of the publication after peer review.

- The final published version features the final layout of the paper including the volume, issue and page numbers.

Link to publication

\footnotetext{
General rights rights.

- You may freely distribute the URL identifying the publication in the public portal. please follow below link for the End User Agreement:

www.umlib.nl/taverne-license

Take down policy

If you believe that this document breaches copyright please contact us at:

repository@maastrichtuniversity.nl

providing details and we will investigate your claim.
}

Copyright and moral rights for the publications made accessible in the public portal are retained by the authors and/or other copyright owners and it is a condition of accessing publications that users recognise and abide by the legal requirements associated with these

- Users may download and print one copy of any publication from the public portal for the purpose of private study or research.

- You may not further distribute the material or use it for any profit-making activity or commercial gain

If the publication is distributed under the terms of Article $25 \mathrm{fa}$ of the Dutch Copyright Act, indicated by the "Taverne" license above, 
Characterization of the Effects of Estrogen on the Murine Heart Under Pathophysiologic Conditions 
The studies presented in this thesis were performed at the Department of Cardiology and the Department of Molecular Genetics, Cardiovascular Research Institute Maastricht (CARIM), Maastricht University, The Netherlands.

ISBN 90-9018608-5

Copyright O Fawzi A. Babiker, Maastricht 2004

All rights reserved. No part of this book may be translated or reproduced in any form by photo, photoprint, microfilm or any other means without written permission from the author. 


\section{Characterization of the Effects of Estrogen on the Murine Heart Under Pathophysiologic Conditions}

\section{PROEFSCHRIFT}

ter verkrijging van de graad van doctor aan de Universiteit Maastricht, op gezag van de Rector Magnificus, prof. Mr. G. P. M. F. Mols, volgens het besluit van het College van Decanen, in het openbaar te verdedigen op donderdag 25 november 2004 om 14.00 uur

door

Fawzi Abdalla Babiker

Geboren to Elzaidab, Soedan 


\section{Promotor:}

Prof. Dr. P. A. F. M. Doevendans

(Universiteit Utrecht, voorheen Universiteit Maastricht)

\section{Co-promotor:}

Dr. G. J. J. M. van Eys

\section{Beoordelingscommissie:}

Prof. dr. M. Daemen (voorzitter)

Prof. dr. Y. van de Graaf (Universiteit Utrecht)

Prof. dr. M. Post

Prof. dr. H. Struijker Boudier

Prof. Dr. F. de Jong (Erasmus Universiteit, Rotterdam)

Financial support by the Netherlands Heart Foundation for the publication of this thesis is gratefully acknowledged. The studies performed in this thesis were supported by a grant from Neterlands Heart Foundation (NHS 99-114).

Additional support was granted by RESCAR foundation St Jude Medical BV, Radi Medical Systems BV, Yamanouchi Pharma BV, Pfizer BV, CD Leycom BV, Agfa Gevaert BV, Sanofi Winthrop BV and Servier Nederland BV. 
To my Kids Mohamed and Ahmed 


\section{Contents}

Chapter 1

General introduction

Chapter 2

Estrogenic hormone action in the heart:

regulatory network and function

Chapter 3

Effects of Transverse Aortic Constriction, and Estrogen-treatment on

Cardiac Gene Expression Profiles in Estrogen Receptor Alpha and

Beta Knockout mice

Chapter 4

$17 \beta$-estradiol antagonizes cardiomyocyte hypertrophy by autocrine/paracrine stimulation of a guanylyl cyclase-A receptor - cGMP- dependent protein kinase pathway

Chapter 5

Estrogen Receptor $\beta$ Protects the Murine Heart Against Left Ventricular Hypertrophy

Chapter 6

Estrogen Modulates Infarct Size Through Estrogen Receptor Specific Mechanisms

Chapter 7

General discussion

Estrogen: The protective elements, the specific receptor effects and the down stream pathways

Summary

Samenvatting

Acknowledgements

Curriculum vitae 


\section{Abbreviations}

ACE: $\quad$ Angiotensin converting enzyme.

AF-1: Trans-activation function-1.

AF-2: $\quad$ Trans-activation function-2.

$\alpha$-sk-actin: $\quad$ Alpha-skeleta-actin.

ANF: Atrial natriuretic factor.

Ang: Angiotensin.

BERKO: Estrogen receptor beta Knockout mouse

BMHC: $\quad$ Beta myosin heavy chain.

CAD: $\quad$ Coronary artery disease.

CHD: Coronary heat disease.

Comp: $\quad$ Cartilage oligomeric matrix protein.

Colla2: $\quad$ Procollagen, type I, alpha 2.

Crap: $\quad$ Cardiac responsive adriamycin protein.

cGK: Cyclic GMP dependent protein kinase.

cGMP: $\quad$ Cyclic guanosine monophosphate.

DBD: $\quad$ DNA binding domain.

E2: $\quad 17 \beta$ estradiol.

EGF: $\quad$ Epidermal growth factor

eNOS: $\quad$ Endothelial nitric oxide synthase.

ET-1: Endothelin-1.

Egr: $\quad$ Early growth response factor

ERT: $\quad$ Estrogen replacement therapy.

ER: $\quad$ Estrogen receptors.

ERE: Estrogen response element.

ERK: $\quad$ Extracellular related kinase

ERKO: $\quad$ Estrogen receptor knockout mouse.

ERRs: Estrogen receptor-related receptors.

FBS: $\quad$ Calf bovine serum.

$\mathrm{GH}$ : Growth hormone.

HBD: Hormone binding domain.

HDL: High density lipoprotein cholesterol.

HRT: Hormone replacement therapy.

HSP: Heat shock proteins.

IGF-1: Insulin-like growth factor.

IGF-1R: Insulin-like growth factor receptor.

Int: Initiator of transcription.

iNOS: Inducible nitric oxide synthase.

JNK: $\quad$-jun $\mathrm{N}$-terminal kinase.

LDL: $\quad$ Low density lipoprotein cholesterol.

LVH: $\quad$ Left ventricular hypertrophy.

MAP: $\quad$ Mitogen activated proteins.

MAPK: Mitogen activated protein kinase.

Map3k6: Mitogen-activated protein kinase kinase kinase 6.

MHC: Myosin heavy chain.

MI: Myocardial infarction

MLC2a: $\quad$ Myosin light chain-2a.

MLC-2a: Regulatory myosin light chain. 
NRVMs: Neonatal rat ventricular myocytes.

NP: $\quad$ Natriuretic peptide.

NO: $\quad$ Nitric oxide.

NOS: $\quad$ Nitric oxide synthase.

NR: Nuclear receptor.

PE: Phenylephrin

SHR: Spontaneous hypertensive rat.

SERM: $\quad$ Selective estrogen receptor modulator.

TAC: $\quad$ Transverse aortic construction.

TGF $\beta$ : Transforming growth factor beta.

Tnfrfl2a: Tumor necrosis factor receptor superfamily, member $12 \mathrm{a}$.

Thbs4: Thrombospondin.

vWF homolog:Von Willebrand factor homolog 


\section{1}

General Introduction 


\section{General Introduction}

\section{Estrogens and estrogen receptors in the murine heart}

\section{Introduction:}

Estrogens are steroid hormones known to influence growth, differentiation, and function of target tissues from birth to adulthood. Target tissues include the female and male reproductive systems such as mammary glands, uterus, vagina, ovaries, testes, epididymis and prostate. ${ }^{1}$ Estrogens also play an important role in bone homeostasis, the central nervous system as well as in the cardiovascular system..$^{1-5}$ In contrast to the well known functions of $17 \beta$-estradiol (E2) (Figure 1.1) in some organs, the possible role of E2 in the cardiovascular system is less understood. Based on epidemiological data, it has been hypothesized that E2 inhibits development of cardiovascular disease in females. Recently however large clinical trials using hormone replacement therapy including E2-supplementation were stopped because the negative effects override the beneficial effects of E2 administration in post-menopausal women. ${ }^{6}$

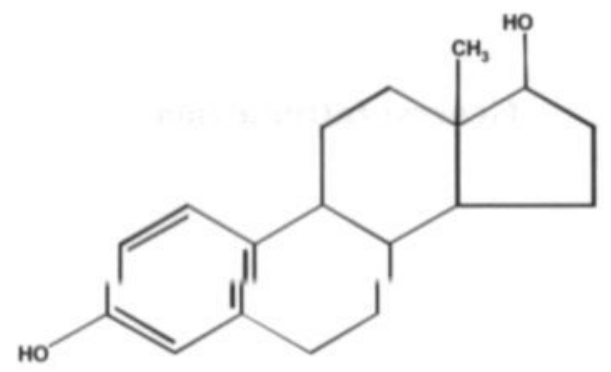

Figure 1.1 Structure of $17 \beta$-estradiol (E2).

In premeopausal females, synthesis of the main physiological estrogen (E2) occurs in the ovaries although there is also E2 synthesis in the peripheral tissues, such as skin and adipose tissue, skeletal muscles, hair follicles and bone tissue. ${ }^{1}$ These peripheral tissues are the main source of E2 in postmenopausal women. In males, estrogens are formed in the testes and in peripheral tissue by the aromatase enzyme, but to a much lower extent compared with pre-menopausal females. ${ }^{1}$

\section{Estrogen synthesis}

The precursor to E2 synthesis is cholesterol, which is derived from animal fat in the diet or from local synthesis. First cholesterol is converted to pregnenolone in the mitochondria by the cholesterol side-chain cleavage enzyme (CYP11A1). All subsequent reactions are microsomal. Pregnenolone is

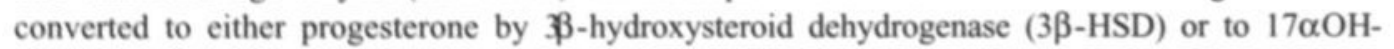
pregnenolone by $17 \alpha$-hydroxylase (CYP17). $17 \alpha \mathrm{OH}$-pregnenolone can be metabolized to $17 \alpha \mathrm{OH}$ progesterone by $\$ 3$-HSD. The 17,20-lyase (CYP17) cleaves the C20,21-side chain and converts $17 \alpha \mathrm{OH}$-progesterone to androstenedione and $17 \alpha \mathrm{OH}$-pregnenolone to dehydroepiandrosterone (DHEA) respectively. Androstenedione can be aromatized to estrone by aromatase (CYP19). In addition androstenedione can be converted by $3 \beta$-HSD to testosterone, which is aromatized to E2 by CYP19 or converted to dihydrotestosterone by 5 á-reductase (Figure 1.2). ${ }^{7.8}$ 


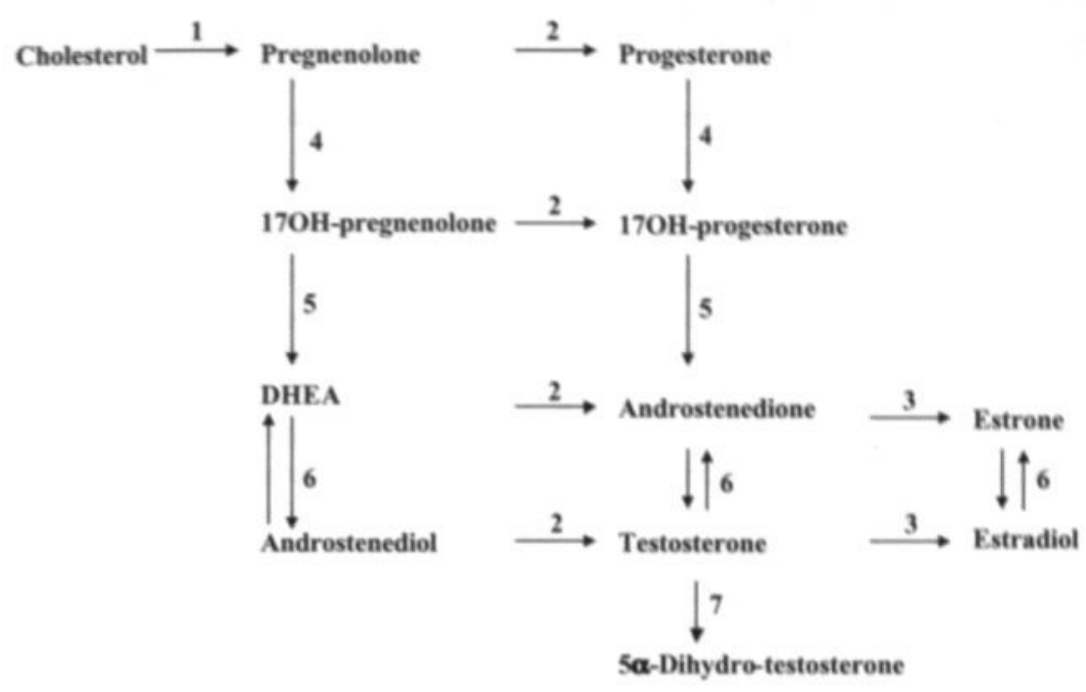

Figure 1.2. Biosynthesis pathway of steroids. Numbers refer to enzymes: (1) p450 side Chain Ceavage en enzyme, (2) 3-hydroxysteroid dehydrogenase, (3) aromatase, (4) $17 \alpha$-hydroxylase, (5) 17, 20-lyase, (6) $17 \beta$-hydroxysteroid dehydrogenase, (7) $5 \alpha$-reductase. Adapted from (Gorelangton and Armstrong ${ }^{7}$ Ojeda, ${ }^{8}$ ).

Levels of free E2 in serum are generally low, since the majority $(70 \%)$ is bound to either albumin or to sex hormone-binding globulin(SHBG). Metabolism of E2 via oxidation or conversion to glucuronide and sulphate conjugates occur predominantly in the liver. Metabolites are excreted to the bile, reabsorbed into the bloodstream and finally excreted via the urine. ${ }^{9}$

\section{Estrogen signaling}

Estrogens diffuse in and out of cells but are retained with high affinity and specificity in target cells by intracellular binding proteins, termed the estrogen receptors (ERs). E2 and other steroid hormones mediate their effects through ligand-activated transcription factors, the nuclear hormone receptors. Common for these receptors is that they regulate transcription upon ligand binding through interaction with specific DNA sequences and by interacting with other transcription factors. ${ }^{10-15}$ Once bound by estrogens, the ER undergoes conformational changes allowing the receptor to interact with chromatin and to modulate transcription of target genes. ${ }^{4,16,17}$

Estrogens have a variety of target tissues both in male and female vertebrates. The effects on these targets can be very different and a single compound can be an agonist in one tissue while being an antagonist in another. Tissue-specificity is thought to mainly result from three processes. (1) Ligands can undergo different metabolism in different tissues, (2) expression of relative amounts of estrogen receptor alpha $(E R \alpha)$ and estrogen receptor beta (ER $\beta$ ) or their co-factors may vary, (3) target gene promoters could vary in accessibility amongst tissues or life stages. ${ }^{18}$ ER $\beta$ has a different tissue distribution than the ER $\alpha$. "Differential binding and activation of ER $\alpha$ and ER $\beta$ by estrogenic compounds ${ }^{19.20}$ may explain some of the observed tissue specific effects. Recently, cell type- and promoter-specific differences in co-factor recruitment were shown to be involved in cellspecific response to selective estrogen receptor modulators (SERMs) in vitro. ${ }^{21}$ Finally additional tissue specificity of E2 signaling can be accomplished via non-classical pathways e.g. through AP-1 responsive elements. ${ }^{19}$ 


\section{Cardiac hypertrophy}

The mammalian heart adapts to increased hemodynamic load such as in case of hypertension, valvular heart disease, and loss of cardiomyocytes, by developing compensatory hypertrophy of the remaining myocardial cells. ${ }^{22,23}$ The molecular response to hypertrophic stimuli of ventricular myocytes is characterized by dedifferentiation. ${ }^{24}$ This dedifferentiation involves re-expression of genes that were transiently expressed during embryonic development. This molecular change could indicate an attempt of cardiomyocytes to return to a stage, in which DNA duplication and mitosis were possible. Major mediators of hypertrophic response are the Endothelin receptor A and $\alpha$ adrenergic receptor and intracellular signaling pathways, which ultimately give rise to selective activation of transcription factors and finally expression of fetal genes like atrial natriuretic factor (ANF). Thus the re-expression of fetal genes is the final outcome of a cascade of molecular events. $23,25,26$

Different receptor-signaling pathways in ventricular cardiomyocytes have been described for sensing hypertrophic stimuli. ${ }^{23}$ For instance, treatment of cultured neonatal rat ventricular myocytes (NRVMs) with phenylephrin (PE) or endothelin-1 (ET-1) results in expression of immediate early genes, the induction of contractile protein synthesis ${ }^{27}$ and the reactivation of a fetal gene program. ${ }^{28 .}$ 94 Endothelin receptor A is the predominant ET-1 receptor isoform found in cardiomyocyte membranes $^{32}$. $\alpha$-Adrenergic receptors have been shown to interact with G-proteins. Mostly, signaling of both growth factors involves activation of the Ras/Raf pathway, but several other routes of intracellular signaling can be used. ${ }^{35}$ In general the signal transduction pathways between the receptor for a hypertrophic stimulus and transcriptional regulation are diverse and highly complex through cross-talk between the pathways involved. ${ }^{36}$

Although there are many similarities in the hypertrophic response induced by different fictors, reports indicate that different fetal gene expression programs exist and the morphologic picture of hypertrophy can vary. For instance, McDonough et al. ${ }^{34}$ showed that during prolonged stimulation with PE, the expression of ANF was maintained for more than 72 hours at a constant level, whereas ET-I gave only a transient rise in ANF levels, Nevertheless treatment with each of these factors results in morphologic signs of cardiomyocyte hypertrophy. Fuller et $\mathrm{af}^{37}$ blocked the re-expression of fetal genes induced by hypertrophic stimuli, by over-expressing mitogen-activated protein kinase phosphatase 1 (MKP1), which is an inactivator of mitogen activated protein kinase and a key protein in the RAS/RAF signaling pathway. ${ }^{35}$ However, this did not result in a significant reduction of morphologic hypertrophy. Thus, although re-expression of fetal genes is a hallmark of hypertrophy, it is not mandatory for hypertrophy.

\section{Myocardial infarction}

Myocardial infarction (MI) is the leading cause of congestive heart failure and death in developed countries. $^{38,39} \mathrm{MI}$ induces scar formation and changes in surviving myocardium, called post-MI ventricular remodeling. Cardiac remodeling is defined by the structural and functional alteration in the heart after an MI event. MI induces architectural remodeling including ventricular dilatation, myocardial hypertrophy, deposition of collagen and apoptosis in the infarcted area. ${ }^{40}$ The early hypertrophy of the viable portion of left ventricular (LV) tissue after ischemic damage is considered an adaptive response to compensate for the acute loss of functional myocardium to preserve cardiac performance. ${ }^{41}$ High rates of cardiomyocyte apoptosis are continuously present in the border zones of the infarct-area and the un-infarcted area over a time period of 12 weeks following MI. ${ }^{42}$ Similar findings have been reported in human studies where the presence of high rates of apoptosis have been observed in hearts of patients dying within 12 to 62 days following acute $\mathrm{Mr}^{43}$

The composition of myocardial tissue will change following injury, the LV contractile function and relaxation pattern adapt. Whether cardiac remodeling is adaptive or maladaptive has been investigated extensively in the animal ${ }^{4-46}$ and man, using imaging techniques such as 
echocardiography ${ }^{47}$, computer tomography ${ }^{48}$, radionuclide ventriculography ${ }^{49}$ and more recently magnetic resonance imaging. ${ }^{50,51}$ Current therapy of $\mathrm{MI}$ in man can improve left ventricular geometry. ${ }^{50}$ Epidemiologic and animal studies have suggested that remodeling of the LV differs between women and men after MI. ${ }^{52}$ In ovarectomized mice E2 replacement therapy reduces infarct size and cardiomyocyte apoptosis. Paradoxically, E2 increased post-MI ventricular remodeling and mortality. ${ }^{53}$ The mechanism of action E2 in post MI remodeling is still unclear.

\section{Aim and Methods}

Cardiac hypertrophy and MI are independent risk factors for cardiovascular morbidity and mortality in men and women. Epidemiological studies indicate that E2 replacement therapy is cardioprotective; the mechanisms involved in this process, however, are poorly understood. We, therefore, studied the effect of E2 on the development of pressure-overload hypertrophy and MI. The first part of the study focused on the in vitro studies to find the important pathways of E2. To further dissect the protective pathways and the role of the ERs in the process we used in vivo studies in murine models. Finally mRNA microarray technology was used to identify the genes involved in the left ventricular remodeling during left ventricular hypertrophy $(\mathrm{LVH})$ in order to unravel the molecular mechanisms underling E2 protective effects.

Until recently E2 replacement therapy was considered to block atherosclerosis. However, recently the large scale E2 supplementation studies have been stopped because of undesired effects on stroke, breast cancer, dath and other possible side effects. Also animal studies have provided variable data. The existence of more ERs may be (in part) responsible for the confusing data. Therefore, we decided to investigate the effects of E2 via ER $\alpha$ and ER $\beta$ respectively on cardiac performance and remodeling. To this end we used two mouse models (ER $\alpha \%$ and ER $\beta \%$ ) in experimental set-up of MI and pressure overload through thoracic aorta constriction (TAC). Changes in the LV wall were analyzed at the morphological and molecular levels by techniques ranging from microscopy to microarrays. Assessment of LV function was performed as previously described. $^{54,55}$

\section{Conclusions}

Chapter 1 and 2 give the background about hypertrophy, where all recent definition and description of myocardial, and LVH were given. A clear account was give about the estrogen and its action on the heart. Description of the pathways of estrogen and its receptor were discussed in an explanatory manner. This chapter also include information about some known cardiac diseases. In chapter 3 we assessed the antagonistic potential of E2 on ventricular cardiomyocyte hypertrophy. In vivo experiment were used to dessect the role of ERs in TAC ( chapter 4) and MI (chapter 5). In chapter 6 we used DNA microarrays to identify the E2 target genes. In the last chapter (Chapter 7) the effects of E2 on ventricular hypertrophy, The pathways of the effects, the relation between E2 and ANF, the role of ERs in the remodeling left ventricle in LVH and MI and E2 target genes expression were discussed. Our hypothesis was that the different ERs had different effects on the myocardium. Dissection of the role of the two receptors may allow us to identify which of the two receptor is required for E2 protection. In this manner it will be easier to concentrate on that receptor and its downstream effectors. Using selective estrogen receptor modulators (SERMS) will enable selecting a suitable agonist which could replace E2 in the treatment of LVH. Some downstream elements could also be used for treatment. 


\section{Acknowledgments}

This work was supported by grants from the Netherlands Heart Foundation (NHS 99-114 and NHS 2000-160) and the Interuniversity Cardiology Institute Netherlands and Wynand Pon foundation to P.A.D., the Netherlands Heart Foundation (D98.015) to M. V. B. and by the Deutsche Forschungsgemeinschaft and BONFOR to $\mathrm{C}$. $\mathrm{G}$ and $\mathrm{M}$ v. E.. Additional support from the RESCAR foundation was greatly appreciated. We thank Organon, Oss, the Netherlands for providing the animals. 


\section{References}

1. Korach KS, Migliaccio S, Davis VL. Estrogens. In principles of pharmacology - Basic concepts and clinical applications. Ed PL Munson. New York: Chapman and Hall. 1994:809-825.

2. Farhat MY, Lavigne MC, Ramwell PW. The vascular protective effects of estrogen. Faseb J. 1996;10:615-24.

3. Turner RT, Riggs BL, Spelsberg TC. Skeletal effects of estrogen. Endocr Rev. 1994;15:275300.

4. Babiker FA, De Windt LJ, van Eickels M, et al. Estrogenic hormone action in the heart: regulatory network and function. Cardiovasc Res. 2002;53:709-19.

5. Babiker FA, De Windt LJ, van Eickels M, et al. 17beta-estradiol antagonizes cardiomyocyte hypertrophy by autocrine/paracrine stimulation of a guanylyl cyclase A receptor-cyclic guanosine monophosphate-dependent protein kinase pathway. Circulation. 2004;109:269. 76.

6. Cockey CD. NHLBI stops estrogen plus progestin trial. AWHONN Lifelines. 2002;6:299307.

7. Gore-Langton RE, Armstrong DT. Follicular Steroidogenesis and Its Control. In The Physiology of Reproduction,. Eds E Knobil \& JD Neil. New York:Raven Press, Ltd. 1994.

8. Ojeda SR. Female reproductive function. In Textbook of Endocrine Physiology,. Eds JE Griffin \& SR Ojeda. New York: Oxford University Press. 1996.

9. Solomon S. The primate placenta as an endocrine organ. In The Physiology of Reproduction,. Eds E Knobil \& JD Neil. New York:Raven Press, Ltd. 1994:863-873.

10. Walter P, Green S, Greene G, et al. Cloning of the human estrogen receptor cDNA. Proc Natl Acad Sci U S A. 1985;82:7889-93.

11. Kuiper GG, Enmark E, Pelto-Huikko M, et al. Cloning of a novel receptor expressed in rat prostate and ovary. Proc Natl Acad Sci US A. 1996;93:5925-30.

12. Kuiper GG, Carlsson B, Grandien K, et al. Comparison of the ligand binding specificity and transcript tissue distribution of estrogen receptors alpha and beta. Endocrinology. 1997; 138:863-70.

13. Shibata H, Spencer TE, Onate SA, et al. Role of co-activators and co-repressors in the mechanism of steroid/thyroid receptor action. Recent Prog Horm Res. 1997;52:141-64; discussion 164-5.

14. Brown M. Estrogen receptor molecular biology. Hematol Oncol Clin North Am. 1994;8:10112.

15. Mendelsohn ME, Karas RH. The protective effects of estrogen on the cardiovascular system. N Engl J Med. 1999;340:1801-11.

16. Jensen TK, Toppari J, Keiding N, et al. Do environmental estrogens contribute to the decline in male reproductive health? Clin Chem. 1995;41:1896-901.

17. Beato M, Herrlich P, Schutz G. Steroid hormone receptors: many actors in search of a plot. Cell. 1995;83:851-7.

18. Katzenellenbogen JA, O'Malley BW, Katzenellenbogen BS. Tripartite steroid hormone receptor pharmacology: interaction with multiple effector sites as a basis for the cell- and promoter-specific action of these hormones. Mol Endocrinol. 1996;10:119-31.

19. Paech K, Webb P, Kuiper GG, et al. Differential ligand activation of estrogen receptors ERalpha and ERbeta at API sites. Science. 1997;277:1508-10.

20. Kuiper GG, Lemmen JG, Carlsson B, et al. Interaction of estrogenic chemicals and phytoestrogens with estrogen receptor beta. Endocrinology. 1998;139:4252-63.

21. Shang Y, Brown M. Molecular determinants for the tissue specificity of SERMs. Science. 2002;295:2465-8. 
22. Grossman W. Cardiac hypertrophy: useful adaptation or pathologic process? Am J Med. 1980;69:576-84.

23. Lembo G, Hunter JJ, Chien KR. Signaling pathways for cardiac growth and hypertrophy. Recent advances and prospects for growth factor therapy. Ann N Y Acad Sci. 1995;752:11527.

24. van Bilsen M, Chien KR. Growth and hypertrophy of the heart: towards an understanding of cardiac specific and inducible gene expression. Cardiovasc Res. 1993;27:1140-9.

25. Wollert KC, Taga T, Saito M, et al. Cardiotrophin-1 activates a distinct form of cardiac muscle cell hypertrophy. Assembly of sarcomeric units in series VIA gp130/leukemia inhibitory factor receptor-dependent pathways. J Biol Chem. 1996;271:9535-45.

26. Neyses L, Vetter H. Molecular biology of oncogenes and cardiovascular hypertrophy. $J$ Hypertens. 1992;10:1447-52.

27. Shubeita HE, McDonough PM, Harris AN, et al. Endothelin induction of inositol phospholipid hydrolysis, sarcomere assembly, and cardiac gene expression in ventricular myocytes. A paracrine mechanism for myocardial cell hypertrophy. J Biol Chem. 1990;265:20555-62.

28. Knowlton KU, Baracchini E, Ross RS, et al. Co-regulation of the atrial natriuretic factor and cardiac myosin light chain-2 genes during alpha-adrenergic stimulation of neonatal rat ventricular cells. Identification of cis sequences within an embryonic and a constitutive contractile protein gene which mediate inducible expression. J Biol Chem. 1991;266:775968.

29. Sei CA, Glembotski CC. Calcium dependence of phenylephrine-, endothelin-, and potassium chloride-stimulated atrial natriuretic factor secretion from long term primary neonatal rat atrial cardiocytes. J Biol Chem. 1990;265:7166-72.

30. Soonpaa MH, Field LJ. Assessment of cardiomyocyte DNA synthesis in normal and injured adult mouse hearts. Am J Physiol. 1997;272:H220-6.

31. Shubeita HE, Martinson EA, Van Bilsen M, et al. Transcriptional activation of the cardiac myosin light chain 2 and atrial natriuretic factor genes by protein kinase $\mathrm{C}$ in neonatal rat ventricular myocytes. Proc Natl Acad Sci U S A. 1992;89:1305-9.

32. Hilar-Dandan R, Merck DT, Lujan JP, et al. Coupling of the type A endothelin receptor to multiple responses in adult rat cardiac myocytes. Mol Pharmacol. 1994;45:1183-90.

33. Brown LA, Nunez DJ, Brookes CI, et al. Selective increase in endothelin-1 and endothelin A receptor subtype in the hypertrophied myocardium of the aorto-venacaval fistula rat. Cardiovasc Res. 1995;29:768-74.

34. McDonough PM, Brown JH, Glembotski CC. Phenylephrine and endothelin differentially stimulate cardiac PI hydrolysis and ANF expression. Am J Physiol. 1993;264:H625-30.

35. Thorburn A, Thorburn J, Chen SY, et al. HRas-dependent pathways can activate morphological and genetic markers of cardiac muscle cell hypertrophy. J Biol Chem. 1993:268:2244-9.

36. van Bilsen M. Signal transduction revisited: recent developments in angiotensin II signaling in the cardiovascular system. Cardiovasc Res. 1997;36:310-22.

37. Fuller SJ, Davies EL, Gillespie-Brown J, et al. Mitogen-activated protein kinase phosphatase 1 inhibits the stimulation of gene expression by hypertrophic agonists in cardiac myocytes. Biochem J. 1997;323 ( Pt 2):313-9.

38. Gheorghiade M, Bonow RO. Chronic heart failure in the United States: a manifestation of coronary artery disease. Circulation. 1998;97:282-9.

39. Cleland JG, Khand A, Clark A. The heart failure epidemic: exactly how big is it? Eur Heart J. 2001:22:623-6. 
40. Pfeffer MA, Braunwald E, Moye LA, et al. Effect of captopril on mortality and morbidity in patients with left ventricular dysfunction after myocardial infarction. Results of the survival and ventricular enlargement trial. The SAVE Investigators. N Engl J Med. 1992;327:669-77.

41. Sadoshima J, Izumo S. The cellular and molecular response of cardiac myocytes to mechanical stress. Annu Rev Physiol. 1997;59:551-71.

42. Palojoki E, Saraste A, Eriksson A, et al. Cardiomyocyte apoptosis and ventricular remodeling after myocardial infarction in rats. Am J Physiol Heart Circ Physiol. 2001;280:H2726-31.

43. Baldi A, Abbate A, Bussani R, et al. Apoptosis and post-infarction left ventricular remodeling. J Mol Cell Cardiol. 2002;34:165-74.

44. Lutgens E, Daemen MJ, de Muinck ED, et al. Chronic myocardial infarction in the mouse: cardiac structural and functional changes. Cardiovasc Res. 1999;41:586-93.

45. Eaton LW, Bulkley BH. Expansion of acute myocardial infarction: its relationship to infaret morphology in a canine model. Circ Res. 1981;49:80-8.

46. Holmes JW, Yamashita H, Waldman LK, et al. Scar remodeling and transmural deformation after infarction in the pig. Circulation. 1994;90:411-20.

47. Eaton LW, Weiss J, Bulkley BH, et al. Regional cardiac dilatation after acute myocardial infarction: recognition by two-dimensional echocardiography. N Engl J Med. 1979;300:5762.

48. Rumberger JA, Behrenbeck T, Breen JR, et al. Nonparallel changes in global left ventricular chamber volume and muscle mass during the first year after transmural myocardial infarction in humans. $J$ Am Coll Cardiol. 1993;21:673-82.

49. Gaudron P, Eilles C, Kugler I, et al. Progressive left ventricular dysfunction and remodeling after myocardial infarction. Potential mechanisms and early predictors. Circulation. 1993;87:755-63.

50. Bellenger NG, Swinburn JM, Rajappan K, et al. Cardiac remodelling in the era of aggressive medical therapy: does it still exist? Int J Cardiol. 2002;83:217-25.

51. Nahrendorf $\mathrm{M}$, Wiesmann $\mathrm{F}$, Hiller $\mathrm{KH}$, et al. In vivo assessment of cardiac remodeling after myocardial infarction in rats by cine-magnetic resonance imaging. $J$ Cardiovasc Magn Reson. 2000;2:171-80.

52. Wu JC, Nasseri BA, Bloch KD, et al. Influence of sex on ventricular remodeling after myocardial infarction in mice. $J$ Am Soc Echocardiogr. 2003;16:1158-62.

53. van Eickels M, Patten RD, Aronovitz MJ, et al. 17-beta-estradiol increases cardiac remodeling and mortality in mice with myocardial infarction. $J \mathrm{Am}$ Coll Cardiol. 2003;41:2084-92.

54. Lips DJ, van der Nagel T, De Windt LJ. Left ventricular pressure-volume measurements in mice: closed-chest versus open-chest. Basic Res Cardiol (in press). 2004.

55. Lips DJ, Bueno OF, Wilkins BJ, et al. MEK1-ERK2 signaling pathway protects myocardium from ischemic injury in vivo. Circulation. 2004;109:1938-41. 


\section{2}

Estrogenic hormone action in the heart: regulatory network and function

Fawzi A. Babiker, Leon J. De Windt, Martin van Eickels, Christian Grohe, Rainer Meyer, Pieter A. Doevendans

PUBLISHED IN CARDIOVASCULAR RESEARCH 2002, VOLUME 53, ISSUE 3, PAGES 709-719 


\begin{abstract}
Cardiovascular diseases are the leading cause of death in the industrialised countries and display significant gender based differences. Estrogen plays an important role in the pathogenesis of heart disease and is able to modulate the progression of cardiovascular disease. The focus on the beneficial influence of estrogen is gradually shifting from the vascular system to the myocardium. The presence of functional estrogen receptors in the myocardium has been demonstrated. Estrogen is important for cardiovascular baseline physiology and modulates the myocardial response under pathologic conditions. Here we summarise the current knowledge of the regulatory network of estrogenic action in the myocardium and its effects on cardiovascular function.
\end{abstract}

\title{
Introduction
}

There are significant gender-based differences in the incidence of a wide variety of cardiovascular diseases $^{1,2}$, like left ventricular hypertrophy $(\mathrm{LVH})$ or coronary artery disease (CAD) and subsequent cardiac remodeling after myocardial infarction (MI). ${ }^{3,4}$ Premenopausal women have a lower prevelance of $\mathrm{LVH}$ than their age-matched male counterparts. ${ }^{3}$ For many years this was attributed largely to differences between men and women in body size and risk factor profiles. Careful analysis of the Framingham Heart Study data, however, has shown that left ventricular mass is significantly greater in men than in women even after indexing for body surface area. ${ }^{5}$. The results of several recent studies demonstrating clinically relevant gender-based differences in the pathophysiology of hypertensive heart disease have raised new questions regarding the mechanisms responsible for the observed differences. The Coronary Artery Risk Development In young Adults (CARDIA) study demonstrated that the higher prevalence of LVH in men remains even after correction for a large number of risk factors and further demonstrated that these differences in left ventricular mass (or wall thickness) begin early in life. These studies suggest that gender-related intrinsic factors may modulate the response to pathophysiological factors that lead to $\mathrm{LVH}{ }^{6}$

In retrospective studies, cardiovascular mortality in postmenopausal women receiving estrogen replacement therapy ( $E R T$ ), with estrogen alone or in combination with progesterone, appears to be lower than in untreated women. ${ }^{7}$ From this perspective, it appears that the hormone $17 \beta$-estradiol (E2) might play an important role in the prevention of heart disease by lowering low-density lipoprotein cholesterol (LDL), increasing plasma levels of high density lipoprotein cholesterol (HDL), promoting coronary vasodilatation, improving glucose metabolism and decreasing serum insulin levels. However, the effects of ERT on the risk factor profile only account for about $50 \%$ of the reduction in cardiovascular disease, indicating that there must exist additional mechanisms whereby estrogen exerts its cardioprotective action.

The therapeutic application of estrogen in heart disease is hampered by the fact that its fundamental myocardial actions are still poorly understood. ${ }^{6,8,9}$ Estrogens increase vasodilation and inhibit the response of blood vessels to injury. ${ }^{4}$ Estrogen induced vasodilatation occurs $5-20$ minutes after administration and is not dependent on changes in gene expression: this action of estrogen is referred to as "nongenomic". The estrogen-induced inhibition of the response to vascular injury and the preventive effect of estrogen against atherosclerosis occur over a period of hours or days after initiation of estrogen treatment and are dependent on tissue specific transcriptional regulation. These actions are referred to as "genomic". 00 The pleiotropic, cellular actions of estrogen mainly result from binding of the hormone to intra-cellular estrogen receptors (ERs). ${ }^{11}$ Despite recent advances in our understanding of the vascular effects of estrogen, the mechanisms through which estrogen modulates cardiac (patho)physiology ${ }^{12}$ are still poorly understood. The scope of the present review, therefore, is to summarize the recent insights on the nongenomic and genomic action of estrogen in the heart. 


\section{Molecular mechanisms of estrogens}

\section{Estrogen Receptors}

The main pathway of estrogen-mediated gene transcription is through the binding of estrogen (the ligand) to the ERs. ${ }^{10,13,14}$ Two ER isoforms have been identified to date: ER $\alpha$ and ER $\beta .{ }^{15,16} \mathrm{ER} \alpha$ contains 595 amino acids, while ER $\beta$ is shorter than ER $\alpha$, containing 530 amino acids. ${ }^{17}$ Both ER $\alpha$ as well as ER $\beta$ belong to the nuclear receptor (NR) gene family of transcription factors. At the molecular level, NR structure can be subdivided into six distinct functional regions, which have been designated region $\mathrm{A}$ through $\mathrm{F} .{ }^{18} \mathrm{NRs}$ have a $\mathrm{N}$-terminal domain of variable length, termed the A/B domain (Figure 2.1A) and this region displays the lowest homology among NR family members. The $\mathrm{A} / \mathrm{B}$ region contains a ligand independent transactivation domain ( $\mathrm{AF}-1)$, whereas a hormone-inducible transcription activating function (AF-2) is present within the hormone binding domain (HBD) of the E region ${ }^{11}$ Both $\mathrm{AF}-1$ and $\mathrm{AF}-2$ are required for maximal ER transcriptional activity.

Adjacent to the A/B domain is the DNA binding domain (DBD) or $\mathrm{C}$ domain, the most conserved region among NRs. This region contains two zinc finger motifs, in which the P-box confers DNAbinding specificity to the different NRs and is critical for target gene recognition (Figure 2.IB). The $\mathrm{C}$ domain is linked to the hinge domain or D domain. The $\mathrm{E}$ domain is less well characterized and displays $53 \%$ homology among NR family members. Finally, the E/F domain is involved in heat shock protein (HSP) interaction, binding with NR (ant)agonist, dimerization properties, cofactor binding, nuclear localization and transactivation function. ${ }^{19}$ Furthermore, ER $\beta$ lacks a large portion of the $\mathrm{F}$ domain. ${ }^{20} \mathrm{It}$ is known that this region is important for the (ant)agonistic effects of certain anti-estrogens. $^{21}$ The gene for ER $\alpha$ has at least three known polymorphisms, PvulI, Xbal, and B variant polymorphisms. ${ }^{22-24}$ In addition, the gene for human ER $\alpha$ contains a polymorphism in the regulatory region of the gene. The importance of ER polymorphisms is unknown in the heart. The ERs were identified in atrial and ventricular myocytes and in cardiac fibroblasts and are operational in both the male and female myocardium. Both the $\alpha$ and $\beta$ isoform are present in the human heart ${ }^{16}$ as well as in rodents. ${ }^{6}$

\section{Transcriptional aspects}

$E R \alpha$ and $E R \beta$ are capable of forming homodimers and heterodimers to stimulate downstream target genes. ${ }^{25}$ The two ER subtypes also have distinct physiologic roles, as suggested by their structural differences in the HBD. ER $\alpha$ homodimers and $E R \alpha / E R \beta$ heterodimers are preferentially formed over ER $\beta$ homodimers. ${ }^{25}$ ERs interact in a protein DNA manner with cognate DNA sequences called hormone responsive cis elements. ${ }^{26}$ Upon estrogen binding the ligand-receptor complex recognizes the consensus sequence AGGTCA as a homo- or heterodimer and activates transcription $^{27}$ (Figure 2.1C). Estrogen receptors may also suppress the transcription of selected target genes by interacting with corepressors. ${ }^{10}$

Little is known about the role of accessory proteins, but they may be required for optimal interaction of ER with estrogen response elements (ERE). ${ }^{28}$ Heat shock proteins of $72 \mathrm{KDa}$ and 90 $\mathrm{KDa}$ (HSP70, HSP90) are thought to be involved in functional modulation of $\mathrm{ER}^{29}$ for instance HSP70 is able to bind $17 \beta$-estradio $P^{30}$, and HSP70 expression is stimulated by estrogens. ${ }^{31}$ Removal of HSP70 results in decreased hormone-ER/ERE association, which is restored by addition of purified HSP70 to the complex, suggesting that HSP70 may act as a transcriptional co-activator. 
A
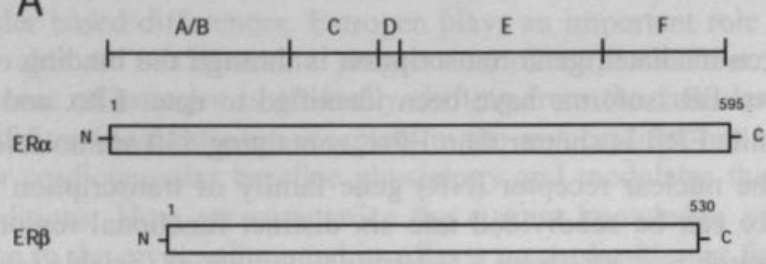

B

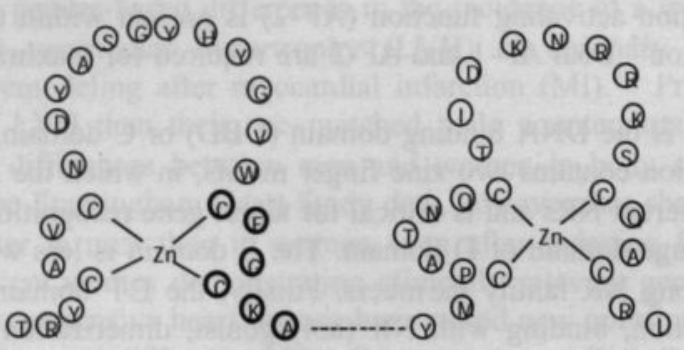

C

\begin{tabular}{lll} 
P-BoX & NR & Core DNA sequence \\
\hline CGSCKV & GR, MR, PR, AR & AGAACA (palindrome) \\
CEGCKA & ER $\alpha$, ER $\beta$ & AGGTCA (palindrome) \\
CEACKA & ERR $\alpha$, ERR $\beta$ & AGGTCA (palindrome) TCAAGGTCA \\
CEGCKG & RAR, RXR, ThR VDR, PPAR, etc & AGGTCA (direct repeat) \\
CESCKG & SF-1, FTZ-F1 & TCAAGGTCA \\
\hline
\end{tabular}

Figure 2.1. Schematic representation of the human estrogen receptor (ER) $\alpha$ and $\beta$. (A) Indicated are the different functional regions (A/B, C, D, E and F) on top and ER $\alpha$ and ER $\beta$ depicted as diagrams. ER $\beta$ is distinct from the $\alpha$ receptor in that it has a shorter $A$ and $F$ region. The number of amino acid residues is indicated above the diagrams, which amount to $66 \mathrm{kDa}$ and $46 \mathrm{kDa}$ for the $\alpha$ and $\beta$ ERs, respectively, although different splice isoforms have been reported for both ER $\alpha$ and $\beta$ which can give rise to smaller protein products. (B) ER $\alpha$ zinc finger organization. Circled residues indicate the P-box motif for ER $\alpha$. (C) Pboxes of the different members of the nuclear receptor (NR) family and the corresponding DNA sequence recognition sites. (GR) Glucocorticoid receptor, (MR) mineralocorticoid receptor, (PR) retinoic acid receptor, (PXR) retinoid $x$ receptor, (thR) thyroid hormone receptor, (VDR) vitamin D receptor, (PPAR) peroxisome proliferator-activated receptor, (SF-1 and FTZ-F1) orphan receptors.

Recent studies suggest that some genomic actions of estrogen can not be attributed to either ER $\alpha$ or ER $\beta$. For example, estrogen continues to protect against vascular injury in ER $\alpha$ and ER $\beta$ double knockout mice, suggesting the presence of a third receptor. ${ }^{32}$ Orphan receptors or estrogen receptor related receptors (ERR) are attractive candidates to fulfil this role. ERRs are members of the NR superfamily too, but their specific ligands remain to be uncovered or not required for activation. Indeed, ERR2 and ERR3 are able to bind specifically EREs and activate reporter genes under 
control of multimerized EREs. ${ }^{33}$ Of interest, ERR-1 is expressed in the heart and vessels. ${ }^{34}$ Taken together, ERR1 may interact with ER via protein-protein interactions ${ }^{35}$, and may fulfil partially redundant functions to cardiac ERs in the control over cardiac (dys)function and pathology.

\section{Estrogen signaling in the cardiovascular system}

\section{Genomic estrogen effects}

The longterm, genomic influence of estrogen on the cardiovascular system mediated via ER $\alpha$ or ER $\beta$, leads to changes in gene expression. Estrogen enters target cells and binds ERs located in the cytoplasm, which undergo conformational changes and translocate to the nucleus to modulate transcription of target genes. ${ }^{36}$ Immunofluorescent staining confirmed the colocalized intracellular distribution pattern of both the $\alpha$ and $\beta$ ER subtypes. ${ }^{37}$ Genomic effects have a delay which is at least in the range of minutes to hours. For instance, nitric oxide synthase (NOS) expression in the myocardium is modulated by estrogen, resulting in both increased expression of inducible (i)NOS and endothelial (e)NOS in cardiomyocytes (Figure 2.2A). ${ }^{37}$. The pure estrogen receptor antagonist ICI 182,780 inhibited estrogen-induced NOS expression in cardiac myocytes ${ }^{37}$ and an earlier study reported that $17 \beta$-estradiol is capable of inducing eNOS gene expression in the endothelium. ${ }^{38}$ In addition, ER, as well as the progesterone receptor, are able to regulate the transcription of the predominant gap junction protein in the myocardium, connexin 43.

Estrogen influences the level of the L-type $\mathrm{Ca}^{2+}$ channel gene expression. In ER $\alpha$ knock out (ERKO) mice, $\mathrm{L}$ type $\mathrm{Ca}^{2+}$ channel mRNA and protein levels are upregulated, leading to a prolonged QT interval ${ }^{39}$ and binding of a dihydropyridine $\mathrm{Ca}^{2+}$ channel antagonist to cardiac membranes was enhanced. ${ }^{39}$ These findings coincided with increased action potential duration and an increased L-type $\mathrm{Ca}^{2+}$ current density in isolated ventricular myocytes from these mice. ${ }^{39}$ In patients with the long QT syndrome, no mutations have been found in $\mathrm{Ca}^{2+}$ channels or ERs.

Estrogen increases the expression of atrial natriuretic factor (ANF), which is known to possess antihypertrophic effects ${ }^{40}$ and may therefore play a role in the modulation of the hypertrophic response in postmenopausal hypertensive heart disease. Estrogen is known to alter several systemic factors that may play a role in cardiovascular physiology and disease. Estrogen affects the renin angiotensin system by inhibiting ACE activity, thus preventing the generation of Ang II while increasing plasma renin and Ang I. ${ }^{41,42}$ Gordon et al. ${ }^{43}$ have demonstrated that estrogen treatment induces significant and rapid angiotensinogen mRNA production, which could be due to the presence of ERE in the promoter region of the angiotensinogen gene. ${ }^{44}$ The proximal renin promoter also contains EREs. ${ }^{45}$ Estrogen deficiency upregulates Ang II receptor subtype $1\left(\mathrm{AT}_{1}\right)$ expression. ${ }^{46}$ Taken together, it is tempting to speculate that the tissue renin and angiotensinogen response to estrogen depends on tissue-specific expression of genes containing either ERE and/or AP-1 sites. ${ }^{47}$

Non-genomic estrogen effects

A number of reported cellular effects of estrogen develop in such a rapid fashion, that they are unlikely to be a consequence of altered gene expression. In contrast to the genomic effects of estrogen, signal transduction pathways of non-genomic estrogenic effects on the myocardium have been much less well characterized. Some effects seem to depend on the presence of the classical ER $\alpha$ and $\beta$ while others are ER independent (Figure 2.2B). There are some indications that membrane impermeable ligand variants (estrogen coupled to BSA) have the ability to modulate L-type $\mathrm{Ca}^{2+}$ channels via a cGMP dependent pathway. ${ }^{48}$ Here estrogens bind to the external surface of the membrane of endometrial cells ${ }^{49}$ or to a membrane receptor on pituitary tumour $\mathrm{GH}_{3} / \mathrm{B} 6$ cells and increases calcium release. ${ }^{50}$ There is no direct evidence for the existence of membrane-bound ERs, and data reporting on the non-genomic action of estrogen in various cell types ${ }^{51}$ including 
cardiomyocytes $^{52}$ suggest that estrogen may act via a membrane bound type receptor through $\mathrm{G}$ protein $\alpha \mathrm{i}^{51}$ (Figure 2.2B).

An acute relaxing action of non-physiological $\mu \mathrm{M}$ concentrations of estradiol on precontracted vascular smooth muscle tissue has been demonstrated. ${ }^{53,54}$ The relaxation was not dependent on the presence of the nuclear ERs and was accompanied by a lower $\mathrm{Ca}^{2+}$ influx into endothelium denuded arteries. ${ }^{53,55}$ The reduced influx seems to be due to a partial block of Ltype calcium channels by estrogen. ${ }^{54,56,57}$

Comparable $\mu \mathrm{M}$ concentrations of estrogen were associated with reduction of the contractile force in the heart, e.g in human atrial trabeculae and ventricular papillary muscles ${ }^{58}$ as well as shortening of ventricular myocytes ${ }^{59}$, which may be explained by an estrogen-mediated reduction in Ltype $\mathrm{Ca}^{2+}$ current conductance as measured in the guinea pig, ${ }^{60,61}$ rat and human. ${ }^{61}$ In addition, studies on whole hearts revealed that $\mu \mathrm{M}$ concentrations of estrogen produced an acute dose-dependent decrease in sinusoidal frequency in rabbit and rat heart. ${ }^{62}$ The $\mathrm{Ca}^{2+}$ antagonistic influence develops within seconds ${ }^{61}$ and may be induced by estrogen without ER involvement. ${ }^{55}$. Cardiac L-type $\mathrm{Ca}^{2+}$ currents are sensitive to NO via a cGMP signaling cascade ${ }^{63}$, suggesting one plausible mechanism through which estrogen is able to influence $\mathrm{L}$-type $\mathrm{Ca}^{2+}$ current density. Indeed, estrogen causes a rapid release of $\mathrm{NO}$ in endothelial cells ${ }^{64}$ as well as adenylate cyclase activation. ${ }^{65}$ Recently Wyckoff et al. ${ }^{51}$ showed a role for $\mathrm{G}$ protein $\alpha \mathrm{i}$ in coupling plasma membrane receptor ER $\alpha$ to eNOS.

In coronary arteries, an increase of intracellular cGMP may lead to phosphorylation of K-channels by means of the cGMP-dependent protein kinase (cGK) and this phosphorylation event increases the open-state probability of K-channels. ${ }^{66}$ The hyperpolarization started 15-20 min after addition of estrogen to the organ bath. Estrogen $(5-10 \mu \mathrm{M})$ is capable of enhancing the open probability of $\mathrm{BK}_{\mathrm{Ca}}{ }^{67}$, and this effect was depending on cGMP, and evident 30-60 min after addition of the hormone. ${ }^{68}$ Conclusively, these studies suggest a role for estrogen in potassium channel regulation. With respect to intracellular signalling. ER-dependent transcriptional activity has been shown to be uniquely sensitive to extracellular signal regulated protein kinase (ERK1/2), but not p38 MAPK phosphorylation. ${ }^{69}$ These findings are of particular interest in view of the recent findings that selective ERK 1/2 activation in the heart is correlated with relatively benign forms of hypertrophy in transgenic mice ${ }^{70}$, while p 38 MAPK activation is more closely associated with malignant forms of (pressure overload) hypertrophy. Furthermore, steroid hormone receptors can be activated by peptide growth factors in the absence of steroid hormone. ${ }^{71}$ There is evidence for a level of crosstalk between ERs and insulin-like growth factor (IGF) signal transduction pathways (Figure 2.2C). Indeed, IGF-I shares important properties with estrogen in the control of cellular proliferation. IGFIR activation stimulates MAPKK and consequently phosphorylation of ERK1/2. Activation of ERK1/2 may, in turn, lead to phosphorylation of ER $\alpha$ and this may provide a plausible mechanism for ligand independent activation of ER $\alpha .^{72}$ Other peptide growth factors like epidermal growth factor (EGF) are able to mimic estradiol actions in a similar fashion. ${ }^{73}$ Conclusively, there is evidence to suggest that the nongenomic effects of $17 \beta$-estradiol may impinge on cardiac NO metabolism, ion homeostasis and intacellular signal transduction pathways. 


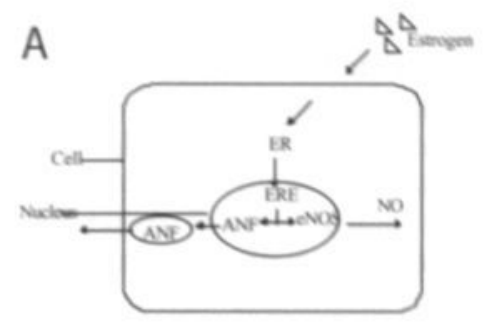

B

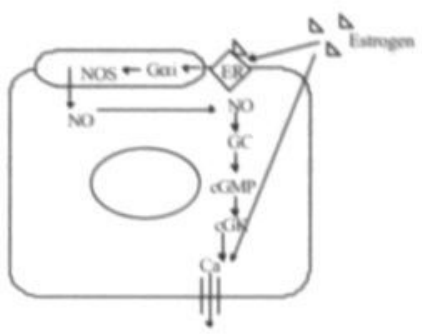

C

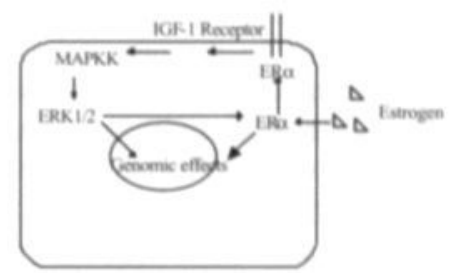

Figure 2.2 ER activation of gene expression. (A) Depicted are estrogens entering the cell by passive diffusion and binding to intracellular ERs $\alpha$ and $\beta$. These receptors undergo conformational changes, form homo or heterodimers and bind to specific sites in the control regions of their target genes (estrogen responsive element) affecting the transcription of genes. (B) Mechanisms of rapid (non genomic), estrogenmediated activation of NO pathways. Indicated is the activation of putative plasma membrane ERs, which results in coupling of the ER with NOS by G protein $\alpha \mathrm{l}$ and increasing NO production. NO activates guanylyl cyclase that stimulates cGMP formation and subsequent cGK activation. One downstream effect of cGK activation is the opening of calcium channels and relaxation effects on the cell. (C) Interaction between ER and IGF-1R signaling cascade. ER $\alpha$ binds to estrogen and activates IGF-1R, which in turn activates ERK1/2 MAPK. ERK1/2 stimulates the activity of ER $\alpha$.

\section{Role of estrogens on cardiac physiology}

\section{Haemodynamic influences}

Significant gender differences exist in baseline cardiovascular function. ${ }^{74}$ A number of studies have shown that healthy women have higher ejection phase indices compared to healthy age-matched men. ${ }^{75}$ Moreover, normotensive women tend to have a greater afterload-corrected fractional shortening under the age of 55 years. ${ }^{76}$ Experimental animal studies support this notion. Papillary muscles from female rats have higher rates of shortening than male. ${ }^{77}$ Pines and co-workers ${ }^{78}$ found 
that premenopausal women have a higher pressure-volume ratio, ejection fraction and ejection rate when compared to postmenopausal women Hormone withdrawal leads to a significant fall in aortic peak flow velocity, mean aortic acceleration time and cardiac index. ${ }^{79}$ Using gonadectomised rats, Schaible et al. ${ }^{80}$ demonstrated a decreased ejection fraction, fractional shortening and ventricular mass in estrogen-depleted female animals.

In addition to the generally improved cardiac function found in females under physiological conditions, gender influences vascular homeostasis. Women have a higher arterial compliance than men until the age of 50, after which arterial stiffness increases. ${ }^{81}$ In spontaneously hypertensive (SHR) rats, low doses of estrogen reduce arterial collagen and stiffness. ${ }^{82}$ Male rabbits exhibit reduced vascular relaxation compared to their female counterparts. ${ }^{83}$ The effects of peripheral injection of estrogen on autonomic tone and reflex control of heart rate can be antagonized by central injection of the ER antagonist ICI $182,780 .{ }^{84}$ In conclusion, there is evidence to suggest that estrogens may positively modulate vascular homeostasis and myocardial function, and hemodynamic function differs in a gender dependent fashion, with distinct profiles in pre-and postmenopausal females.

\section{Role of estrogens in cardiac pathology}

\section{Hypertrophy}

Limited information is available about early changes occurring in the left ventricle during pressure overload. $^{85}$ Cardiac hypertrophy occurs in response to either pressure or volume overload. In response to this hemodynamic stress, myocytes enlarge until wall stress is normalized. However, myocyte lengthening with addition of new sarcomeres in series is sometimes prevailing, leading to eccentric forms of hypertrophy, in which ventricular chamber dilation is accompanied by a proportional or even reduced increase in wall thickness. Lateral expansion of myocytes with the addition of new sarcomeres in parallel presents the typical pattern of myocyte growth after pressure overload (concentric hypertrophy), in which wall thickness increases with minor chamber enlargement. ${ }^{86}$ Reactive compensatory hypertrophy after myocyte loss (e.g. in the non infarcted portion of the heart following an acute MI) is characterised by different degrees of myocyte lengthening and widening. ${ }^{86}$

LVH is associated with an increased frequency of ventricular arrhythmias in the absence of CAD. ${ }^{87}$ The terminal phase of hypertrophy is the initiation of heart failure, a common cardiac disorder with a highly unfavourable outcome. ${ }^{88}$ Experimental data from clinical studies and animal models suggest that estrogen may modulate cardiac hypertrophy. ${ }^{89}$ In fact, estrogen deficiency potentiates, while estrogen replacement attenuates the development of both right and left ventricular hypertrophy in rodent models of $\mathrm{LVH}^{90}$ Estrogen treatment attenuates myocyte hypertrophy, as determined by cross-sectional area. ${ }^{91}$

We have recently demonstrated that estrogen attenuates the hypertrophic response to pressure overload in mice. ${ }^{12}$ Female, ovariectomized $\mathrm{C} 57 \mathrm{BL} / 6$ mice were randomised to receive either a physiologic dose of $17 \beta$-estradiol or placebo for one week before they underwent transverse aortic constriction (TAC) or a sham operation. Estrogen supplementation reduced pressure overload hypertrophy by $31 \%$ and $26 \%$ compared to placebo at 4 and 8 weeks after TAC. Estrogensupplementation had no effect on the degree of interstitial fibrosis in the hypertrophied hearts. Western blot analysis revealed that estrogen blocked TAC-induced p38 MAPK activation, while no effect was observed on the activation of ERK1/2 and $c$-Jun $\mathrm{N}$-terminal kinase (JNK). Interestingly, estrogen treatment led to an increased expression of ANF in animals with pressure overload. ${ }^{12}$ 


\section{Heart failure}

Congestive heart failure is a major clinical problem resulting in significant morbidity and mortality. $^{92}$ Although considerable progress has been made elucidating the pathophysiologic mechanisms that lead to failure, many details concerning the etiology and progression remain unknown. ${ }^{93}$ Heart failure is in part due to ventricular dilation and inadequate wall thickening that leads to impaired cardiac performance. ${ }^{94}$ Hypertension is associated with the development of congestive heart failure by excessive stimulation of LVH. Reports on the natural history of untreated hypertension indicate that at least $50 \%$ of subjects develop congestive heart failure. ${ }^{95}$ The adaptive changes of the heart withstand the deleterious effects of cardiac overload only temporarily. The ensuing heart failure demonstrates insufficient adaptation of the heart to overload to maintain proper excitation-contraction coupling. ${ }^{96}$ Changes in the content and isoforms of proteins involved in $\mathrm{Ca}^{2+}$ handling, sarcomeric function and in extracellular matrix composition may all contribute to impairment of diastolic and systolic function of the heart. ${ }^{97}$ Hypertensive and ischaemic heart diseases are by far the most common causes of heart failure and are associated with pronounced systolic dysfunction, although some patients, particularly elderly females, have diastolic dysfunction. ${ }^{98} \mathrm{MI}$ may lead to ventricular remodelling with compensatory dilation and hypertrophy and subsequent systolic and diastolic dysfunction resulting in failure. ${ }^{98}$ Although studies on the effect of estrogen on the cardiovascular function in animals with heart failure are very few, chronic administration of estrogen in rats with sustained heart failure reduced total peripheral resistance and left ventricular end-diastolic pressure. ${ }^{99}$ The systemic effects of estrogens are favourable in animal models with cardiac failure.

The epidemiological evidence of protective effects of estrogens against heart failure in man is strong. Currently the specific molecular pathways are unknown, but prevention of cardiomyocyte apoptosis may play a role. ${ }^{100}$

\section{Myocardial ischemia}

Ischemia results in cardiac injury ranging from short-term reversible contractile dysfunction to cellular necrosis and infarct with irreversible loss of function. Intermediate is myocardial prolonged reversible contractile dysfunction. ${ }^{101} \mathrm{~A}$ consistent male to female ratio for $\mathrm{CHD}$ death rates ranging from 2 to 5 in a population with very different heart disease rates and lifestyles has suggested that sex hormones have a significant influence on the vasculature. ${ }^{102}$ Sex hormone replacement might reduce coronary mortality in postmenopausal women. This hypothesis is supported by a number of retrospective and observational studies demonstrating an inverse relationship between estrogen use and coronary event end points such as $\mathrm{MI}$ and death from ischemic heart disease. ${ }^{103-103}$ Acute administration of estrogen by either the intramuscular or intracoronary route similarly prevented ischemic $^{106,107}$ and reperfusion ${ }^{107}$ arrhythmias and reduced infarct size. ${ }^{107}$ Importantly, estrogen also increased distal coronary perfusion during both ischemia and reperfusion. ${ }^{106}$ ERT, which provides exogenous estrogen to postmenopausal women, increases the circulating estrogen concentration and significantly decreases the morbidity and mortality of coronary heart disease in these patients. ${ }^{108}$ Thus estrogen appears to preserve endothelium-dependent coronary artery dilation and reduce infarct size, in experimental models of regional ischemia-reperfusion. ${ }^{107,109}$ Estrogens appear to be cardioprotective under ischemic conditions, probably due to improved vascular function.

\section{Hormone replacement therapy and human studies}

Evidence from multiple observational studies suggested a marked reduction in the risk of CHD associated with postmenopausal estrogen use in primary prevention. A similar effect was observed when estrogens were opposed with progestins. Recently published studies suggested $30 \%$ and $34 \%$ reduction in the risk among users of unopposed and opposed therapy, respectively compared with 
non users. ${ }^{110}$ Current and recent use of hormone replacement therapy (HRT) was associated with an overall $28 \%$ reduction in the risk of first MI when compared with non users. ${ }^{111}$ In the Nurses health study there was still a strong inverse association between current HRT and the risk of CAD after controlling for many risk factors. ${ }^{111}$ The risk of major coronary disease was substantially decreased among current users of estrogen and progestin, as well as among current users of estrogen alone ${ }^{104}$ Still some null finding is present in the literature, Hulley et $\mathrm{al}^{12}$ found during 4.1 years, that treatment with oral conjugated equine estrogen plus medroxyprogesterone acetate did not reduce the overall rate of CHD events in postmenopausal women with established coronary disease (HERS: Heart and Estrogen/Progestin Replacement Study). Also The CARS (Coumadin Aspirin Reinfarction Study) showed unexpected results. In this study the incidence of unstable angina was markedly increased. ${ }^{113}$ Contradiction of these findings with the observational studies could be because of the CAD risk profile and the duration of ERT, which is supposed to be preventive rather than curative.

Other compounds in clinical use can activate estrogen receptors. Tamoxifen a non-steroidal triphenylene derivative used in treatment of breast cancer, acts as an estrogen agonist in some tissues (e.g. the uterus) but as estrogen antagonist in other tissues (e.g. the breast). Tamoxifen has also estrogen like effects on the cardiovascular system. ${ }^{114}$ It does produce a significant reduction in the levels of low-density lipoprotein (LDL) cholesterol and fibrinogen. ${ }^{115}$ Randomised, placebocontrolled clinical trials showed a rapid and sustained reduction in LDL cholesterol levels by approximately $12 \%$ accompanied by $15 \%$ increase in high density lipoprotein- 2 cholesterol. Raloxifene reduced serum triglycerides and serum fibrinogen levels by $7 \%$ and $10 \%$ respectively. ${ }^{116}$ Toremifene, droloxifene, idoxifene, TAT-59, and GW5638, are known to have similar action to tamoxifen while Ly353381 showed a clear similarity to raloxifene. ICI 182,780 demonstrates a pure antiestrogenic profile on all genes and in all tissues studied to date, and could be a superior antitumour agent. ${ }^{117}$

Many phytoestrogens with mixed estrogen agonist and antagonist properties have been identified. Phytoestrogens can have both estrogenic and antiestrogenic effects. ${ }^{118}$ Soy consumption significantly decreased total cholesterol, LDL Cholesterol, and triglyceride levels. The cardiovascular benefits of soy phytoestrogens appear to be equal for males and females. ${ }^{119}$ All heart studies thus far focused on vascular effects and not on a possible influence of estrogen on left ventricular mass.

\section{Conclusions}

Cardiac hypertrophy, MI and heart failure are important clinical problems in the industrialised countries. Although several methods of control and treatment have improved our clinical care, new therapeutic targets are still needed. Clinical data indicates that estrogen may have beneficial short and long-term cardiovascular effects; thus, it is important to consider the role of estrogen as a therapeutic agent for the treatment of cardiovascular diseases. The mechanisms that mediate the rapid effects of estrogen are not fully understood, but current data suggest involvement of enhanced NO release, effects on calcium handling and regulation of potassium currents. The long-term effects of estrogen are due to changes in cardiomyocyte gene expression, mediated by ER $\alpha$ and ER $\beta$. The identity and effects of these target genes remain to be uncovered. Direct myocardial effects of physiological estrogen levels on cardiac structure and function appear to be of great value. Still a large number of questions remains to be addressed such as the various estrogen dependent pathways, cross-talk and phenotypical consequences. Selective estrogen receptor modulators (SERMs) should be studied and classified according to their effects on the cardiovascular system and some of them could be selected to be used as alternatives for HRT. These SERMs could be more appropriate tools for the future treatment of selected heart diseases. 


\section{Acknowledgements}

This work was supported by grants from the Netherlands Heart Foundation (NHS 99-114) and the Interuniversitary Cardiology institute Netherlands (to P.A.D.) and the Deutsche Forschungsgemeinschaft and BONFOR 0-708 (to C.G.). L.J.D.W. is supported by a Bekales Foundation Award in Cardiology and the Netherlands Foundation for Scientific Research (NWO 902-16-275). 


\section{References}

1. Grady D, Rubin SM, Petitti DB, et al. Hormone therapy to prevent disease and prolong life in postmenopausal women. Ann Intern Med. 1992;117:1016-37.

2. Matthews KA, Wing RR, Kuller LH, et al. Influences of natural menopause on psychological characteristics and symptoms of middle-aged healthy women. J Consult Clin Psychol. 1990;58:345-51.

3. Gardin JM, Wagenknecht LE, Anton-Culver H, et al. Relationship of cardiovascular risk factors to echocardiographic left ventricular mass in healthy young black and white adult men and women. The CARDIA study. Coronary Artery Risk Development in Young Adults. Circulation. 1995;92:380-7.

4. Mendelsohn ME, Karas RH. Estrogen and the blood vessel wall. Curr Opin Cardiol. 1994;9:619-26.

5. Levy D, Garrison RJ, Savage DD, et al. Prognostic implications of echocardiographically determined left ventricular mass in the Framingham Heart Study [see comments]. $N$ Engl J Med. 1990;322:1561-6.

6. Grohe C, Kahlert S, Lobbert K, et al. Cardiac myocytes and fibroblasts contain functional estrogen receptors. FEBS Lett. 1997;416:107-12.

7. Pines A, Mijatovic V, van der Mooren MJ, et al. Hormone replacement therapy and cardioprotection: basic concepts and clinical considerations. Eur J Obstet Gynecol Reprod Biol. 1997;71:193-7.

8. Kuroski de Bold ML. Estrogen, natriuretic peptides and the renin-angiotensin system. Cardiovasc Res. 1999;41:524-31.

9. Grohe C, Kahlert S, Lobbert K, et al. Expression of oestrogen receptor alpha and beta in rat heart: role of local oestrogen synthesis. J Endocrinol. 1998;156:R1-7.

10. Mendelsohn ME, Karas RH. The protective effects of estrogen on the cardiovascular system. N Engl J Med. 1999;340:1801-11.

11. Flouriot $\mathrm{G}$, Brand $\mathrm{H}$, Denger $\mathrm{S}$, et al. Identification of a new isoform of the human estrogen receptor-alpha (hER-alpha) that is encoded by distinct transcripts and that is able to repress hER-alpha activation function 1. Embo J. 2000;19:4688-700.

12. van Eickels M, Bronsaer RJ, Grohe C, et al. 17 beta-estradiol attenuates the development of cardiac hypertrophy. Circulation. 2001;104:1419-23.

13. Simoncini T, Hafezi-Moghadam A, Brazil DP, et al. Interaction of oestrogen receptor with the regulatory subunit of phosphatidylinositol-3-OH kinase. Nature. 2000;407:538-41.

14. Kuiper GG, Carlsson B, Grandien K, et al. Comparison of the ligand binding specificity and transcript tissue distribution of estrogen receptors alpha and beta. Endocrinology. 1997:138:863-70.

15. Kuiper GG, Enmark E, Pelto-Huikko M, et al. Cloning of a novel receptor expressed in rat prostate and ovary. Proc Natl Acad Sci US A. 1996;93:5925-30.

16. Brandenberger AW, Tee MK, Lee JY, et al. Tissue distribution of estrogen receptors alpha (ER-alpha) and beta (ER- beta) mRNA in the midgestational human fetus. $J$ Clin Endocrinol Metab. 1997:82:3509-12.

17. Ogawa $\mathrm{S}$, Inoue $\mathrm{S}$, Watanabe $\mathrm{T}$, et al. The complete primary structure of human estrogen receptor beta (hER beta) and its heterodimerization with ER alpha in vivo and in vitro. Biochem Biophys Res Commun. 1998;243:122-6.

18. Parker MG. Structure and function of nuclear hormone receptors. Semin Cancer Biol. 1990;1:81-7.

19. Gustafsson JA. Estrogen receptor beta--a new dimension in estrogen mechanism of action. $J$ Endocrinol. 1999;163:379-83. 
20. Mosselman S, Polman J, Dijkema R. ER beta: identification and characterization of a novel human estrogen receptor. FEBS Lett. 1996;392:49-53.

21. Montano MM, Muller V, Trobaugh A, et al. The carboxy-terminal $\mathrm{F}$ domain of the human estrogen receptor: role in the transcriptional activity of the receptor and the effectiveness of antiestrogens as estrogen antagonists. Mol Endocrinol. 1995;9:814-25.

22. Taylor JA, Li Y, You M, et al. B region variant of the estrogen receptor gene. Nucleic Acids Res. 1992;20:2895.

23. Heimdal K, Andersen TI, Skrede M, et al. Association studies of estrogen receptor polymorphisms in a Norwegian testicular cancer population. Cancer Epidemiol Biomarkers Prev. 1995;4:123-6.

24. Matsubara Y, Murata M, Kawano K, et al. Genotype distribution of estrogen receptor polymorphisms in men and postmenopausal women from healthy and coronary populations and its relation to serum lipid levels. Arterioscler Thromb Vasc Biol. 1997;17:3006-12.

25. Cowley SM, Hoare S, Mosselman S, et al. Estrogen receptors alpha and beta form heterodimers on DNA. J Biol Chem. 1997;272:19858-62.

26. Evans RM. The steroid and thyroid hormone receptor superfamily. Science, 1988;240:88995.

27. Doevendans PA, van Bilsen M. Transcription factors and the cardiac gene programme. Int $J$ Biochem Cell Biol. 1996;28:387-403.

28. Landel CC, Potthoff SJ, Nardulli AM, et al. Estrogen receptor accessory proteins augment receptor-DNA interaction and DNA bending. J Steroid Biochem Mol Biol. 1997;63:59-73.

29. Koshiyama M, Konishi I, Nanbu K, et al. Immunohistochemical localization of heat shock proteins HSP70 and HSP90 in the human endometrium: correlation with sex steroid receptors and $\mathrm{Ki} 67$ antigen expression. J Clin Endocrinol Metab. 1995;80:1106-12.

30. Gacad MA, Adams JS. Proteins in the heat shock-70 family specifically bind 25hydroxyvitamin D3 and 17beta-estradiol. J Clin Endocrinol Metab. 1998;83:1264-7.

31. Tang PZ, Gannon MJ, Andrew A, et al. Evidence for oestrogenic regulation of heat shock protein expression in human endometrium and steroid-responsive cell lines. Eur $J$ Endocrinol. 1995;133:598-605.

32. Hawkins MB, Thornton JW, Crews D, et al. Identification of a third distinct estrogen receptor and reclassification of estrogen receptors in teleosts. Proc Natl Acad Sci USA. 2000;97:10751-6.

33. Hong $\mathrm{H}$, Yang L, Stallcup MR. Hormone-independent transcriptional activation and coactivator binding by novel orphan nuclear receptor ERR3. J Biol Chem. 1999;274:2261826.

34. Duvekot JJ, Cheriex EC, Pieters FA, et al. Early pregnancy changes in hemodynamics and volume homeostasis are consecutive adjustments triggered by a primary fall in systemic vascular tone. Am J Obstet Gynecol. 1993;169:1382-92.

35. Yang N, Shigeta H, Shi $\mathrm{H}$, et al. Estrogen-related receptor, hERR1, modulates estrogen receptor-mediated response of human lactoferrin gene promoter. $J$ Biol Chem. 1996;271:5795-804.

36. Murdoch FE, Gorski J. The role of ligand in estrogen receptor regulation of gene expression. Mol Cell Endocrinol. 1991;78:C103-8.

37. Nuedling S, Kahlert S, Loebbert K, et al. 17 Beta-estradiol stimulates expression of endothelial and inducible NO synthase in rat myocardium in-vitro and in-vivo. Cardiovasc Res. 1999;43:666-74.

38. MacRitchie AN, Jun SS, Chen Z, et al. Estrogen upregulates endothelial nitric oxide synthase gene expression in fetal pulmonary artery endothelium. Circ Res. 1997;81:355-62. 
39. Johnson BD, Zheng W, Korach KS, et al. Increased expression of the cardiac L-type calcium channel in estrogen receptor-deficient mice. J Gen Physiol. 1997;110:135-40.

40. Horio T, Nishikimi T, Yoshihara F, et al. Inhibitory regulation of hypertrophy by endogenous atrial natriuretic peptide in cultured cardiac myocytes. Hypertension. 2000;35:19-24.

41. Brosnihan KB, Weddle D, Anthony MS, et al. Effects of chronic hormone replacement on the renin-angiotensin system in cynomolgus monkeys. J Hypertens. 1997;15:719-26.

42. Chen YF, Naftilan AJ, Oparil S. Androgen-dependent angiotensinogen and renin messenger RNA expression in hypertensive rats. Hypertension. 1992;19:456-63.

43. Gordon MS, Chin WW, Shupnik MA. Regulation of angiotensinogen gene expression by estrogen. J Hypertens. 1992;10:361-6.

44. Wheeler MA, Pontari M, Dokita S, et al. Age-dependent changes in particulate and soluble guanylyl cyclase activities in urinary tract smooth muscle. Mol Cell Biochem. 1997;169:115-24.

45. Griendling KK, Murphy TJ, Alexander RW. Molecular biology of the renin-angiotensin system. Circulation. 1993;87:1816-28.

46. Wassmann S, Baumer AT, Strehlow K, et al. Endothelial dysfunction and oxidative stress during estrogen deficiency in spontaneously hypertensive rats. Circulation. 2001;103:43541.

47. Rosenzweig A, Halazonetis TD, Seidman JG, et al. Proximal regulatory domains of rat atrial natriuretic factor gene. Circulation. 1991;84:1256-65.

48. Mermelstein PG, Becker JB, Surmeier DJ. Estradiol reduces calcium currents in rat neostriatal neurons via a membrane recęntor. I Nounnssi j906; 16:595.504.

49. Pietras RJ, Szego CM. Specific binding sites for oestrogen at the outer surfaces of isolated endometrial cells. Nature. 1977;265:69-72.

50. Pappas TC, Gametchu B, Watson CS. Membrane estrogen receptors identified by multiple antibody labeling and impeded-ligand binding. Faseb J. 1995;9:404-10.

51. Wyckoff $\mathrm{MH}$, Chambliss KL, Mineo C, et al. Plasma membrane estrogen receptors are coupled to endothelial nitric-oxide synthase through Galpha(i). $J$ Biol Chem. 2001:276:27071-6.

52. Farhat MY, Abi-Younes S, Ramwell PW. Non-genomic effects of estrogen and the vessel wall. Biochem Pharmacol. 1996;51:571-6.

53. Han SZ, Karaki $\mathrm{H}$, Ouchi $\mathrm{Y}$, et al. 17 beta-Estradiol inhibits $\mathrm{Ca} 2+$ influx and $\mathrm{Ca} 2+$ release induced by thromboxane A2 in porcine coronary artery. Circulation. 1995;91:2619-26.

54. Kitazawa T, Hamada E, Kitazawa K, et al. Non-genomic mechanism of 17 beta-oestradiol induced inhibition of contraction in mammalian vascular smooth muscle. $J$ Physiol. 1997:499:497-511.

55. Freay AD, Curtis SW, Korach KS, et al. Mechanism of vascular smooth muscle relaxation by estrogen in depolarized rat and mouse aorta. Role of nuclear estrogen receptor and $\mathrm{Ca} 2+$ uptake. Circ Res. 1997;81:242-8.

56. Zhang F, Ram JL, Standley PR, et al. 17 beta-Estradiol attenuates voltage-dependent $\mathrm{Ca} 2+$ currents in A7r5 vascular smooth muscle cell line. Am J Physiol. 1994;266:C975-80.

57. Ruehlmann DO, Steinert JR, Valverde MA, et al. Environmental estrogenic pollutants induce acute vascular relaxation by inhibiting L-type Ca2+ channels in smooth muscle cells. Faseb J. 1998:12:613-9.

58. Sitzler G, Lenz O, Kilter $\mathrm{H}$, et al. Investigation of the negative inotropic effects of 17 betaoestradiol in human isolated myocardial tissues. Br J Pharmacol. 1996;119:43-8. 
59. Jiang C, Poole-Wilson PA, Sarrel PM, et al. Effect of 17 beta-oestradiol on contraction, $\mathrm{Ca} 2+$ current and intracellular free $\mathrm{Ca} 2+$ in guinea-pig isolated cardiac myocytes. $\mathrm{Br} J$ Pharmacol. 1992;106:739-45.

60. Grohe C, Kahlert S, Lobbert K, et al. Modulation of hypertensive heart disease by estrogen. Steroids. 1996;61:201-4.

61. Meyer R, Linz KW, Surges R, et al. Rapid modulation of Ltype calcium current by acutely applied oestrogens in isolated cardiac myocytes from human, guinea-pig and rat. Exp Physiol. 1998;83:305-21.

62. Eckstein N, Nadler E, Barnea O, et al. Acute effects of 17 beta-estradiol on the rat heart. Am JObstet Gynecol. 1994;171:844-8.

63. Wahler GM, Dollinger SJ. Nitric oxide donor SIN-1 inhibits mammalian cardiac calcium current through cGMP-dependent protein kinase. Am J Physiol. 1995;268:C45-54.

64. Caulin-Glaser T, Garcia-Cardena G, Sarrel P, et al. 17 beta-estradiol regulation of human endothelial cell basal nitric oxide release, independent of cytosolic $\mathrm{Ca} 2+$ mobilization. Circ Res. 1997;81:885-92.

65. Aronica SM, Kraus WL, Katzenellenbogen BS. Estrogen action via the cAMP signaling pathway: stimulation of adenylate cyclase and cAMP-regulated gene transcription. Proc Natl Acad Sci US A. 1994;91:8517-21.

66. Wellman GC, Bonev AD, Nelson MT, et al. Gender differences in coronary artery diameter involve estrogen, nitric oxide, and $\mathrm{Ca}(2+)$-dependent $\mathrm{K}+$ channels. Circ Res. 1996;79:102430.

67. White RE, Darkow DJ, Lang JL. Estrogen relaxes coronary arteries by opening BKCa channels through a cGMP-dependent mechanism. Circ Res. 1995;77:936-42.

68. Darkow DJ, Lu L, White RE. Estrogen relaxation of wronary artery smooth muscle is mediated by nitric oxide and cGMP. Am J Physiol. 1997;272:H2765-73.

69. Kato S, Endoh H, Masuhiro Y, et al. Activation of the estrogen receptor through phosphorylation by mitogen- activated protein kinase. Science. 1995;270:1491-4.

70. Bueno OF, De Windt LJ, Tymitz KM, et al. The MEK1-ERK1/2 signaling pathway promotes compensated cardiac hypertrophy in transgenic mice. Embo J. 2000;19:6341-50.

71. Power RF, Mani SK, Codina J, et al. Dopaminergic and ligand-independent activation of steroid hormone receptors. Science. 1991;254:1636-9.

72. Kahlert S, Nuedling S, van Eickels M, et al. Estrogen receptor alpha rapidly activates the IGF-1 receptor pathway. J Biol Chem. 2000;275:18447-53.

73. Ignar-Trowbridge DM, Teng CT, Ross KA, et al. Peptide growth factors elicit estrogen receptor-dependent transcriptional activation of an estrogen-responsive element. Mol Endocrinol. 1993;7:992-8.

74. Hayward CS, Kelly RP, Collins P. The roles of gender, the menopause and hormone replacement on cardiovascular function. Cardiovasc Res. 2000;46:28-49.

75. Buonanno C, Arbustini E, Rossi L, et al. Left ventricular function in men and women. Another difference between sexes. Eur Heart J. 1982;3:525-8.

76. de Simone G, Devereux RB, Roman MJ, et al. Gender differences in left ventricular anatomy, blood viscosity and volume regulatory hormones in normal adults. Am J Cardiol. 1991;68:1704-8.

77. Capasso JM, Remily RM, Smith RH, et al. Sex differences in myocardial contractility in the rat. Basic Res Cardiol. 1983;78:156-71.

78. Pines A, Fisman EZ, Shemesh J, et al. Menopause-related changes in left ventricular function in healthy women. Cardiology. 1992;80:413-6. 
79. Eckstein N, Pines A, Fisman EZ, et al. The effect of the hypoestrogenic state, induced by gonadotropin- releasing hormone agonist, on Doppler-derived parameters of aortic flow. $J$ Clin Endocrinol Metab. 1993;77:910-2.

80. Schaible TF, Scheuer J. Comparison of heart function in male and female rats. Basic Res Cardiol. 1984;79:402-12.

81. Laogun AA, Gosling RG. In vivo arterial compliance in man. Clin Phys Physiol Meas. 1982;3:201-12.

82. Blacher J, Dabire H, Pomies JP, et al. Long-term cardiovascular effects of high "osteoprotective" dose levels of 17 beta-estradiol in spontaneously hypertensive rats. Cardiovasc Drugs Ther. 2000;14:303-7.

83. Kojda G, Husgen B, Hacker A, et al. Impairment of endothelium-dependent vasorelaxation in experimental atherosclerosis is dependent on gender. Cardiovasc Res. 1998;37:738-47.

84. Saleh TM, Connell BJ. 17beta-estradiol modulates baroreflex sensitivity and autonomic tone of female rats. J Auton Nerv Syst. 2000;80:148-61.

85. Nediani C, Formigli L, Perna AM, et al. Early changes induced in the left ventricle by pressure overload. An experimental study on swine heart. J Mol Cell Cardiol. 2000;32:13142.

86. Anversa P, Ricci R, Olivetti G. Quantitative structural analysis of the myocardium during physiologic growth and induced cardiac hypertrophy: a review. $J$ Am Coll Cardiol. 1986;7:1140-9.

87. Ghali JK, Kadakia S, Cooper RS, et al. Impact of left ventricular hypertrophy on ventricular arrhythmias in the absence of coronary artery disease. J Am Coll Cardiol. 1991;17:1277-82.

88. Cleland JG, Swedberg K. Poole-Wilson PA. Successes and failures of current treatment of heart failure. Lancet. 1998;352 Suppl 1:SI19-28.

89. Scheuer J, Malhotra A, Schaible TF, et al. Effects of gonadectomy and hormonal replacement on rat hearts. Circ Res. 1987;61:12-9.

90. Farhat MY, Chen MF, Bhatti T, et al. Protection by oestradiol against the development of cardiovascular changes associated with monocrotaline pulmonary hypertension in rats. $\mathrm{Br} \mathrm{J}$ Pharmacol. 1993;110:719-23.

91. Douglas PS, Katz SE, Weinberg EO, et al. Hypertrophic remodeling: gender differences in the early response to left ventricular pressure overload. J Am Coll Cardiol. 1998;32:111825 .

92. Lyn D, Liu X, Bennett NA, et al. Gene expression profile in mouse myocardium after ischemia. Physiol Genomics. 2000;2:93-100.

93. MacLellan WR. Advances in the molecular mechanisms of heart failure. Curr Opin Cardiol. 2000;15:128-35.

94. Volterrani M, Giustina A, Manelli F, et al. Role of growth hormone in chronic heart failure: therapeutic implications. Ital Heart J. 2000;1:732-8.

95. Himmelmann A. Hypertension: an important precursor of heart failure. Blood Press. 1999;8:253-60.

96. Studer R, Reinecke H, Bilger J, et al. Gene expression of the cardiac $\mathrm{Na}(+)-\mathrm{Ca} 2+$ exchanger in end-stage human heart failure. Circ Res. 1994;75:443-53.

97. Van der laarse A, Ruwhof C, van Wamel JET, et al. Molecular cardiology, part2: Molecular aspects of cardiac hypertrophy and heart failure. Cardiology. 1997;4:328 - 333.

98. Pezzano A. [Cardiac failure in ischemic cardiopathy]. Ital Heart J. 2000;1 Suppl 2:67-71.

99. Nekooeian AA, Pang CC. Estrogen restores role of basal nitric oxide in control of vascular tone in rats with chronic heart failure. Am J Physiol. 1998;274:H2094-9.

100. Camper-Kirby D, Welch S, Walker A, et al. Myocardial Akt activation and gender: increased nuclear activity in females versus males. Circ Res. 2001;88:1020-7. 
101. Braunwald E, Kloner RA. The stunned myocardium: prolonged, postischemic ventricular dysfunction. Circulation. 1982;66:1146-9.

102. Barrett-Connor E. Sex differences in coronary heart disease. Why are women so superior? The 1995 Ancel Keys Lecture. Circulation. 1997;95:252-64.

103. Abu-Halawa SA, Thompson K, Kirkeeide RL, et al. Estrogen replacement therapy and outcome of coronary balloon angioplasty in postmenopausal women. $\mathrm{Am} \mathrm{J} \mathrm{Cardiol}$. 1998;82:409-13.

104. Grodstein F, Stamp fer MJ, Manson JE, et al. Postmenopausal estrogen and progestin use and the risk of cardiovascular disease. $N$ Engl J Med. 1996;335:453-61.

105. Heckbert SR, Weiss NS, Koepsell TD, et al. Duration of estrogen replacement therapy in relation to the risk of incident myocardial infarction in postmenopausal women. Arch Intern Med. 1997; 157:1330-6.

106. McHugh NA, Cook SM, Schairer JL, et al. Ischemia- and reperfusion-induced ventricular arrhythmias in dogs: effects of estrogen. Am J Physiol. 1995;268:H2569-73.

107. Node K, Kitakaze M, Kosaka H, et al. Amelioration of ischemia- and reperfusion-induced myocardial injury by 17 beta-estradiol: role of nitric oxide and calcium-activated potassium channels. Circulation. 1997;96:1953-63.

108. Stampfer MJ, Colditz GA, Willett WC, et al. Postmenopausal estrogen therapy and cardiovascular disease. Ten-year follow-up from the nurses' health study. $N$ Engl $J$ Med. 1991;325:756-62.

109. Kim YD, Chen B, Beauregard J, et al. 17 beta-Estradiol prevents dysfunction of canine coronary endothelium and myocardium and reperfusion arrhythmias after brief ischemia/reperfusion. Circulation. 1996;94:2901-8.

110. Barrett-Connor E, Grady D. Hormone replacement therapy, heart disease, and other considerations. Annu Rev Public Health. 1998;19:55-72.

111. Varas-Lorenzo C, Garcia-Rodriguez LA, Perez-Gutthann S, et al. Hormone replacement therapy and incidence of acute myocardial infarction. A population-based nested casecontrol study. Circulation. 2000;101:2572-8.

112. Hulley S, Grady D, Bush T, et al. Randomized trial of estrogen plus progestin for secondary prevention of coronary heart disease in postmenopausal women. Heart and Estrogen/progestin Replacement Study (HERS) Research Group. Jama. 1998;280:605-13.

113. Alexander KP, Newby LK, Hellkamp AS, et al. Initiation of hormone replacement therapy after acute myocardial infarction is associated with more cardiac events during follow-up. $J$ Am Coll Cardiol. 2001;38:1-7.

114. Fitzpatrick LA. Selective estrogen receptor modulators and phytoestrogens: new therapies for the postmenopausal women. Mayo Clin Proc. 1999;74:601-7.

115. Burger HG. Selective oestrogen receptor modulators. Horm Res. 2000;53:25-9.

116. Barrett-Connor E, Cox DA, Anderson PW. The Potential of SERMs for Reducing the Risk of Coronary Heart Disease. Trends Endocrinol Metab. 1999;10:320-325.

117. Osborne CK, Zhao H, Fuqua SA. Selective estrogen receptor modulators: structure, function, and clinical use. J Clin Oncol. 2000;18:3172-86.

118. Knight DC, Eden JA. Phytoestrogens--a short review. Maturitas. 1995;22:167-75.

119. Clarkson TB, Anthony MS. Phytoestrogens and coronary heart disease. Baillieres Clin Endocrinol Metab. 1998;12:589-604. 


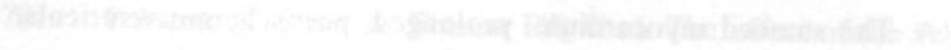

$\operatorname{cath}^{2} \sin ^{2}$ Whanans

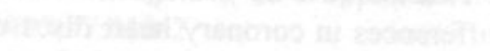

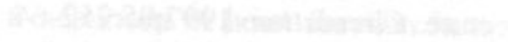

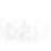


Effects of Transverse Aortic Constriction, and Estrogen-treatment on Cardiac Gene Expression Profiles in Estrogen Receptor Alpha and Beta Knockout Mice

Fawzi A. Babiker, Guillaume van Eys, Daniel J. Lips, Christian Grohé, Pieter Zandberg, Martin van Eickels, Pieter A. Doevendans. 


\section{Abstract}

Introduction: Pressure-overload necessitates the left ventricle (LV) to adapt to changing conditions by left ventricular hypertrophy $(\mathrm{LVH})$. It has been shown to be a major risk factor fo: cardiovascular morbidity and is a well accepted prognostic indicator for subsequent cardiac dysfunction. Estrogen (E2) is known to antagonize LVH. To obtain more complete understanding of the mechanisms of E2 function, it is necessary to identify the target genes for estrogen receptors (ERs). To study the beneficial effects of E2-treatment on pressure overload induced LVH, we used DNA microarray technology to profile gene expression in LVH and E2-treatment in ER $\alpha$ knockout (ERKO) and ER $\beta$ knockout (BERKO) mice.

Methods and Results: 10 weeks old female mice underwent transverse aortic constriction (TAC) or sham operation. Four weeks after intervention hemodynamic function was assessed, and animals were sacrificed. Total RNA was isolated from LV tissue. For comparative microarray hybridization, cRNAs were synthesized from the RNA samples and applied on microarrays. TAC and E2treatment led to a change in expression of several genes in the experimental animals. A number of genes, divided in groups, were selected for further analysis. Structural genes including those which are usually expressed in the fetal period (fetal genes) such as beta myosin heavy chain ( $\mathrm{BMHC}$ ), regulatory myosin light chain (MLC-2a) and alpha-skeleta-actin ( $\alpha$-sk-actin), were induced by TAC and down regulated by E2-treatment. Expression of stress genes like heat shock proteins (HSP) HSPla, HSPIb and HSP8 decreased by TAC and E2-treatment, but only in the presence of ER $\beta$. Growth factors such as transforming growth factor beta (TGF $\beta$ ) were found to be induced by TAC in both mouse models and down regulated by E2-treatment in presence of ER $\beta$. TAC also increased the expression of cell adhesion molecules such as cartilage oligomeric matrix protein (Comp), procollagen, type 1, alpha 2 (Colla2), tumor necrosis factor receptor superfamily, member 12a (Tnfrfl2a) and thrombospondin (Thbs4) in both animal models and E2-treatment decreased the expression of these genes via ER $\beta$ and increased it in presence of ER $\alpha$.

Conclusion: These findings demonstrate that TAC induced expression of several clusters of genes. E2-treatment reduces the levels of pressure overload induced genes. This inhibitory effect is ER $\beta$ mediated.

\section{Introduction}

Cardiac hypertrophy is a common complication of hypertension, and is recognized as a risk factor for the development of congestive heart failure. ' Hypertrophy, an increase in cell size without cell division, is an adaptive process employed by post-mitotic muscle cells. ${ }^{2}$ In response to humoral and mechanical stimuli, the myocardium adapts to the increased work load through the hypertrophy of myocytes. Characteristics of the myocardial hypertrophic response include an increase in contractile protein content, induction of a more efficient contractile phenotype and the expression of several embryonic genetic markers. In vitro, rat cardiomyocytes, react with a characteristic succession of changes in gene expression. ${ }^{3}$ Some of these changes are considered to be markers of hypertrophy. These markers include the so-called early response genes (Egr-1, hsp70, c-fos, c-jun, c-myc), for which increased expression within $30 \mathrm{~min}$ of exposure to a hypertrophic stimulus has been reported. In cultured ventricular rat cardiomyocytes, re-expression of fetal genes, such $\beta \mathrm{MHC}, \alpha$-sk-actin and ANF, may occur after 6-12 h., ${ }^{4}$ but accumulation of the these proteins, $\beta M \mathrm{MC}^{5}, \alpha$-sk-actin ${ }^{6}$ and $\mathrm{ANF}^{7,8}$ can only be demonstrated after several days in culture. An upregulation of some contractile proteins, such as ventricular MLC-2 may follow after 12-24 h in culture. In the heart this transient response of fetal gene expression reflected a general pattern of growth induction in terminally differentiated cells that have lost the ability to undergo DNA replication. ${ }^{10-12}$ In vivo, in spontaneously hypertensive rats it has been shown that maladaptive remodeling of cardiac myocytes because of pressure overload begins long before the onset of clinical signs or impaired heart 
function in the progression of heart failure. ${ }^{13}$ Also in male rats aortic banding leads to re-expression of LV hypertrophic genes, including $\beta \mathrm{MHC}, \alpha$-sk-actin and ANF. ${ }^{14} \mathrm{E} 2$ is a potent mitogen that is involved in a wide scope of processes in mammalian cells. ${ }^{15}$ The functions of E2 are largely mediated through two distinct ER isoforms, ER $\alpha$ and ER $\beta .{ }^{16-19}$ ERs are ligand-modulated DNAbinding transcription factors, that regulate the expression of genes controlling cell growth and differentiation. ${ }^{20}$ Following E2 binding, the ER modulates gene expression, either by directly binding to specific DNA response elements or indirectly via protein-protein interactions in the regulatory regions of the E2-target genes. Activation of transcription by the ligand-bound receptor occurs through its association with specific transcriptional coactivators, such as the SRC/ pl60 family. ${ }^{21-23}$ Both $E R \alpha$ and $E R \beta$ have homology at the amino acid level within the ligand- and DNAbinding domains. However, differences between these ER isoforms exist in terms of tissue specificity and response to various ER agonists and antagonists. ${ }^{24}$

Identification of E2 target genes will reveal the effects of E2 on cardiac remodeling and the ER involved. Although we and others have identified a number of E2-responsive genes, we suppose that a large part of E2-regulated genes are unknown. ${ }^{25,26}$ DNA microarray technology permits the simultaneous analysis of a large number of transcribed genes. Array studies can provide gene expression profiles of tissues under well-defined experimental conditions. Combining such data with gene-expression profiles of large numbers of tissues from patients will ultimately result in the definition of gene-expression patterns associated with a particular cardiac condition and ER status as has been unraveled for instance in breast cancer. ${ }^{27}$ Already microarray studies have helped to define gene expression in an in vitro model and identified novel E2-responsive genes of potential clinical relevance. ${ }^{28}$ Furthermore, a few studies have compared the regulation of endogenous genes via $E R \alpha$ and $E R \beta$ in human osteoblastic cell lines expressing either $E R \alpha$ or $E R \beta{ }^{29}$

The aim of this study was to get an overview of the gene expression due to effects of E2 on TAC induced pressure overload. We used two mouse models, ER $\alpha$ knockout (ERKO) and ER $\beta$ knockout (BERKO) to differentiate for the ER involved in the E2 modulation of pressure overload induced gene expression.

\section{Material and methods}

\section{Animals}

The study comprises 16 groups of animals (Table 3.1). ERKO mice were produced as described previously by Lubahn et al. ${ }^{30}$ BERKO mice were generated and provided by Organon (Oss, the Netherlands) (Chapter 4). The animals were housed under standard conditions. The study was approved by the animal ethics committee of the University of Maastricht. For ovariectomy, pellet placement and transverse aortic constriction (TAC), animals were anesthetized with ketamine (100 $\mathrm{mg} / \mathrm{kg}$, intraperitoneal) and xylazine $(10 \mathrm{mg} / \mathrm{kg}$, intraperitoneal). Animals were randomly assigned to continuous $0.18 \mathrm{mg} \mathrm{E}_{2}$ supplementation or placebo via a subcutaneous pellet (Innovative Research, Sarasota, USA). $E_{2}$ serum levels were evaluated with a radioimmunoassay (DPC Biermann, Bad Nauheim, Germany) and by macroscopic observation of the uteri post mortem in a subset of animals.

TAC was performed, as described previously by Rockman et al. ${ }^{31}$ Ten weeks old WT, ERKO and BERKO mice provided by Organon (Oss, the Netherlands) were anesthetized. Mice were intubated and connected to a rodent ventilator. The chest was entered through the second intercostal space at the left upper sternal border through a small incision. The pericardium was opened and the transverse aorta was isolated. Aortic constriction was performed by tying a 7-0 nylon suture ligature against a 27-gauge needle to yield a narrowing $0.4 \mathrm{~mm}$ in diameter, when the needle was removed to obtain a reproducible TAC with $65-70 \%$ lumen reduction. After TAC the chest was closed, the 
A

\begin{tabular}{|l|l|l|}
\hline Group & Intervention & Treatment \\
\hline ERKO & TAC & placebo \\
\hline ERKO & TAC & E2 \\
\hline ERKO & Sham & placebo \\
\hline ERKO & Sham & E2 \\
\hline
\end{tabular}

B

\begin{tabular}{|l|l|l|}
\hline Group & Intervention & Treatment \\
\hline BERKO & TAC & placebo \\
\hline BERKO & TAC & E2 \\
\hline BERKO & Sham & placebo \\
\hline BERKO & Sham & E2 \\
\hline
\end{tabular}

Table 3.1. Study groups, Treatment groups of WT and ERKO mice (A) and treatment groups of WT and BERKO mice (B).

pneumothorax was evacuated, and the mouse was extubated and allowed to recover from anesthesia. Sham-operated animals underwent the same surgical procedure except for TAC.

\section{RNA Extraction and Microarrays}

Briefly total RNA was isolated from LV tissue using Trizol Reagent (Invitrogen). The total RNA was further purified using RNeasy columns (Qiagen, Crawley, UK) then cDNA from each sample was prepared according to the protocol recommended by Affymetrix Inc. $10 \mu \mathrm{g}$ of total RNA was reverse transcribed with a T7 oligo-dT primer using the Superscript Choice system (Invitrogen). Invitro transcription was performed using the ENZO Bioarray high yield RNA T7 labelling kit (Enzo, Farmingdale, NY). The resulting cRNA was cleaned up using RNeasy spin columns (Qiagen) and fragmented for 35 minutes at $94^{\circ} \mathrm{C}$ in $40 \mathrm{mM}$ Tris-acetate, $\mathrm{pH} 8.1,100 \mathrm{mM} \mathrm{KOAc}, 30 \mathrm{mM} \mathrm{MgOAc}$. The fragmented cRNAs from hearts of controls and treated mice were subjected to expression analysis using Affymetrix mouse MG-U74Av2 oligonucleotide microarrays (Affymetrix, Santa Clara, CA). These micro-arrays contain oligonucleotides corresponding to approximately 12000 known mouse genes and expressed sequence tags (ESTs). A full gene listing is available at: http://www.affymetrix.com/products/arrays/specific/mgu74.affx. Hybridisation to mouse MGU74Av2 arrays and laser scanning was carried out using a GeneChip Fluidics Station 400 and an Agilent GeneArray scanner. Scanned images were analysed using the Affymetrix GeneChip Microarray Suite (version 5.0) and scaled transcript abundance data for each pair of samples was compared. The Microarray Suite (version 5.0) software uses a standard alogarithm (http://www.affymetrix.com/products/software/index.affx) to determine whether the signal for each transcript differs significantly between the pair of samples and classifies them as decreased, increased or no change. We only considered genes with more than 2 fold increase or decrease for further analysis. These cutoff values provide a conservative estimate of the numbers of genes whose expression level is altered by TAC or E2 treatment.

\section{Results}

E2 replacement led to a reconstitution of physiological estrogen levels $(122 \mathrm{pg} / \mathrm{ml}$ in E2 treated versus $<5 \mathrm{pg} / \mathrm{ml}$ in placebo treated). All measured $\mathrm{E}_{2}$ levels in animals receiving placebo were under the detection level. To obtain gene profiles due to TAC and E2-treatment, hybridizations were done using cDNA samples from TAC and E2 treated ERKO and BERKO mice four weeks after intervention (Table 3.1 and Figure 3.1). The number of genes that differed more than 2-fold 
between two experimental groups are given in table 3.2. In ERKO mice TAC led to change of expression of 103 genes in E2-treated, and 154 genes in placebo-treated ERKO

ERKO

\begin{tabular}{|l|r|r|r|}
\hline Treatment & Number of genes & Upreguiated & Dewn reguiated \\
\hline E2-treatment in TAC & 260 & 73 & 103 \\
\hline E2-treatment in sham & 93 & 37 & 62 \\
\hline TAC in E2 treated & 103 & 55 & 40 \\
\hline TAC in piacebo treated & 154 & 104 & 50 \\
\hline
\end{tabular}

BERKO

\begin{tabular}{|l|r|r|r|}
\hline Treatment & Number of genes & Upreguiated & Dewn reguiated \\
\hline E2-treatment in TAC & 150 & 90 & 61 \\
\hline E-treatment in sham & 151 & 100 & 51 \\
\hline TAC in E2 treated & 340 & 139 & 201 \\
\hline TAC in placebo treated & 240 & 205 & 35 \\
\hline
\end{tabular}

Table 3.2. Number of genes up- or down-regulated with TAC and E2-treatment in ERKO and BERKO mice

mice as compared to E2-treated and placebo-treated sham mice, respectively. In the absence of ER $\alpha$ the expression of 266 genes changed in TAC E2-treated and 93 in sham E2-treated mice as compared to placebo-treated TAC and sham ERKO mice, respectively. In BERKO mice TAC changed expression of 340 genes in E2-treated and 240 genes in placebo-treated mice compared to E2-treated and placebo-treated sham BERKO mice respectively. Absence of ER $\beta$ in presence of E2 changed the expression of 340 in TAC and 240 in sham E2-treated BERKO mice compared to placebo-treated TAC and sham BERKO mice respectively.

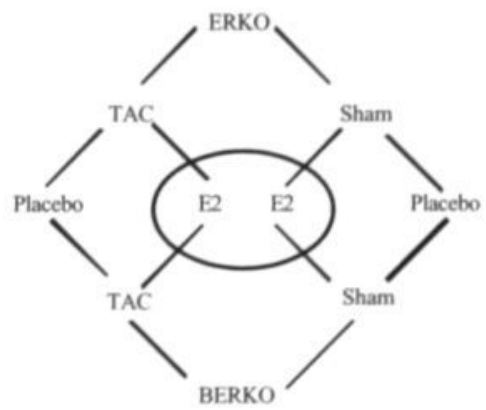

Figure 3.1. Schematic representation showing the animal groups and treatment in ERKO and BERKO mice. The circle represents the treatment and conditions compared in this study.

From the different experimental animal groups we selected clusters of genes for further comparisons. These clusters consisted of genes coding for structural proteins (cytoskeletal genes), stress proteins, growth factors proteins, cell adhesion proteins, metabolic proteins and signaling proteins (Table 3.3 and 3.4).

In ERKO and BERKO mice structural genes (cytoskeletal genes) such as $\beta \mathrm{MHC}, \mathrm{MLC}-2 \mathrm{a}$ and $\alpha$ sk-actin show a significant increase in their expression after TAC. Only in ERKO mice E2treatment resulted in a significant decrease in the expression of these genes (Table 3.3, 3.4 and Figure 3.2) indicating mediation of antihypertrophic E2 effects through the ER $\beta$. Stress genes like 
Hsp8, Hspla and Hsplb showed a decreased expression after TAC or E2-treatment in ERKO mice. However, in BERKO mice both TAC and E2-treatment, induced Hsp la (Table 3.3 and 3.4). The expression of the growth factor genes such as TGF $\beta$ increased significantly with TAC in both ERKO and BERKO mice in the absence of E2-treatment. Only in the ERKO mice E2-treatment decreased the expression of these genes (Table 3.3 and 3.4) again suggesting that suppression of TAC induced remodeling by $\mathrm{E} 2$ is mediated by ER $\beta$. TAC increased the expression of cell adhesion molecules such as Comp, Colla2, Tnfrfl2a and Thbs4 in both animal models and E2-treatment decreased the expression of these genes via ER $\beta$. Interestingly, ER $\alpha$ had the opposite effect of ER $\beta$, it significantly increased the expression of these genes with E2-treatment in BERKO mice (Table 3.3 and 3.4). Signaling proteins like mitogen-activated protein kinase kinase kinase 6 (Map3k6) and cardiac responsive adriamycin protein (Crap) showed a tendency to a decreased expression with E2treatment via ER $\beta$. However, TAC increased the expression of these genes only in the presence of E2 and ER $\beta$ (Table 3.3 and 3.4). There are a few genes that do not fit in one of these groups. However, the change in their expression levels are consistent and strong. Von Willebrand factor

\begin{tabular}{|c|c|c|c|c|c|c|c|c|}
\hline Gene name & $\begin{array}{l}\text { Ciene code } \\
\text { on chipp }\end{array}$ & $\begin{array}{l}\text { ERKO } \\
\text { TAC } \\
\text { E } 2 \mathrm{nP}\end{array}$ & $\begin{array}{l}\text { BERKO } \\
\text { TAC } \\
\text { PZnP }\end{array}$ & $\begin{array}{l}\text { ERKO } \\
\text { Sham } \\
\text { E2 } \mathrm{P} P\end{array}$ & $\begin{array}{l}\text { BERKO } \\
\text { Sham } \\
\text { F2ns P }\end{array}$ & $\begin{array}{l}\text { Cellular } \\
\text { location }\end{array}$ & Accesuion no & Function \\
\hline Cartilays ofigomers protein & Comp & -1 & & & \begin{tabular}{|c|c} 
\\
\end{tabular} & Extracel_space & NM 016085 & Cell adlestion \\
\hline Fregelligysn & Cell $A^{2}$ & 49 & 23 & & $\because$ & Fstrassi_space & $A W 545978$ & Celli adherion \\
\hline 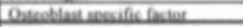 & $\operatorname{lon}$ & -65 & $\pi_{1}$ & 2.2 & 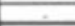 & Estrassh upaces & BLnoses & Cell adlowion. \\
\hline 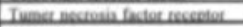 & Infunfin & & & 57 & $\bar{L}$ & Membrans & BES10567 & Cellodithevion \\
\hline Thumbausondin 4 & Thibut & 49 & 324 & & 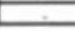 & Fethosilubass & SMM 011582 & Cellodithevien \\
\hline 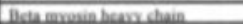 & Munt? & 149 & $\bar{x}$ & 41 & 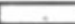 & 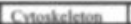 & SIM Os:0728 & 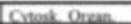 \\
\hline 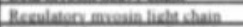 & Molne & 16 & & & 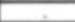 & 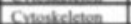 & SM 022579 & Conot Oram \\
\hline 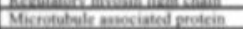 & Mtarib & $\frac{10}{49}$ & 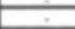 & & & Miscrotubules & Bifग & Cytos Rog \\
\hline Alphinitedeniastin & Actal & 41 & - & 36 & 21 & Cytonkelction & NM 007392 & $\begin{array}{l}\text { Mundie devel. } \\
\end{array}$ \\
\hline Cotsum hinding protesin & 510009 & i1 & - & 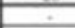 & $\div$ & & NM 00914 & C. binding \\
\hline Solvete camier & Sicelth2 & 73 & $\rightarrow$ & $\rightarrow$ & $\rightarrow$ & \begin{tabular}{|l|} 
Membrane \\
\end{tabular} & AB037192 & lees Transport \\
\hline Heal chosi materin \& & & & & & & & 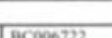 & \\
\hline 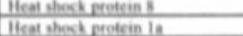 & 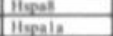 & $\therefore$ & 1714 & $\frac{-23}{41}$ & $\because$ & - & \begin{tabular}{|l} 
BCo06722 \\
AW763756
\end{tabular} & 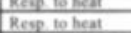 \\
\hline Ifeal chosk protsin if & Heralb & 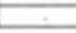 & 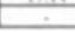 & 57 & 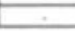 & & MI2573 & Compas inh \\
\hline Anityin and SOCS bu & Ant & 139 & 21 & - & . & - & AV113827 & Surnaliogs \\
\hline Anhymu reseal demain & Ankritlo & 46 & & 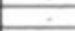 & 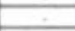 & E & NM 131971 & \begin{tabular}{|l} 
Sugnaling \\
\end{tabular} \\
\hline Retied binding proutrin & Rigl & & 26 & - & $\because$ & 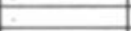 & NM 011294 & Sugrouling \\
\hline 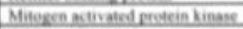 & Mapli6 & .21 & $=$ & 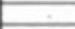 & 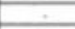 & 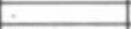 & NM Olowen & Signaling \\
\hline Adrampsin protein & Crop & .26 & & 4 & 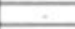 & Cytoplaum & NM 01408 & \begin{tabular}{|l} 
Sumpaling \\
\end{tabular} \\
\hline 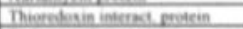 & Tonip & 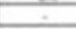 & 25 & 26 & $\because$ & Chaplasm & NM 023719 & Sumbaling \\
\hline 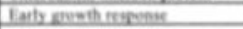 & Inel & - & $\because$ & 12 & 65 & Nusklous & SM 007913 & Signaling \\
\hline 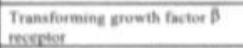 & Tufteri & $=$ & $=$ & $?$ & ? & membrame & NM 000370 & Growth \\
\hline Transforming yuusth foctas of & $\sqrt{T a^{2} 2^{2}}$ & 12 & $\because$ & 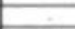 & 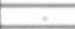 & Frtracel_agese & AW049985 & Growth \\
\hline 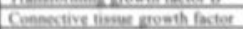 & कर & -65 & 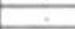 & -2 & 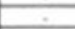 & $\begin{array}{ll}\text { Noxkew } \\
\end{array}$ & रM श0217 & Gonowth \\
\hline Mesitroghin & Fin & 11 & 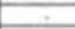 & & & Futroxel same & BCoogos & Growth facturs \\
\hline 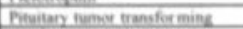 & Puisi & 21 & 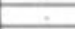 & -61 & .1111 & maxkes & रM 019917 & Cell promth \\
\hline Distherf hromoloy & 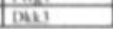 & 46 & - & 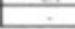 & -1 & Eatracel spece & AK004553 & Derschorment \\
\hline Amylane I & $A \mathrm{my}$ & 46 & . & 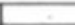 & + & - & NM 007446 & Metaboliem \\
\hline 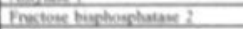 & $7 x^{2}$ & 57 & 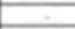 & 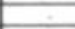 & $\because$ & & NM 007094 & \begin{tabular}{|l} 
Mrtakoliem \\
\end{tabular} \\
\hline Cotherein & and & 51 & - & 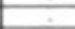 & - & Futronel gpese & NM 007802 & Protenlyzis \\
\hline 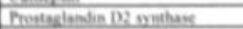 & Pugh & & - & 4 & 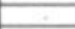 & Futresel upase & SM & Mecabolium \\
\hline 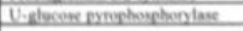 & $0=2$ & $?$ & $\because$ & 4 & 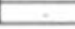 & Futraxel saxes & AV170025 & Mrabolinen \\
\hline EST deyueme sianilar to ANF & Ani & 450 & - & 459 & 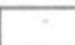 & & BM122009 & \\
\hline Fitromentulie & Fmel & .788 & 16 & $\longrightarrow$ & 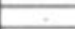 & Futmasel spase & $8 \times 860526$ & \\
\hline 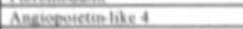 & Angreti & 21 & 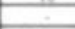 & - & $=$ & Kaniain cemp & NM 0:0881 & \\
\hline Somolipin & $\sin$ & 219 & - & 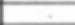 & 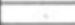 & Mermbrases & SM 025540 & \\
\hline RIKENCDNA geses & II10018205 & 61 & 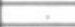 & & & Futmed spases & & \\
\hline 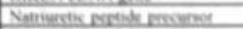 & Nint & & & 46 & 2 & Eutresel seme & SM 0egro & Homoes ativis \\
\hline 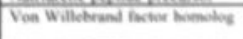 & vwy & $=$ & 26 & 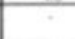 & $\div$ & 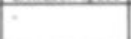 & Bac6 7216 & \\
\hline
\end{tabular}

Table 3.3. Gene regulated by E2-treatment in ERKO and BERKO mice four weeks after TAC 
homolog (vWF homolog) increased with TAC in ERKO mice and with E2-treatment via ER $\alpha$ in BERKO mice. An EST sequence with moderate similarity to ANF showed an increase in expression with TAC and a decrease in expression with E2-treatment in ERKO mice. Comparing ERKO and BERKO mice showed that structural, cell adhesion molecules, signaling and growth factor proteins decreased with E2-treatment in presence of ER $\beta$ and not ER $\alpha$. For these genes ER $\alpha$ showed an opposite effect to ER $\beta$. Stress proteins showed a decrease in expression in ERKO mice while there is no clear effect in BERKO mice (Table 3.3 and 3.4).

\begin{tabular}{|c|c|c|c|c|c|c|c|c|}
\hline Gene name & $\begin{array}{l}\text { Gene code } \\
\text { on chip }\end{array}$ & $\begin{array}{l}\text { ERKOE2 } \\
\text { TAC w } \\
\text { Shan }\end{array}$ & $\begin{array}{l}\text { BERKOEZ2 } \\
\text { TAC w } \\
\text { Shan }\end{array}$ & $\begin{array}{l}\text { ERKOP } \\
\text { TAC w } \\
\text { Shaen }\end{array}$ & $\begin{array}{l}\text { BtroKOP } \\
\text { TAC w } \\
\text { Sham }\end{array}$ & $\begin{array}{l}\text { Celludar } \\
\text { lacaten }\end{array}$ & Accensiven no & Funtion \\
\hline 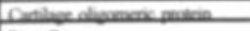 & Conen & & 12 & 81 & & Fulacel wave & 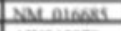 & 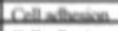 \\
\hline Brovlhese & Coll w2 & & 21 & 4 & & Futracel nave & Awsusezs & callabllaba. \\
\hline 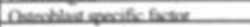 & no & & & as & & Filuacel gove & miness & Coll aflivasu \\
\hline 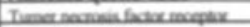 & Tnlagen & 12 & 101 & & & Mankax & massosw2 & cellativian \\
\hline Dinubugondind & Dabal & 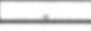 & 52 & 6s & & Eytracel apace & DQM & 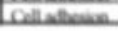 \\
\hline 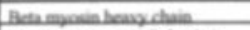 & Mbat & 2 & 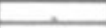 & 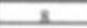 & + & Davaluktax & SML & Pand Orean \\
\hline Peplatog mgowis ledechain & Mblea2 & at & t. & 2 & 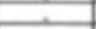 & Chobalative & Nacoser28 & Oolub Oryas \\
\hline 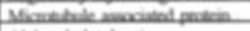 & Mtiaplb & & - & 6.5 & 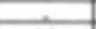 & Masablaba & 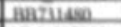 & Cowak Rey \\
\hline Ablavedeletalactis & Aalal & 19 & 2 & & 22 & Davelalatus & sML_onzon: & Mandedevel. \\
\hline Colving bindine onotoin. & $5 \operatorname{simn} 2$ & & & 61 & & & 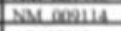 & Cubinaling \\
\hline 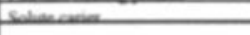 & Showlan & & & & & Mnaderan & Dagasues & Lum Dnamequat: \\
\hline Hestod povicins & Hepal & -1 & & 48 & . & & $\operatorname{lom} 232$ & Rew in heal \\
\hline Hendod packin la & Hagla & 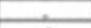 & 112.42 & -21 & a & & Aw7anz:4 & Rey in leat \\
\hline 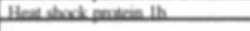 & Healh & -2 & & -86 & 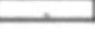 & La & 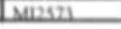 & 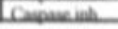 \\
\hline Adgrin and SocShan & Abl & 119 & 21 & - & 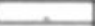 & S & Avแ1423 & Sigualiay \\
\hline Algran upost dwain & Andouling & -2 & & & 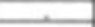 & t. & NML111921 & Signaling \\
\hline Petiand holing muloin & Whal & & 26 & & & H. & NMe 011244 & Sugnaling \\
\hline 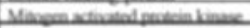 & Mandlis & & & & & & 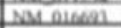 & Sugabling \\
\hline 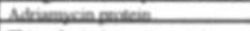 & Con & 21 & 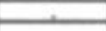 & 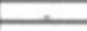 & 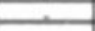 & Dandana & Bay-oLual & Sivenaline \\
\hline Dicmbavin interact patcin & Traip & 15 & . & & - & Colaglawn & MM- อ21219 & Signaling \\
\hline Fandy emusth response & Ferl & 28 & 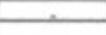 & 2 & 21 & Nunclens & INM 007213 & Sienaliag \\
\hline $\begin{array}{l}\text { Transforming growth factor } \beta \\
\text { moneptix }\end{array}$ & Tgfbel & - & - & 6.1 & - & membrane & NM_ 009370 & Growth \\
\hline 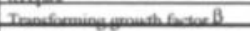 & Tefle 2 & - & 26 & 21 & + & Extracel pance & Aw040028 & Cimualh \\
\hline Connocture tivene emuath factor & ouf & 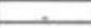 & 26 & 41 & a & Nuclens & NMeno217 & Cimmath \\
\hline Pleintmuphin & Pin & 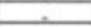 & 2 & 23 & - & Futracel yace & Horopost & Canudh fack \\
\hline Bituitary tumos mansforming & Prel & 65 & 6.1 & 2 & 21. & nuadeas & NM_e19212 & Cell gamalh \\
\hline Didkunfhamolog & Dwa & & & 28 & سمبـ & Entracel save & LAKOOBS51 & Developament \\
\hline Amglavel & Amyl & - & 21 & 1111 & + & & NM_ong46 & Cacholy Meta \\
\hline Envane hisphouphutase? & Plp2 & & 35 & 25 & . & & NM nomoen & Cactuh Mata \\
\hline Cathepsin & Couk & - & 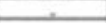 & . & 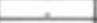 & Futracel space & NM_ $902 \times 02$ & Protonlyais \\
\hline Brostadandin D2 sonthave & Pheds. & 21 & 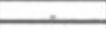 & 2 & ㄴ. & Entracel pace & NM_elesss & Medaboling \\
\hline Iheluonsenomphonghoglex & Llen? & & & & & Entracel space & LAvarones & Meabulivem \\
\hline EST sequence similar to ANF & $\begin{array}{l}\text { ANF } \\
\text { homologe }\end{array}$ & 3.03 & 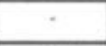 & 3.84 & 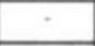 & - & BM122000 & - \\
\hline Fihromodulin & Fmod & . & 5971 & 15 & & Fitracel yace & Hasough & \\
\hline Anviopoictiolite4 & Anepela & 43 & & - & & Kuniuin comp & NM_easse & \\
\hline Satrolipin & $\sin$ & 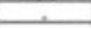 & & - & & Memhone & NML 025440 & \\
\hline BNKENCDNA wanc & Huponst.os & & & & & Futracel vance & & 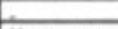 \\
\hline Natrinetic peptide procuroes & \begin{tabular}{|l|} 
Nonh \\
\end{tabular} & 26 & 28 & & سـ & Entracel wave & DM_ 008226 & Hemune actil \\
\hline Von Willebrand factor bomolog & $\begin{array}{l}\text { VWF } \\
\text { bomolog }\end{array}$ & $\cdot$ & $\cdot$ & 2.3 & $\overline{-}$ & - & BE667216 & 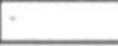 \\
\hline
\end{tabular}

Table 3.4. Genes regulated by TAC in ERKO and BERKO mice four weeks after TAC.

\section{Discussion}

\section{Technology}

Microarray technology has become a common tool for developing expression profiles. Initially used in the analysis of cell lines and homogeneous tissues, this technique has been applied to more complex tissues. ${ }^{32}$ DNA microarray technology permits the transcriptional analysis of a large number of genes and gene products simultaneously. ${ }^{27}$ Microarray studies have helped to establish gene expression data derived from experimental models and to identify genes of potential clinical relevance. ${ }^{28,33}$ In this study we used microarrays to determine the effect of TAC and E2-treatment 
on the gene expression profile in hearts of ERKO and BERKO mice. To limit the possibility of false positives, due to the reported limited sensitivity of the microarray method ${ }^{34,35}$, only those genes upor downregulated more than 2 -fold on the microarray were included in the analysis.

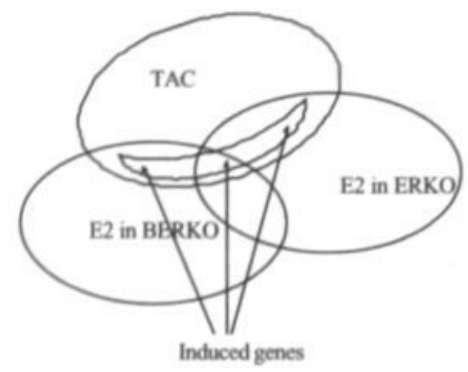

Figure 3.2. Schematic representation showing areas of interference between TAC and E2 treatment in both mouse models. The arrow indicate the position of the fetal genes.

\section{Changes in gene expression following aortic banding}

Hypertrophy is accompanied by distinct qualitative and quantitative changes in gene expression. ${ }^{12,36}$ In this study we confirmed that TAC induced hypertrophy is associated with increased expression of cytoskeletal genes. Among these genes are a number of genes normally expressed in the fetal heart. The expression of $\beta$ MHC, MLC-2a, and $\alpha$-sk-actin was increased by TAC in both models. Other groups have demonstrated re-expression of fetal genes such as $\beta \mathrm{MHC}$ and $\alpha$-sk-actin ${ }^{37}$ and MLC- $2 a{ }^{38}$ Also significant accumulation of the re-expressed proteins, for example, $\beta \mathrm{MHC}^{5,39}$ and $\alpha$-sm-actin ${ }^{6}$ was demonstrated following hypertrophy induction. Re-expression of the atrial MLC-1 was observed in the left ventricles of patients with various forms of compensatory hypertrophy. ${ }^{40}$ This MLC-1 is identical to the embryonal skeletal muscle MLC-1 and is normally expressed in fetal but not in adult ventricular tissue. The amount of MLC-1 in the left ventricle is correlated with the hemodynamic load that the heart must bear and diminishes in patients after successful improvement of the hemodynamic performance. ${ }^{41}$ The upregulated group of structural genes in mice with TAC corroborates with data from patients and animal experiments. These data are in agreement with previously published data from patients and animals and obtained by other methods and support the validity of the array techniques. In addition to these confirmatory data, proteins not previously associated with LVH such as microtubule associated protein (Mtaplb) and calcium binding protein $(\mathrm{S} 100 \mathrm{a} 9)$ were shown to be upregulated. Further research will be required to validate these results.

Our data showed an increase in the expression of cell adhesion genes like Comp, Colla2, Osf2, Tnfrsf, and Thbs 4 with hypertrophy. Cell adhesion proteins are involved in cardiac emodeling. Animal models as well as patient studies have shown changes in expression levels of these proteins. Hypertensive patients with concomitant risk factors indicating an adverse prognosis have elevated levels of circulating cell adhesion molecules like E-selectin, intercellular adhesion molecule-1 (ICAM-1), vascular adhesion molecule-1 (VCAM-1) and E-selectin. ${ }^{4244}$ Previous studies show that angiotensin II stimulates the release of ICAM- 1 in vitro and in vivo. ${ }^{45,46}$ Wang and Gerdes ${ }^{47}$ noticed a change in the distribution of beta-catenin and vinculin in hypertrophic hearts. ICAM-1 was also found to be involved in the remodeling of hypertrophic hearts in rats. ${ }^{48}$ ET-1 produces hypertrophy in NRVM and activates $6 \mathrm{cal}$ adhesion kinase (FAK). ${ }^{49}$ Surprisingly, the most mentioned cell adhesion molecules (ICAM-1 and VCAM) are not found to be affected in the array analysis. These molecules are shed during the early phase of cardiac remodeling. Absence in the analysis may therefore be due to temporal changes following aortic banding. 
Our array analysis displayed a decrease in the expression of stress genes HSPIb, HSP8 and HSPla with TAC in ERKO. In BERKO mice TAC increased the expression of HSPla while the expression of HSPIb and HSP8 was not affected. There is convincing proof that (over-) expression of stress proteins is an important mechanism of cytoprotection, also in the heart. ${ }^{50-52}$ Overexpression of hsp70 and hsp90 by transfection of plasmid vectors has been shown to protect cardiac cells against $\mathrm{LVH}$, but overexpression of hsp56 had no effect. ${ }^{53}$ Izumo et al ${ }^{10}$ did observe an increase in hsp70 levels following TAC. On the contrary, Tajima et al. ${ }^{54}$ showed that $\mathrm{Hsp} 72$ was down regulated in hypertrophic hearts. Thus, reports of previous studies vary for the different HSP genes. Taking pressure overload as a hypertrophy inducing condition we expected the expression of these genes to increase with TAC.

We noticed that the expression of growth factors genes such as TGF $\beta$ increased with TAC in both mouse models. These genes are known to be very important in the modulation of LV after pressure overload. The expression of these genes increased with hypertrophy and decreased with treatment. In pressure overload induced hypertrophy, TGF $\beta$ expression is upregulated three to four fold in adult rat cardiomyocytes, but not in mon-myocytes. ${ }^{55}$ TGF $\beta$ mRNA expression in cardiomyocytes has previously been shown to be increased during LVH induced either by pressure overload or by norepinephrine treatment. ${ }^{55.56}$ An increase in TGFâ expression is also observed during LVH development in rats, a monogenetic model of hypertension. ${ }^{57}$ Increased expression of TGFâ was observed in non-failing hypertrophy after abdominal aortic constriction. ${ }^{58}$ This indicates that E2 protects the heart against LVH via ER $\beta$ by controlling the expression of many genes including various growth factors.

\section{Effect of estrogens on gene expression following TAC}

Monroe and co-workers ${ }^{29}$ elegantly demonstrated by microarrays in an osteoblast cell line with either ER $\alpha$ or ER $\beta$ overexpression, that the two receptors affect different sets of genes. The data presented here also show distinct expression profiles in the hearts of ERKO versus BERKO mice, confirming that the two receptors interact with different sets of genes. Previously, it was shown that E2 was able to reduce LVH after TAC. ${ }^{59}$ We deduced then that the cardiac protective effects of E2 were effectuated via ER $\beta$.

E2-treatment decreased the expression of the structural genes such as $\beta$ MHC, MLC-2a, and $\alpha$-skactin, but only if the ER $\beta$ was present in the treated mice. The protective effects of E2 are in line with the reduced LVH in ERKO mice. ${ }^{59}$, (Chapter5). The expression of stress genes like HSPIb, HSP8 and HSPla is decreased with E2-treatment by ER $\beta$. ER $\alpha$ with E2-treatment increased the expression of HSPla while the expression of HSPIb and HSP8 was not affected. From this we can deduce that the effects of E2 on stress genes can be distinct for the different receptors. Depending on the condition, he different HSPs are presumed to be involved in different processes in the cardiomyocytes. A recent study ${ }^{60}$ reported that HSP72 levels were increased in the hearts of male rats after exercise, but not of females indicating that E2 decreased the expression of this gene. Recently it was proven that E2 increases levels of HSP72 in male rat cardiac myocytes, but has no effect on HSP27, HSP60, or HSP90. ${ }^{61}$ Few studies have addressed the effects of E2 on HSP expression, and gender differences have not previously been reported except for higher levels of HSP72 in serum of normal adult females versus males. ${ }^{62}$ The role of stress genes in cardiac remodeling deserves more attention. Bearing in mind the protective effects of E2, we expected decreased expression in TAC mice with E2-treatment. Surprisingly, we found a decrease after E2treatment in the absence of TAC. This indicates that E2 keeps stress genes at a low level in cardiac tissue. In general HSPs are known to facilitate the transition from one condition to another. Their expression increases at the onset of the adaptation e.g. hypertrophy and MI and change in 
expression coincides with the induced tissue modulation. The time of sacrifice of the TAC mice after 4 weeks may have been too late to detect a transient rise in HSP expression.

E2-treatment decreased the expression of growth factor genes such as TGF $\beta$ in mice. However, there were no changes in the expression level of this gene in E2-treated BERKO mice. In line with this result, improved ventricular function by combined angiotensin and endothelin receptor blockade was associated with reduced gene expression of TGF $\beta{ }^{63}$ TGF $\beta$ was also shown to be E2regulated in another microarray analysis. ${ }^{64,65}$ Our data support this notion as our results showed an increase of TGF $\beta$ with hypertrophy in both ERKO and BERKO mice, but only a down regulation by E2 in ERKO mice. The beneficial effect of E2, therefore is mediated by the ER $\beta$, which is in line with our results which showed that E2-treatment decreased LVH in ERKO (Chapter 4).

Signaling genes such as MAP3K6 decrease only with E2-treatment in ERKO. E2 could be one of the ligands, that decrease the expression of MAP3K6. Once activated the MAPKs phosphorylate serine or threonine residues in various nuclear and extranuclear substrates. ${ }^{66}$ Many important substrates for MAPKs are transcription factors that have been shown to be phosphorylated after MAPK translocation to the nucleus. ${ }^{67}$

Some individual genes such as VWF are upregulated by TAC. E2-treatment down regulated this TAC induced expression via ER $\beta$. This could mean that presence of E2 prevents the expression of VWF in hypertrophic hearts in the presence of ER $\beta$. VWF is a large secreted protein involved in blood clotting through interaction with factor VIII. ${ }^{68}$ The gene expression profile for VWF exhibited a strong 4.9 -fold induction by E2 in the U2OS-ER $\alpha$ cell line on microarray analysis. It has been suggested previously that VWF is associated with E2 signaling. ${ }^{68}$ E2 has a suppresive effect on the expression of VWF in presence of ER $\beta$, which could indicate a specific role for VWF in bypertropby, but its function in the cardiac system needs further evaluation.

Finally expression of a sequence with a moderate similarity to ANF (ANF homolog) was found to increase with TAC and decrease with E2-treatment in the presence of ER $\beta$. Although this sequence is not identical to ANF, the EST showed an increased expression with TAC. We and other groups have demonstrated re-expression of fetal genes such as ANF after E2 supplementation. ${ }^{25,37,59}$ Accumulation of the re-expressed proteins, for example $\mathrm{ANF}^{7}$ was demonstrated following hypertrophy. The ANF like EST showed a decrease with E2-treatment, which is opposite to the response of $\mathrm{ANF}{ }^{25.59}$ Further studies will be of importance to detect the relation of this sequence to ANF and E2. So these differences in gene expression between TAC ERKO and BERKO in presence of E2-treatment support the hypothesis that ER $\beta$ is essential for blocking the development of hypertrophy. This is in line with previous studies, which showed the importance of ER $\beta$ for the effects of E2 on the myocardium.

\section{Limitations of the study}

The study is limited by the fact that only at 4 weeks after TAC/treatment remodeling was analysed. Temporal aspects are therefore not taken into account. In the array analysis a number of genes known to be activated after TAC are not found. Nevertheless, some genes of interest have been identified by this limited study, and can now be investigated in more detail. Including temporal aspects and focusing on the ER $\beta$ mediated pathways may provide a more detailed picture of the molecular events following TAC and the way E2 influences LVH.

\section{Conclusion}

Although this is a preliminary study, which requires further validation, the results suggest a different response of the two receptors to E2-treatment. E2-treatment suppresses TAC induced expression of genes via $E R \beta$ and not $E R \alpha$. Further analysis are required to validate these findings. 


\section{Acknowledgments}

This work was supported by grants from the Netherlands Heart Foundation (NHS 99-114 and NHS 2000-160) and the Interuniversity Cardiology Institute Netherlands, Bekalis and Wynand Pon foundation to P.A.D., the Netherlands Heart Foundation (D98.015) to M. V. B. and by the Deutsche Forschungsgemeinschaft and BONFOR to $\mathrm{C}$. $\mathrm{G}$ and $\mathrm{M}$ v. E.. Additional support from the RESCAR foundation was greatly appreciated. We thank Organon, Oss, the Netherlands for providing the animals. 


\section{References}

1. Kannel WB, Levy D, Cupples LA. Left ventricular hypertrophy and risk of cardiac failure: insights from the Framingham Study. J Cardiovasc Pharmacol. 1987;10 Suppl 6:S135-40.

2. Morgan HE, Baker KM. Cardiac hypertrophy. Mechanical, neural, and endocrine dependence. Circulation. 1991;83:13-25.

3. Glennon PE, Sugden PH, Poole-Wilson PA. Cellular mechanisms of cardiac hypertrophy. Br Heart J. 1995;73:496-9.

4. Hefti MA, Harder BA, Eppenberger HM, et al. Signaling pathways in cardiac myocyte hypertrophy. J Mol Cell Cardiol. 1997;29:2873-92.

5. Eppenberger ME, Hauser I, Baechi T, et al. Immunocytochemical analysis of the regeneration of myofibrils in long-term cultures of adult cardiomyocytes of the rat. Dev Biol. 1988;130:1-15.

6. Eppenberger-Eberhardt M, Flamme I, Kurer V, et al. Reexpression of alpha-smooth muscle actin isoform in cultured adult rat cardiomyocytes. Dev Biol. 1990;139:269-78.

7. Eppenberger-Eberhardt M, Messerli M, Eppenberger HM, et al. New occurrence of atrial natriuretic factor and storage in secretorially active granules in adult rat ventricular cardiomyocytes in long-term culture. J Mol Cell Cardiol. 1993;25:753-7.

8. Eppenberger-Eberhardt M, Aigner S, Donath MY, et al. IGF-I and bFGF differentially influence atrial natriuretic factor and alpha-smooth muscle actin expression in cultured atrial compared to ventricular adult rat cardiomyocytes. J Mol Cell Cardiol. 1997;29:2027-39.

9. Long CS, Ordahl CP, Simpson PC. Alpha 1-adrenergic receptor stimulation of sarcomeric actin isogene transcription in hypertrophy of cultured rat heart muscle cells. J Clin Invest. 1989:83:1078-82.

10. Izumo S, NadałGinard B, Mahdavi V. Protooncogene induction and reprogramming of cardiac gene expression produced by pressure overload. Proc Natl Acad Sci USA. 1988;85:339-43.

11. Komuro I, Kurabayashi M, Takaku F, et al. Expression of cellular oncogenes in the myocardium during the developmental stage and pressure-overloaded hypertrophy of the rat heart. Circ Res. 1988;62:1075-9.

12. van Bilsen M, Chien KR. Growth and hypertrophy of the heart: towards an understanding of cardiac specific and inducible gene expression. Cardiovasc Res. 1993;27:1140-9.

13. Onodera T, Tamura T, Said S, et al. Maladaptive remodeling of cardiac myocyte shape begins long before failure in hypertension. Hypertension. 1998;32:753-7.

14. Weinberg EO, Thienelt CD, Katz SE, et al. Gender differences in molecular remodeling in pressure overload hypertrophy. J Am Coll Cardiol. 1999;34:264-73.

15. Katzenellenbogen BS. Estrogen receptors: bioactivities and interactions with cell signaling pathways. Biol Reprod. 1996;54:287-93.

16. Mangelsdorf DJ, Thummel C, Beato M, et al. The nuclear receptor superfamily: the second decade. Cell. 1995;83:835-9.

17. Kuiper GG, Enmark E, Pelto-Huikko M, et al. Cloning of a novel receptor expressed in rat prostate and ovary. Proc Natl Acad Sci US A. 1996;93:5925-30.

18. Mosselman S, Polman J, Dijkema R. ER beta: identification and characterization of a novel human estrogen receptor. FEBS Lett. 1996;392:49-53.

19. Tremblay GB, Tremblay A, Copeland NG, et al. Cloning, chromosomal localization, and functional analysis of the murine estrogen receptor beta. Mol Endocrinol. 1997;11:353-65.

20. Clemons M, Goss P. Estrogen and the risk of breast cancer. N Engl J Med. 2001:344:27685 .

21. Onate SA, Tsai SY, Tsai MJ, et al. Sequence and characterization of a coactivator for the steroid hormone receptor superfamily. Science. 1995;270:1354-7. 
22. Voegel JJ, Heine MJ, Zechel C, et al. TIF2, a $160 \mathrm{kDa}$ transcriptional mediator for the ligand-dependent activation function AF-2 of nuclear receptors. Embo J. 1996;15:3667-75.

23. $\mathrm{Li} \mathrm{H}$, Gomes PJ, Chen JD. RAC3, a steroid/nuclear receptor-associated coactivator that is related to SRC-1 and TIF2. Proc Natl Acad Sci US A. 1997;94:8479-84.

24. Paech K, Webb P, Kuiper GG, et al. Differential ligand activation of estrogen receptors ERalpha and ERbeta at AP1 sites. Science. 1997;277:1508-10.

25. Babiker FA, De Windt LJ, van Eickels M, et al. 17beta-estradiol antagonizes cardiomyocyte hypertrophy by autocrine/paracrine stimulation of a guanylyl cyclase A receptor-cyclic guanosine monophosphate-dependent protein kinase pathway. Circulation. 2004;109:269. 76.

26. Wang DY, Fulthorpe R, Liss SN, et al. Identification of estrogen-responsive genes by complementary deoxyribonucleic acid microarray and characterization of a novel early estrogen- induced gene: EEIG1. Mol Endocrinol. 2004;18:402-11.

27. van ' $t$ Veer $\mathrm{U}$, Dai $\mathrm{H}$, van de Vijver MJ, et al. Gene expression profiling predicts clinical outcome of breast cancer. Nature. 2002;415:530-6.

28. Finlin BS, Gau CL, Murphy GA, et al. RERG is a novel ras-related, estrogen-regulated and growth-inhibitory gene in breast cancer. J Biol Chem. 2001;276:42259-67.

29. Monroe DG, Getz BJ, Johnsen SA, et al. Estrogen receptor isoform-specific regulation of endogenous gene expression in human osteoblastic cell lines expressing either ERalpha or ERbeta. J Cell Biochem. 2003;90:315-26.

30. Lubahn DB, Moyer JS, Golding TS, et al. Alteration of reproductive function but not prenatal sexual development after insertional disruption of the mouse estrogen receptor gene. Proc Natl Acad Sci U S A. 1993;90:11162-6.

31. Rockman HA, Ross RS, Harris AN, et al. Segregation of atrial-specific and inducible expression of an atrial natriuretic factor transgene in an in vivo murine model of cardiac hypertrophy. Proc Natl Acad Sci US A. 1991;88:8277-81.

32. Glanzer JG, Haydon PG, Eberwine JH. Expression profile analysis of neurodegenerative disease: advances in specificity and resolution. Neurochem Res. 2004;29:1161-8.

33. Bouras T, Southey MC, Chang AC, et al. Stanniocalcin 2 is an estrogen-responsive gene coexpressed with the estrogen receptor in human breast cancer. Cancer Res. 2002;62:128995.

34. Shiffman D, Porter JG. Gene expression profiling of cardiovascular disease models. Curr Opin Biotechnol. 2000;11:598-601.

35. de Jong DS, van Zoelen EJ, Bauerschmidt S, et al. Microarray analysis of bone morphogenetic protein, transforming growth factor beta, and activin early response genes during osteoblastic cell differentiation. J Bone Miner Res. 2002;17:2119-29.

36. Boheler KR, Chassagne C, Martin X, et al. Cardiac expressions of alpha- and beta-myosin heavy chains and sarcomeric alpha-actins are regulated through transcriptional mechanisms. Results from nuclear run-on assays in isolated rat cardiac nuclei. $J$ Biol Chem. 1992;267:12979-85.

37. Schaub MC, Hefti MA, Harder BA, et al. Various hypertrophic simuli induce distinct phenotypes in cardiomyocytes. J Mol Med. 1997;75:901-20.

38. Lee HR, Henderson SA, Reynolds R, et al. Alpha 1-adrenergic stimulation of cardiac gene transcription in neonatal rat myocardial cells. Effects on myosin light chain-2 gene expression. J Biol Chem. 1988;263:7352-8.

39. Nag AC, Cheng M. DNA synthesis of adult mammalian cardiac muscle cells in long-term culture. Tissue Cell. 1986;18:491-7. 
40. Hirzel HO, Tuchschmid CR, Schneider J, et al. Relationship between myosin isoenzyme composition, hemodynamics, and myocardial structure in various forms of human cardiac hypertrophy. Circ Res. 1985;57:729-40.

41. Kurabayashi M, Komuro I, Shibasaki Y, et al. Functional identification of the transcriptiona regulatory elements within the promoter region of the human ventricular myosin alkali light chain gene. J Biol Chem. 1990;265:19271-8.

42. Boehme MW, Waldherr R, Kist A, et al. Kinetics of soluble TNF-receptors and soluble adhesion molecules ICAM-1, E-selectin and VCAM-1 under systemic rhTNF alpha therapy. Eur J Clin Invest. 1996;26:404-10.

43. Ferri C, Desideri G, Valenti M, et al. Early upregulation of endothelial adhesion molecules in obese hypertensive men. Hypertension. 1999;34:568-73.

44. Malmqvist K, Wallen HN, Held C, et al. Soluble cell adhesion molecules in hypertensive concentric left ventricular hypertrophy. J Hypertens. 2002;20:1563-9.

45. Pastore L, Tessitore A, Martinotti S, et al. Angiotensin II stimulates intercellular adhesion molecule-1 (ICAM-1) expression by human vascular endothelial cells and increases soluble ICAM-1 release in vivo. Circulation. 1999;100:1646-52.

46. Grafe M, Auch-Schwelk W, Zakrzewicz A, et al. Angiotensin II-induced leukocyte adhesion on human coronary endothelial cells is mediated by E-selectin. Circ Res. 1997;81:804-11.

47. Wang X, Gerdes AM. Chronic pressure overload cardiac hypertrophy and failure in guinea pigs: III. Intercalated disc remodeling. J Mol Cell Cardiol. 1999;31:333-43.

48. Kuwahara F, Kai H, Tokuda K, et al. Roles of intercellular adhesion molecule-1 in hypertensive cardiac remodeling. Hypertension. 2003;41:819-23.

49. Eble DM, Strait JB, Govindarajan G, et al. Endothelin-induced cardiac myocyte hypertrophy: role for focal adhesion kinase. Am J Physiol Heart Circ Physiol. 2000;278:H1695-707.

50. Plumier JC, Ross BM, Currie RW, et al. Transgenic mice expressing the human heat shock protein 70 have improved post-ischemic myocardial recovery. J Clin Invest. 1995;95:185460 .

51. Marber MS, Mestril R, Chi SH, et al. Overexpression of the rat inducible 70-kD heat stress protein in a transgenic mouse increases the resistance of the heart to ischemic injury. $J$ Clin Invest. 1995;95:1446-56.

52. Radford NB, Fina M, Benjamin IJ, et al. Cardioprotective effects of 70-kDa heat shock protein in trans genic mice. Proc Natl Acad Sci US A. 1996;93:2339-42.

53. Cumming DV, Heads RJ, Watson A, et al. Differential protection of primary rat cardiocytes by transfection of specific heat stress proteins. J Mol Cell Cardiol. 1996;28:2343-9.

54. Tajima M, Isoyama S, Nitta Y, et al. Attenuation of heat shock protein expression by coronary occlusion in hypertrophied hearts. Am J Physiol. 1997;273:H526-33.

55. Takahashi N, Calderone A, Izzo NJ, Jr., et al. Hypertrophic stimuli induce transforming growth factor-beta 1 expression in rat ventricular myocytes. J Clin Invest. 1994;94:1470-6.

56. Brand T, Schneider MD. The TGF beta superfamily in myocardium: ligands, receptors, transduction, and function. J Mol Cell Cardiol. 1995;27:5-18.

57. Pinto YM, Pinto-Sietsma SJ, Philipp T, et al. Reduction in left ventricular messenger RNA for transforming growth factor beta(1) attenuates left ventricular fibrosis and improves survival without lowering blood pressure in the hypertensive TGR(mRen2)27 Rat. Hypertension. 2000;36:747-54.

58. Everett AD, Tufro-McReddie A, Fisher A, et al. Angiotensin receptor regulates cardiac hypertrophy and transforming growth factor-beta 1 expression. Hypertension. 1994;23:58792. 
59. van Eickels M, Grohe C, Cleutjens JP, et al. 17beta-estradiol attenuates the development of pressure-overload hypertrophy. Circulation. 2001;104:1419-23.

60. Paroo Z, Haist JV, Karmazyn M, et al. Exercise improves postischemic cardiac function in males but not females: consequences of a novel sex-specific heat shock protein 70 response. Circ Res. 2002;90:911-7.

61. Knowlton AA, Sun L. Heat-shock factor-1, steroid hormones, and regulation of heat-shock protein expression in the heart. Am J Physiol Heart Circ Physiol. 2001;280:H455-64.

62. Pockley AG, Shepherd J, Corton JM. Detection of heat shock protein $70(\mathrm{Hsp} 70)$ and antiHsp70 antibodies in the serum of normal individuals. Immunol Invest. 1998;27:367-77.

63. Tzanidis A, Lim S, Hannan RD, et al. Combined angiotensin and endothelin receptor blockade attenuates adverse cardiac remodeling post-myocardial infarction in the rat: possible role of transforming growth factor beta(1). J Mol Cell Cardiol. 2001;33:969-81.

64. Robinson JA, Harris SA, Riggs BL, et al. Estrogen regulation of human osteoblastic cell proliferation and differentiation. Endocrinology. 1997;138:2919-27.

65. Khosla S, Melton LJ, 3rd, Riggs BL. Osteoporosis: gender differences and similarities. Lupus. 1999;8:393-6.

66. Seger R, Krebs EG. The MAPK signaling cascade. Faseb J. 1995;9:726-35.

67. Treisman R. Regulation of transcription by MAP kinase cascades. Curr Opin Cell Biol. 1996;8:205-15.

68. Budde U, Schneppenheim R. Von Willebrand factor and von Willebrand disease. Rev Clin Exp Hematol. 2001;5:335-68; quiz following 431. 


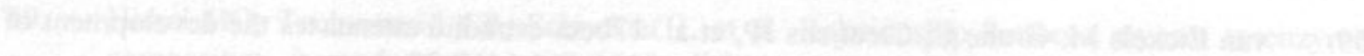

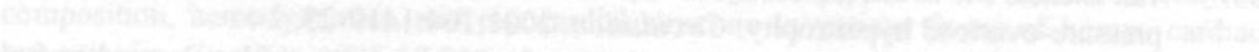

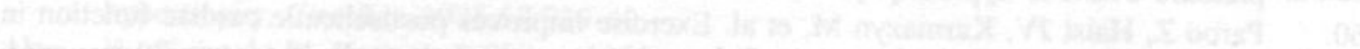

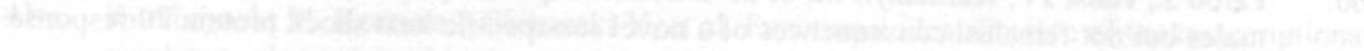
-

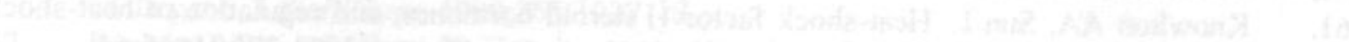

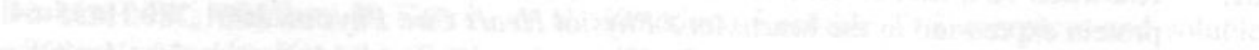

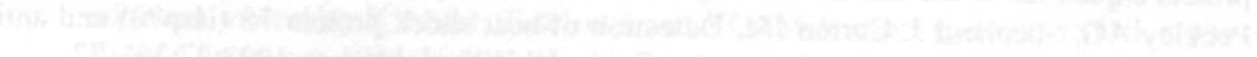

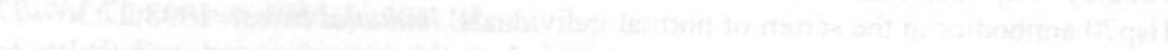

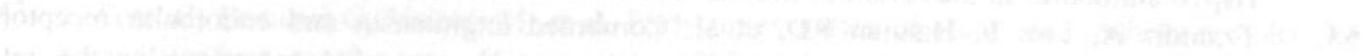

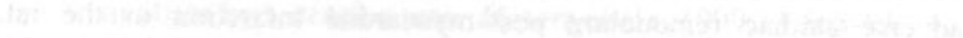

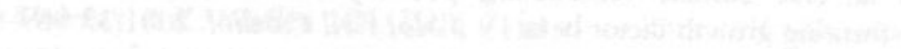


17/-estradiol Antagonizes Cardiomyocyte Hypertrophy by Autocrine/Paracrine Stimulation of a Guanylyl Cyclase A Receptor - Cyclic Guanosine Monophosphate-Dependent Protein Kinase Pathway

Fawzi A. Babiker MS, Leon J. De Windt PhD, Martin van Eickels MD, Victor Thijssen PhD, Ronald J.P. Bronsaer MS, Christian Grohé MD, Marc van Bilsen PhD, Pieter A. Doevendans MD, PhD. 


\begin{abstract}
Background: Significant gender-related differences exist in the development of left ventricular hypertrophy (LVH). In addition, administration of $17 \beta$-estradiol (E2) to ovariectomized female mice attenuates the development of $\mathrm{LVH}$, demonstrating an antagonistic role for $\mathrm{E} 2$ in this process, although no molecular mechanism has been proposed for this phenomenon.

Methods and Results: E2 attenuated phenylephrine (PE) and endothelin-1 (ET-1) induced hypertrophy in neonatal cardiomyocytes, and E2 directly induced atrial natriuretic factor (ANF) expression as assessed by Northern blot, immunocytochemical analyses, and transient transfection assays using ANF promoter deletion fragments. Both the anti-hypertrophic effects and ANFinduction could be blocked by the estrogen receptor antagonist ICI 182,780, which demonstrates a genomic, estrogen receptor-dependent pathway. To mimick E2-induced auto/paracrine effects through stimulation of the guanylyl cyclase A receptor (ANF receptor), cardiomyocytes were stimulated with phenylephrine or endothelin-1 in the presence of exogenous ANF or 8-bromo-cyclic guanosine monophosphate (cGMP), both of which attenuated agonist-induced hypertrophy. Both estrogen and ANF increased cGMP activity. The antihypertrophic effect of ANF could be reduced with extracellular ANF antibodies in a dose-dependent manner. cGMP-dependent protein kinase mediates the anti-hypertrophic effects of E2, so cardiomyocytes were agonist stimulated in the presence of cGMP-dependent protein kinase blocker KT-5823. KT-5823 not only reversed the antihypertrophic properties of E2, ANF and 8-bromo-cGMP, but also evoked potentiation of hypertrophy.

Conclusions: E2 mediated induction of ANF in cardiac hypertrophy contributes to its antagonistic effects in LVH.
\end{abstract}

\title{
Introduction
}

The mammalian heart elicits hypertrophy in response to stimuli that elevate wall stress in an attempt to decrease wall tension. ${ }^{1}$ Cardiomyocyte hypertrophy is characterized by an increase in cellular volume and enhanced sarcomeric organization of individual myocytes. ${ }^{2}$ The molecular response of ventricular myocytes to left ventricular hypertrophy $(\mathrm{LVH})$ involves the reinduction of genes transiently expressed during embryogenesis, ${ }^{2}$ and is initiated by complex cascades of cytoplasmic signaling events. ${ }^{3}$

Sex hormones such as estrogen have properties that are of potential benefit to inhibit the progression of cardiac disease. The incidence and severity of cardiovascular disease, including $\mathrm{LVH}$, in premenopausal women is lower than in men of comparable age, even after correcting for various risk factors. ${ }^{4}$ However, the molecular effects of estrogen on ventricular cardiomyocytes which may account for this clinical observation, are less well understood. Cardiomyocytes express functional estrogen receptors (ERs) and estrogen treatment modulates the expression of cardiacspecific genes. ${ }^{5}$ Recently, we demonstrated that female, ovariectomized mice develop a more robust $\mathrm{LVH}$ response in a model of pressure-overload than ovariectomized mice with replacement of physiological levels of $17 \beta$-estradiol. In particular, more pronounced ventricular expression of atrial natriuretic factor (ANF) in the banded, estrogen-supplemented group, as compared to vehicletreated, banded animals was noticeable. ${ }^{6}$

ANF is a peptide hormone, that under physiological conditions displays a restricted atrial expression pattern in the adult heart. ${ }^{7}$ Increasing evidence favors the notion that ANF may function as a local endocrine inhibitor of $\mathrm{LVH}^{8}{ }^{8}$ In support of this notion, ANF administration to cultured cardiomyocytes has been associated with growth-limiting effects.

Here, we studied the relationship between estrogen-mediated inhibitor of hypertrophy, ANF expression and guanylyl cyclase A receptor (GC-A) signaling in cultured cardiomyocytes. E2 exerted profound anti-hypertrophic effects on ventricular myocytes and this finding was accompanied by a direct stimulation of ANF transcription. Both ANF and 8-bromo-cGMP exhibited 
similar anti-hypertrophic effects in a dose-dependent manner, suggesting autocrine/paracrine stimulation of GC-A receptor signalling following estrogen administration.

\section{Methods}

\section{Materials}

17ß-estradiol (E2), 17 $\alpha$-estradiol, hydroxytamoxifen, phenylephrine (PE), endothelin (ET-1), 8 bromo-cGMP, ANF, KT-5823, antiserum to sarcomeric $\alpha$-actinin (EA-53), tetramethylrhodamine $\beta$-isothiocyanate (TRITC)-conjugated goat anti-mouse antibodies, and fluorescein isothiocyanate (FITC) goat anti-rabbit ant ibodies, were purchased from (Sigma Aldrich, Steinheim, Germany). ICI 182,780 was a kind gift of Dr. A. Wakeling (AstraZeneca, Wilmington, Del), and monoclonal and polyclonal anti-ANF antibodies were obtained from Peninsula Laboratories. Vectashield was purchased from Vector Laboratories. Animals were handled according to the guidelines of the animal welfare committee of the university of Maastricht. Primary cultures of 1-4 day old Lewis neonatal rat ventricular myocytes (NRVM) were obtained as described previously. ${ }^{10}$

\section{Transfection analysis: Luciferase}

Human embryonic kidney (HEK293) cells were maintained in DMEM (Life Technologies, Paisley, UK) supplemented with $10 \%$ calf bovine serum (FBS) and transiently transfected with pGL3 vectors containing ANF promoter deletion fragments encompassing 700bp(ANF-700luc) or 150bp (ANF-150 luc) of the proximal rat ANF promoter, ${ }^{11}$ an estrogen receptor-á expression vector (HEG0, kind gift of Dr. P. Chambon, Université Louis Pasteur/college de France, Illkirch, France), and SV40- $\beta$ Gal (Promega) using the lipid-based reagent Fugene 6 (Roche Molecular Biochemicals) as described previously. ${ }^{12} \mathrm{~A}$ set of 3 individual transfection experiments was performed and measured 3 times. NRVM were treated with E2 $\left(10^{-9} \mathrm{~mol} / \mathrm{L}\right)$ and $/$ or ICI $182,782\left(10^{-5} \mathrm{~mol} / \mathrm{L}\right)$ for 48 hrs and harvested as described earlier. Data are presented as relative luciferase activity based on the luciferase/galactosidase $(\mathrm{Luc} / \mathrm{Gal})$ ratio.

\section{Northern Blot analysis}

Total RNA was isolated from cardiomyocytes with TRIzol reagent (Life Technologies). Northern blot hybridizations were performed by use of a modified protocol. ${ }^{13}$ In brief, a 600 bp fragment of rat ANF cDNA or a 300 bp fragment of rat GAPDH cDNA, were labelled with ${ }^{32}$ P-dCTP (Dupont de Nemours, NV) using a random labeling kit (Life Technologies), added to the hybridization solution at $1 \times 10^{6} \mathrm{cpm} / \mathrm{mL}$ and incubated overnight at $58^{\circ} \mathrm{C}$. Stringent post-hybridization wash conditions were used $\left(0.1 \times \mathrm{SSC}, 0.1 \% \mathrm{SDS}\right.$ at $\left.58^{\circ} \mathrm{C}\right)$.

\section{Immunocytochemistry}

Cardiomyocytes were prepared for immunocytochemistry as described previously. ${ }^{10}$ Morphological changes were documented with a Nikon Eclipse CFL60 Epifluoresence Microscope. Surface area measurements were performed on fixed cardiomyocytes using NIH image analysis software (Ascion). At least 100 NRVM in 20 to 25 fields were examined in each experiment, and data are expressed as pooled averages of 3 independent experiments.

\section{Biochemical Analysis}

Lactate dehydrogenase (LDH) activity was measured. TUNEL assay was performed with the CardioTACS kit (Trevigen) according to the manufacturer's instructions on both stimulated and nonstimulated NRVM. ${ }^{14} \mathrm{NRVM}$ were treated with an ice cold lysis buffer containing $0.5 \%$ Nonidet P40, $150 \mathrm{mmol} \mathrm{NaCl}, 10 \mathrm{mmol}$ Tris- $\mathrm{HCl}$ pH 8.0, 0.5mmol EDTA in the presence of a cocktail of proteinase inhibitors $(2 \mu \mathrm{g} / \mu \mathrm{l}$ leupeptin, $10 \mu \mathrm{g} / \mathrm{mL}$ PMSF (Sigma), $2 \mu \mathrm{g} / \mathrm{mL}$ soybean trypsin 
inhibitor (Gibco BRL). The amount of protein was estimated by the method of Bradford. ANF levels were measured using radioimmunoassay.

\section{Statistical Analysis}

Data are expressed as mean \pm SEM. For all statistical analysis, Instat 3.0 GraphPad software was used. Differences between experimental groups were evaluated for statistical significance by either one-way ANOVA followed by Bonferroni's post hoc test or a Student's t-test when appropriate. P values $<0.05$ were considered to be statistically significant.

\section{Results}

\section{Estrogen antagonizes cardiomyocyte hypertrophy}

NRVM were exposed to the hypertrophic agonist PE $\left(10^{-5} \mathrm{~mol} / \mathrm{L}\right)$ for $48 \mathrm{hrs}$. PE induced a typical hypertrophic phenotype characterized by increased cell surface-area and enhanced sarcomeric organization compared with cells exposed to vehicle treatment (Figure 4.1, A and B). The presence of E2 in a physiological concentration $\left(10^{-9} \mathrm{~mol} / \mathrm{L}\right)$ attenuated the PE-induced hypertrophic morphology (Figure 4.1C ) substantially. Co-adminstration of the ER antagonist ICI 182,780 (10 ${ }^{-5}$ $\mathrm{mol} / \mathrm{L}$ ) resulted in reappearance of the hypertrophic morphology and sarcomeric organization (Figure 41D). E2 treatment alone resulted in a reduction in cardiomyocyte size (Figure 4.1E). Similar results were obtained when the NRVM were exposed to $10^{-5}$ ET-1 in the presence or absence of E2 (data not shown).

'Z E auministration caused' an approximate increase of $69 \%$ in cell surface area. In line with the immunocytochemical observations, the presence of E2 reduced the PE-induced increase in cell surface area by $85 \%$ ( $\mathrm{P}<0.05$ vs $\mathrm{PE}$ alone). The effect of E2 on PE-induced hypertrophy was fully reversed by coincubation with ICI 182,780 (Figure 4.1F). Similar findings were obtained for cardiomyocytes stimulated with ET-1 (data not shown).

To further demonstrate the antihypertrophic effect of E2, total cellular protein content of cardiomyocytes subjected to the different treatment conditions was determined. PE-induced hypertrophy was associated with a $21 \pm 2 \%$ increase in total cellular protein content $(\mathrm{P}<0.05$ vs untreated cells; Figure 4.1G). E2 traetment prevented the PE-induced increase in protein synthesis, whereas treatment with ICI 182,780 reversed the E2-mediated anti-hypertrophic effects (Figure 4.1G). E2 stimulation alone evoked a small but significant reduction in total cellular protein content, an effect abolished in the presence of ICI 182,780 (Figure 4.1G).

To exclude the potential of E2-mediated cellular stress and toxicity in our experimental model, LDH activity in the culture medium was determined as a marker of viability. No difference in LDH was detected under any condition tested as compared to untreated cardiomyocytes (data not shown). Furthermore, in a subset of experiments, E2-treated cardiomyocytes were subjected to TUNEL staining, but no induction of cardiomyocyte apoptosis was evident (data not shown). Taken together, these results indicate that E2 specifically antagonizes agonist-induced cardiomyocyte hypertrophy. Moreover, the effects were efficiently reversed by addition of the ER antagonist ICI 182,780 , confirming that ER-dependent mechanisms are involved. 

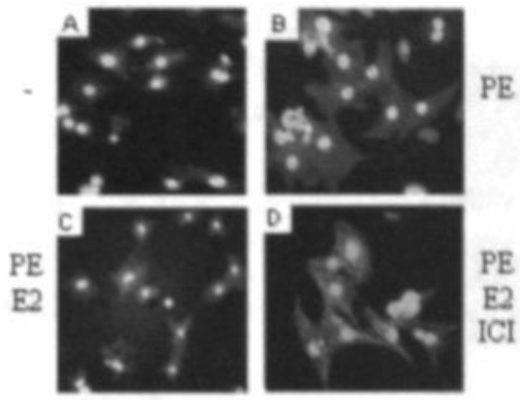

E2

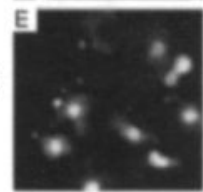

$\mathbf{F}$

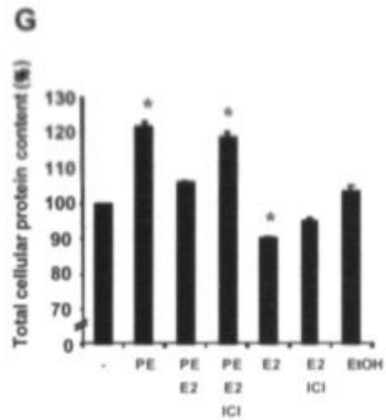

Figure 4.1. E2 antagonizes PE-induced cardiomyocyte hypertrophy. Cardiomyocytes were identified with $\alpha$ actinin antibody (red signal) and nuclei were stained with bis-benzamide (white). Cardiomyocytes stimulated with PE $\left(10^{\circ} 5 \mathrm{~mol} / \mathrm{L}\right)$ demonstrated a significant hypertrophic response $(B)$ compared to non treated $f$ ) cultured myocytes (A). Costimulation with E2 (109mol/L) attenuated myocyte hypertrophy (C), whereas costimulation with ICl $182,780\left(10^{-5} \mathrm{~mol} / \mathrm{L}\right)$ resulted in hypertrophic and sarcomeric reorganization (D). Stimulation with $E 2$ alone resulted in a significant reduction in cardiomyocyte surface area $(E)$. Quantification of cell surface area (F) and total protein content $(G)$ of 3 independent experiments. ${ }^{*} P<0.05$ vs. control $(-)$ conditions.

\section{Estrogen specifically induces ANF gene expression}

ANF immunoreactivity of cardiomyocytes was analyzed in the presence of PE and/or E2. $\alpha$ adrenergic stimulation resulted in an increased intensity of perinuclear ANF staining in a larger number of cardiomyocytes compared to non-treated cardiomyocytes (Figure 4.2, A and B). Costimulation with $\mathrm{PE}$ and $\mathrm{E} 2$, a condition that was associated with attenuation of all morphological aspects of myocyte hypertrophy (Figure 4.1C), did not diminish ANF immunoreactivity (Figure 4.2C), whereas the presence of ICI 182,780 did reduce ANF (Figure 4.2D). In fact, E2 treatment of NRVM in the absence of PE was sufficient to induce the typical perinuclear ANF staining (Figure 4.2E). 


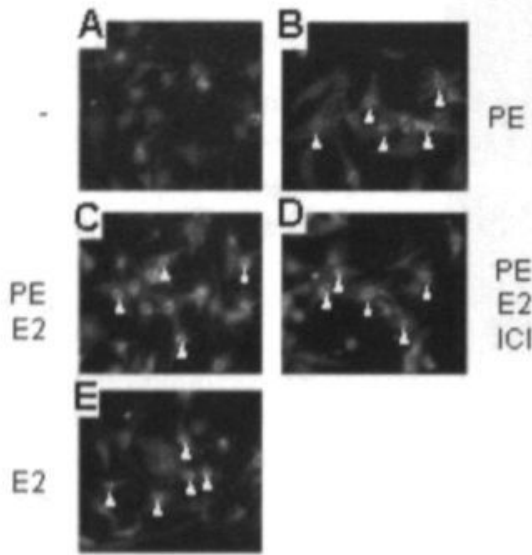

$\mathbf{F}$

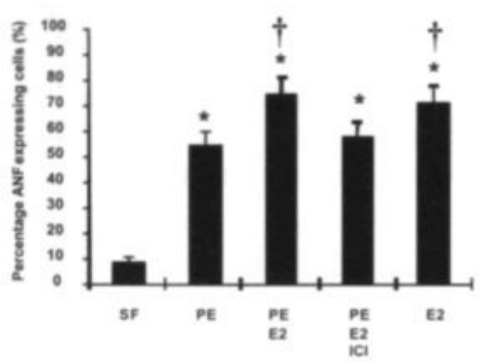

Figure 4.2. E2 stimulates ANF mRNA expression. Cardiomyocytes were stained with ANF antibody (green). Cardiomyocytes were stimulated with PE $(105 \mathrm{~mol} / \mathrm{L})$, with or without presence of E2 $(109 \mathrm{~mol} / \mathrm{L})$ and/or $\mathrm{ICl}$ $182,782(105 \mathrm{~mol} / \mathrm{L})$ for $48 \mathrm{hrs}$ and immunostained with an antibody against ANF. Cells cultured under serum free conditions $(f)$ revealed no ANF protein expression (A), whereas PE (B) induced a typical perinuclear ANF protein expression (white arrow). Presence of E2 (C) increased ANF protein expression which is reduced in presence of $\mathrm{ICl} 182,780$ (D). Stimulation of cardiomyocytes with E2 alone resulted in an abundant ANF expression (E). Quantification of percent ANF expressing cells (F) from 3 independent experiments. " $P<0.05$ vs. control $(-)$ conditions; $\uparrow$ indicates $P<0.05$ vs. $P E$.

Quantification of ANF-positive cardiomyocytes supported the immunocytochemical observations. Only $8 \pm 2 \%$ of cardiomyocytes cultured under serum free conditions displayed the characteristic perinuclear ANF staining pattern. In contrast, $54 \pm 4 \%$ of PE-stimulated cardiomyocytes revealed intense ANF immunoreactivity ( $\mathrm{P}<0.05$ vs serum free; Figure $4.2 \mathrm{~F}$ ). Co-stimulation with $\mathrm{PE}$ and E2 resulted in additional induction of ANF immunoreactivity in a larger number of cells $(73 \pm 9 \%$, $\mathrm{P}<0.05$ vs serum free and PE; Figure $4.2 \mathrm{~F}$ ), whereas ICI 182,780 reduced this percentage back to the level of PE stimulation alone. Most strikingly, E2 stimulation of cardiomyocytes already resulted in ANF expression in $64 \pm 8 \%$ of the cells $(\mathrm{P}<0.05$ vs serum free; Figure $4.2 \mathrm{~F})$.

A

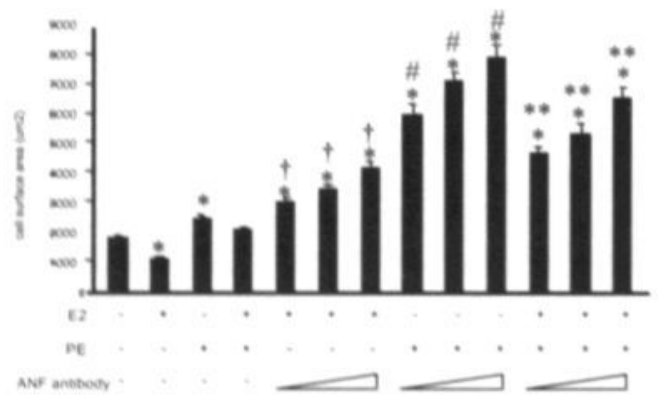

B

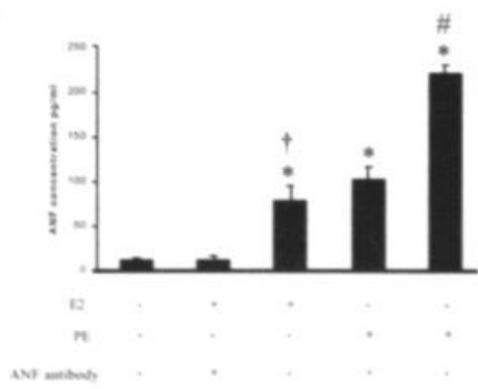

Figure 4.3. ANF antibody reverses the antihypertrophic properties of estrogen in cardiomyocytes (A). $\cdot \mathrm{P}<0.05$ vs. control (-) conditions, $\uparrow \mathrm{P}<0.05$ vs. $\mathrm{E} 2$, \#P<0.05 vs. $\mathrm{PE}$, and $\cdots P<0.05$ vs. $\mathrm{PE} / \mathrm{E} 2$. ANF antibody depleted ANF in the culture medium (B). ${ }^{*} \mathrm{P}<0.05$ vs. control $(-), \uparrow P<0.05$ vs. E2 and ANF antibody, and $\# \mathrm{P}<0.05$ vs. PE and ANF antibody. 
The induction of ANF after E2 stimulation was confirmed by Northern blot analyses. We showed an approximate 2 -fold induction in ANF mRNA expression after either serum (10\% FBS) or PE stimulation. E2 stimulation alone of NRVM resulted in a 5-fold induction in ANF mRNA, an effect that could be abrogated in the presence of the ER antagonist ICI 182,780.

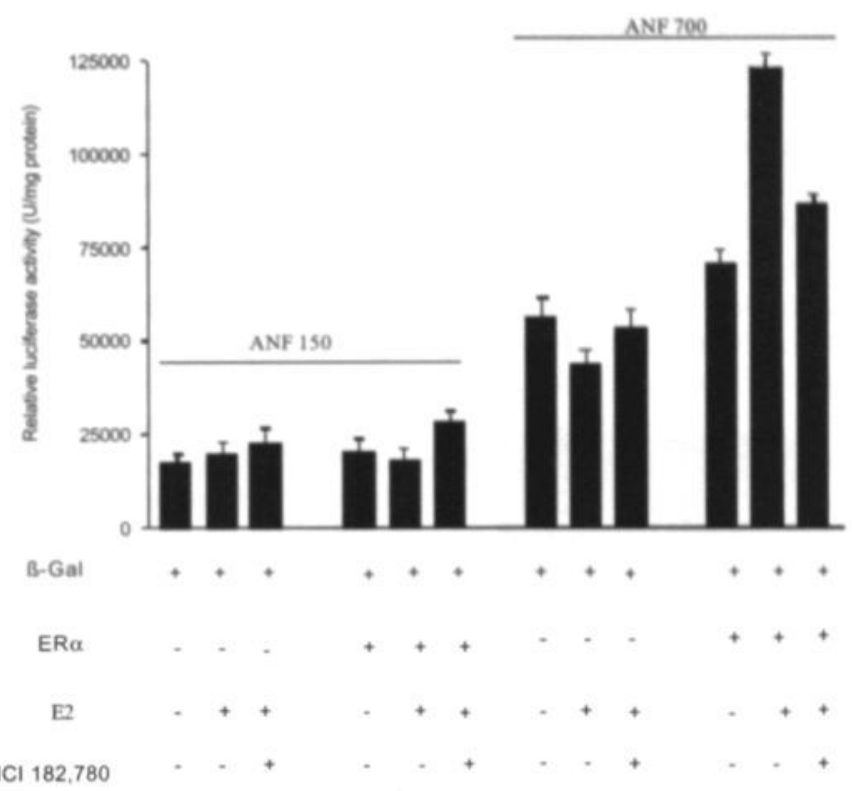

Figure 4.4. Results of transient transfection using ANF promoter deletion fragments in cultured HEK293 cells. ANF promoter fragments included -150 and -700 bp of proximal ANF promoter. After stimulation with $17 \beta$-estradiol $\left(10^{\circ} 9 \mathrm{~mol} / \mathrm{L}\right)$ and/or $\mathrm{ICl} 182,782\left(10^{-5} \mathrm{~mol} / \mathrm{L}\right)$ for 48 hours.

To address the requirement of extracellular presence of ANF in the inhibitory effects of E2 on cardiomyocyte hypertrophy, an antibody directed against ANF was added in increasing concentrations. The E2-inhibition of cardiomyocyte hypertrophy was abrogated in a dose-dependent manner. In addition, PE and antibodies-treated cardiomyocytes showed a dose-dependent increase in the overall surface area compared with PE-treatment alone (Figure 4.3A). The presence of the antibody led to reduced bio-availability of ANF (Figure 4.3B).

To further dissect the role of E2 in the transcriptional control of the ANF gene, ANF promoter deletion fragments (linked to a luciferase reporter) were tested for their ability to induce luciferase expression following E2 stimulation. A deletion fragment of $700 \mathrm{bp}$ of the ANF promoter demonstrated substantial transactivation following E2 treatment, and this effect was attenuated in the presence of ICI 182,780 . The proximal $150 \mathrm{bp}$ fragment of the ANF promoter, showed a reduced response to E2, suggesting that the estrogen responsive transactivation elements are located within the region between -150 and -700 bp of the proximal promoter (Figure 4.4).

\section{E2 activates the guanylyl cyclase-A receptor}

Accumulation of ANF may result in autocrine/paracrine stimulation of NRVM through its cognate transmembrane GC-A receptor. E2 and ANF increased cGMP activity by $14.58 \pm 3.5$, and $26.21 \pm$ $5.8 \mathrm{pmol} / \mathrm{mg}$ protein respectively compared to control (below detection level). We found that administration of either ANF $\left(10^{-5} \mathrm{~mol} / \mathrm{L}\right)$ or $8 \mathrm{Br}-\mathrm{cGMP}\left(10^{-5} \mathrm{~mol} / \mathrm{L}\right)$ resulted in attenuation of 
cardiomyocyte hypertrophy. Both agents decreased cardiomyocyte surface area by $50 \%$ (Figun 4.5A, c and e) compared to PE stimulation alone (Figure 4.5A, b). The level of inhibition achievel by ANF or $8 \mathrm{Br}$-cGMP addition was comparable with that due to coadministration of E2 (10 $\mathrm{mol} / \mathrm{L}$; Figure $4.5 \mathrm{~A}, \mathrm{~g}$ ). Quantification of the cell surface areas supported the immunocytochemica observations (Figure 4.5B).

Cardiomyocytes were stimulated with PE and E2, ANF or \&-Br-cGMP in the presence of cGMP dependent protein kinase (cGK) blocker, KT-5823 (10 $\left.{ }^{-6} \mathrm{~mol} / \mathrm{L}\right)$. KT-5832 completely abolished th antagonistic growth potential of E2, ANF or 8-Br-cGMP of cardiomyocytes following Pl administration (Figure 5A, d, f and h). Indeed, PE stimulation in the presence of cGK inhibition resulted in significantly larger cardiomyocytes compared to those stimulated with PE alone (Figur $4.5 \mathrm{~A}, \mathrm{~b}$ and $\mathrm{I}$ ). This property of KT-5823 was not because of growth-evoking properties of KT 5823 alone (Figure 4.5A, j) or specific to PE-stimulation alone, because potentiation o cardiomyocyte hypertrophy was also observed after stimulation with ET-1 $\left(10^{-7} \mathrm{~mol} / \mathrm{L}\right)$ or CT$\left(10^{-9} \mathrm{~mol} / \mathrm{L}\right)$ in the presence of KT-5823 (data not shown). Quantification of the cell surface areas supported the immunocytochemical observations (Figure 4.5B).
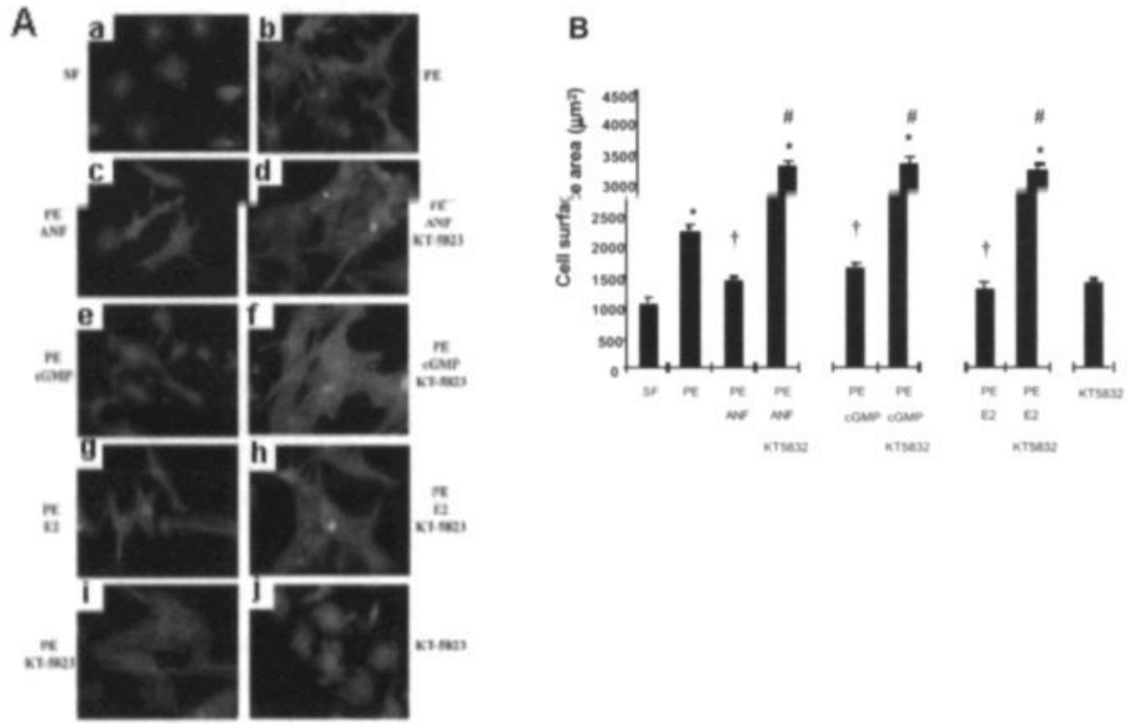

Figure 4.5. A, Antihypertrophic effects of estrogen involve autocrine stimulation of the GC-A receptor and cGMP. Cardiomyocytes were identified with $\alpha$-actinin antibody (red signal) and nuclei were stained with bisbenzamide (white). Cardiomyocytes stimulated with PE $\left(10^{-5} \mathrm{~mol} / \mathrm{L}\right)$ demonstrated a significant hypertrophic response (b) compared to myocytes cultured under control (SF) conditions (a). Stimulation of the GC-A receptor with ANF $\left(10^{-5} \mathrm{~mol} / \mathrm{L}\right)$ resulted in a significant attenuation of PE-induced cardiomyocyte hypertrophy (c). Similarly, addition of $8-B r-c G M P\left(10^{-5} \mathrm{~mol} / \mathrm{L}\right)$ blocked PE-mediated cardiomyocyte hypertrophy (e). The effects of ANF and cGMP where comparable to that of E2 (g). Anti-hypertrophic effects of ANF or 8-Br-cGMP could be reversed by inhibition of the cGMP-dependent protein kinase (cGK) with KT5823 (10 $\left.{ }^{-6} \mathrm{~mol} / \mathrm{L}\right)(\mathrm{d}, \mathrm{f}$, and $\mathrm{h}$ ). Cardiomyocytes cultured in the presence of PE and K-T5823 alone demonstrated a more massive hypertrophic response (i) than PE-stimulated cardiomyocytes (b). B. Quantification of cell surface area of 3 independent experiments. $P<0.05$ vs. serum free conditions, $\uparrow P<0.05$ vs. $P E$. 


\section{Discussion}

\section{Estrogen antagonizes cardiomyocyte hypertrophy}

Various observations suggest that estrogen may play an important role in modulating cardiac hypertrophy. ${ }^{15}$ Gender-related differences have been observed in the development of pressure overload hypertrophy. ${ }^{16}$ Recently we were able to demonstrate that estrogen attenuates the development of pressure overload hypertrophy. An interesting correlation between ANF expression, hypertrophy and estrogen was observed. ${ }^{6}$ The present study provides for the first time evidence that estrogen modulates ANF through a genomic, ER-dependent pathway in NRVM. Estrogen-induced ANF accumulation in the ventricular myocyte most likely results in ANF receptor activation in an autocrine/paracrine manner, which in turn evokes cytoplasmic cGMP signaling downstream of the GC-A receptor. Thus E2 increases the expression of ANF which antagonizes LVH.

\section{Estrogen and ANF induction}

ANF gene expression in ventricular myocytes occurs in response to diverse hypertrophic stimuli in multiple mammalian species, including humans. ANF induction has therefore been considered to be one of the conserved molecular features of ventricular cell hypertrophy. In human failing and hypertrophied hearts, the expression of ANF is markedly induced, and considerable levels of the peptide are detected in cardiomyopathic ventricles. ${ }^{17}$ The present findings demonstrate that estrogen is able to induce ANF gene expression. Because we were not able to find a consensus ER binding element in the proximal ANF promoter, it is feasible that ERs may influence ANF promoter activity indirectly through interactions with other cofactors such as Sp-1. ${ }^{18}$ In this light it is of interest that multiple important cis-acting elements, such as Spl sites, have been recognized in the ANF promoter. ${ }^{19}$ In fact, transcriptionally active Spl-ER complexes have been identified and shown to influence promoter activity of other genes, thereby providing a possible explanation on how ER may influence transactivation of the ANF promoter in the absence of a functional ER-binding element. ${ }^{20}$ Previously, Hong et al, ${ }^{21}$ demonstrated that ovariectomy decreased atrial ANF mRNA transcripts in rats. Female wistar rats treated with estrogen demonstrated increased ANF gene expression. The present study supports the notion that estrogen may be an important factor for transactivation of the ANF gene.

\section{ANF and cardiomyocyte hypertrophy}

Previous studies have already provided substantial evidence for an antagonistic role of ANF on the development of LVH. On several accounts, ANF was shown to possess growth inhibitory properties on cultured NRVM. ${ }^{9}$ Calderone et al. ${ }^{22}$ demonstrated that exogenous ANF and cGMP inhibit the protein synthesis in NRVM.

Single Nucleotide Polymorphisms (SNPs) within the first 650 bp of the ANF promoter gene of Wistar-Kyoto rats were demonstrated to influence promoter activity, in keeping with a higher LV ANF concentration under basal conditions compared to Wistar-Kyoto Hyperactive (WKHA) rats with a larger LV mass. ${ }^{23}$ That study showed that rats with lower ANF levels had an increased left ventricular mass. Genetically modified mice with complete absence of the GC-A receptor demonstrated elevated blood pressure and marked cardiac hypertrophy with interstitial fibrosis, ${ }^{24}$ thereby illustrating the importance for the GC-A receptor for the suppression of LVH. Mice with a disrupted pro-ANF gene lack circulating and tissue ANF, and exhibit increased heart weight and blood pressure when maintained on intermediate salt diets, ${ }^{25}$ again showing the importance of ANF signaling to block LVH. Conversely, hearts from mice with cardiac-restricted overexpression of the GC-A receptor were smaller than their wildtype counterparts and had distinct antihypertrophic properties, independent of vascular tone. ${ }^{26}$ Taken together these studies support the relevance of the ANF GC-A receptor pathway to prevent hypertrophy. 


\section{cGMP-dependent protein kinase and cardiomyocyte hypertrophy}

New observations suggest that cGMP signaling may play a crucial role in the anti-hypertroph effects of estrogen and/or ANF on NRVM. Estrogen rapidly activates calcium-activated potassiu channels. Such activation occurs through a pathway dependent on nitric oxide (NO) and cGMP? Furthermore, most of the actions of ANF are mediated through activation of its transmembrane G6 A receptor. ${ }^{28}$ Receptor-generated cGMP binds to cGK, which is thought to mediate the princip. biological functions of cGMP. Estrogen also stimulates NO production through activation $i$ endothelial NO synthase via non-genomic and genomic effects. ${ }^{29}$ This may be associated wit synergistic stimulation of cGK in cardiomyocytes. Both stimulations through ANF induction c endothelial NO synthase activation result in blocking hypertrophy.

Here we report that E2 treatment counterbalanced morphological and biochemical parameters c myocyte hypertrophy after stimulation with PE or ET-1. A marked upregulation of ANF mRN. and protein levels accompanied the morphological observations mediated through an ER-mediate pathway. Treatment with E2 activates the ANF receptor in an autocrine/paracrine fashion, whic leads to increased activation of cGMP and cGK. In summary, we show here that estrogen is critical mediator of ANF regulation in cardiac hypertrophy. These observations may help t understand the gender-based differences found in cardiac disease.

\section{Acknowledgements}

This work was supported by grants from the Netherlands Foundation for Scientific Research (NW 902-16-275) and a Bekales Foundation Award in Cardiolggv to Dr De.windt: tbe. Netberlands. Hen Foundation (NHS 99-114 and NHS 2000-160) and the Interuniversity Cardiology Institute Netherlands and Wynand Pon foundation to Dr Doevendans; the Netherlands Heart Foundation (D98.015) to Dr van Bilsen; and by the Deutsche Forschungsgemeinschaft and BON-FOR to Drs Grohé and van Eickels. We thank Guillaume van Eys $\mathrm{PhD}$, for his valuable help and comments, and Marjanne Markerink for technical assistance with cGMP analysis. 


\section{References}

1. Levy D, Garrison RJ, Savage DD, et al. Prognostic implications of echocardiographically determined left ventricular mass in the Framingham Heart Study [see comments]. $N$ Engl J Med. 1990;322:1561-6.

2. Hunter JJ, Chien KR. Signaling pathways for cardiac hypertrophy and failure. $N$ Engl J Med. 1999;341:1276-83.

3. Molkentin J, Dorn IG. Cytoplasmic signaling pathways that regulate cardiac hypertrophy. Annu Rev Physiol. 2001;63:391-426.

4. Marcus R, Krause L, Weder AB, et al. Sex-specific determinants of increased left ventricular mass in the Tecumseh Blood Pressure Study. Circulation. 1994;90:928-36.

5. Grohe C, Kahlert S, Lobbert K, et al. Cardiac myocytes and fibroblasts contain functional estrogen receptors. FEBS Lett. 1997;416:107-12.

6. van Eickels M. GC, Cleutjens J.P.M, Jans sen B.J., Wellens H.J.J., Doevendans P.A. 17 $\beta$ estradiol attenuates the development of pressure overload hypertrophy. Circulation. 2001;104:1419-23.

7. Levin ER, Gardner DG, Samson WK. Natriuretic peptides. $N$ Engl J Med. 1998;339:321-8.

8. Rockman HA, Ross RS, Harris AN, et al. Segregation of atrialspecific and inducible expression of an atrial natriuretic factor transgene in an in vivo murine model of cardiac hypertrophy. Proc Natl Acad Sci US A. 1991;88:8277-81.

9. Silberbach M, Gorenc T, Hershberger RE, et al. Extracellular signal-regulated protein kinase activation is required for the anti-hypertrophic effect of atrial natriuretic factor in neonatal rat ventricular myocytes. J Biol Chem . 1999;274:24858-64.

10. Taigen T, De Windt LJ, Lim HW, et al. Targeted inhibition of calcineurin prevents agonistinduced cardiomyocyte hypertrophy. Proc Natl Acad Sci US A. 2000;97:1196-201.

11. Knowlton KU, Baracchini E, Ross RS, et al. Co-regulation of the atrial natriuretic factor and

- cardiac myosin light chain-2 genes during alpha-adrenergic stimulation of neonatal rat ventricular cells. Identification of cis sequences within an embryonic and a constitutive contractile protein gene which mediate inducible expression. J Biol Chem. 1991;266:775968.

12. Nuedling S, Karas RH, Mendelsohn ME, et al. Activation of estrogen receptor beta is a prerequisite for estrogen-dependent upregulation of nitric oxide synthases in neonatal rat cardiac myocytes. FEBS Lett. 2001;502:103-8.

13. De Windt LJ, Willemsen $\mathrm{PH}$, Popping S, et al. Cloning and cellular distribution of a group II phospholipase A2 expressed in the heart. J Mol Cell Cardiol. 1997;29:2095-106.

14. Gavrieli Y, Sherman Y, Ben-Sasson SA. Identification of programmed cell death in situ via specific labeling of nuclear DNA fragmentation. J Cell Biol. 1992;119:493-501.

15. Mendelsohn ME, Karas RH. Estrogen and the blood vessel wall. Curr Opin Cardiol. 1994;9:619-26.

16. Weinberg EO, Thienelt CD, Katz SE, et al. Gender differences in molecular remodeling in pressure overload hypertrophy. J Am Coll Cardiol. 1999;34:264-73.

17. Chien $\mathrm{KR}, \mathrm{Knowlton} \mathrm{KU}$, Zhu $\mathrm{H}$, et al. Regulation of cardiac gene expression during myocardial growth and hypertrophy: molecular studies of an adaptive physiologic response. Faseb J. 1991;5:3037-46.

18. de Jager T, Pelzer T, Muller-Botz S, et al. Mechanisms of estrogen receptor action in the myocardium. Rapid gene activation via the ERK1/2 pathway and serum response elements. J Biol Chem. 2001;276:27873-80.

19. Sprenkle AB, Murray SF, Glembotski CC. Involvement of multiple cis elements in basat and alpha-adrenergic agonist-inducible atrial natriuretic factor transcription. Roles for serum response elements and an SP-1-like element. Circ Res. 1995;77:1060-9. 
20. Wang F, Samudio I, Safe S. Transcriptional activation of cathepsin D gene expression by 17beta- estradiol: mechanism of aryl hydrocarbon receptor-mediated inhibition. Mol Cell Endocrinol. 2001;172:91-103.

21. Hong M, Yan Q, Tao B, et al. Estradiol, progesterone and testosterone exposures affect the atrial natriuretic peptide gene expression in vivo in rats. Biol Chem Hoppe Seyler. 1992;373:213-8.

22. Calderone A, Thaik CM, Takahashi N, et al. Nitric oxide, atrial natriuretic peptide, and cyclic GMP inhibit the growth-promoting effects of norepinephrine in cardiac myocytes and fibroblasts. J Clin Invest. 1998;101:812-8.

23. Deschepper CF, Masciotra S, Zahabi A, et al. Functional alterations of the Nppa promoter are linked to cardiac ventricular hypertrophy in WKY/WKHA rat crosses. Circ Res. 2001;88:223-8.

24. Pandey $\mathrm{KN}$, Oliver PM, Maeda N, et al. Hypertension associated with decreased testosterone levels in natriuretic peptide receptor-A gene-knockout and gene-duplicated mutant mouse models. Endocrinology. 1999;140:5112-9.

25. Oliver PM, Fox JE, Kim R, et al. Hypertension, cardiac hypertrophy, and sudden death in mice lacking natriuretic peptide receptor A. Proc Natl Acad Sci U S A. 1997;94:14730-5.

26. Kishimoto II, Rossi K, Garbers DL. A genetic model provides evidence that the receptor for atrial natriuretic peptide (guanylyl cyclase-A) inhibits cardiac ventricular myocyte hypertrophy. Proc Natl Acad Sci US A. 2001;98:2703-2706.

27. Wellman $G C$, Bonev $A D$, Nelson $M T$, et al. Gender differences in coronary artery diameter involve estrogen, nitric oxide, and $\mathrm{Ca}(2+)$-dependent $\mathrm{K}+$ channels. Circ Res. 1996;79:102430.

28. Chinkers M, Garbers DL. The protein kinase domain of the ANP receptor is required for signaling. Science. 1989;245:1392-4.

29. Babiker FA, De Windt LJ, van Eickels M, et al. Estrogenic hormone action in the heart: regulatory network and function. Cardiovasc Res. 2002;53:709-19. 
Estrogen Receptor $\beta$ Protects the Murine Heart Against Left Ventricular Hypertrophy

Fawzi A. Babiker, Daniel Lips, Els Delvaux, Pieter Zandberg, Guillaume van Eys, Martin van Eickels,Christian Grohé, Ben Janssen, Pieter A. Doevendans.

SUBMITTED 


\begin{abstract}
Background: Significant gender-related differences exist in the development of left ventricular hypertrophy (LVH). In addition, estrogen (E2) administration to ovariectomized female mice attenuates the development of $\mathrm{LVH}$ demonstrating an antagonistic role for 17 $\beta$-estradiol (E2). E2 exerts a variety of important physiological effects, which are mediated via the two known estrogen receptors (ERs), ER $\alpha$ and ER $\beta$. The mechanisms involved in this process, however, are poorly understood. We therefore used $\operatorname{ER} \alpha$ knockout (ERKO) and ER $\beta$ knockout (BERKO) mice to differentiate the effect of E2 on the development of pressure-overload hypertrophy.

Methods and Results: Ovariectomized mice, lacking one of the two ERs were given E2 or placebo subcutaneously using 60 day release pellets. They underwent transverse aortic constriction (TAC) or sham operation. E2 significantly increased uterine weight in BERKO and in WT littermates, but not in ERKO. TAC led to a significant increase in ventricular mass compared with sham operation. E2 treatment 4 weeks after TAC reduced cardiac hypertrophy significantly in WT and ERKO mice compared with placebo and BERKO. No differences were observed between the E2 and placebotreated animals that were sham operated. Furthermore, E2 blocked the increased phosphorylation of p38-mitogen-activated protein kinase (MAPK) observed in TAC placebo-treated WT and ERKO animals. E2 led also to an increase in atrial natriuretic peptide (ANF) in the hypertrophied ventricles of WT and ERKO, while no significant levels of ANF were detected in the ventricles of E2 treated sham and BERKO mice.

Conclusions: These findings demonstrate that hormone replacement therapy with E2 reduces the effects of pressure-overload on the heart. The protective effect of E2 is mediated via ER $\beta$ and not $\mathrm{ER} \alpha$.
\end{abstract}

\title{
Introduction
}

The increase of left ventricular mass represents a structural mechanism of compensation of the heart in response to pressure overload. The resulting left ventricular hypertrophy (LVH) is an important negative predictor of cardiac morbidity and mortality. It is one of the gender-related differences in the incidence of a wide variety of cardiovascular diseases.' Premenopausal women have a lower prevelance of LVH than men. ${ }^{2}$ The Coronary Artery Risk Development In young Adults (CARDIA) study demonstrated a higher prevalence of $\mathrm{LVH}$ in man, even after correction for a large number of risk factors. It further demonstrated that the difference in left ventricular size begins early in life (i.e. prior to menopause), suggesting that intrinsic factors are involved in the induction of $\mathrm{LVH}^{3}{ }^{3} \mathrm{It}$ has been demonstrated that estrogens are able to attenuate hypertrophic responses. Estrogens appear to act as cardioprotective steroid hormones. Therapeutic application of estrogen (E2) in heart disease is questionable. ${ }^{4,5}$. Recently, the results from 2 large randomized clinical trials, the Heart and Estrogen/progestin Replacement Study (HERS) ${ }^{6}$ and the Women's Health Initiative (WHI) ${ }^{7}$ have been published. These clinical studies demonstrated that at present the risks associated with hormone therapy outweigh the benefits for women taking continuous estrogen and progestin regimens. However the underlying mechanisms of E2 protection of the myocardium are not fully understood. Further elucidation of the mechanism may provide leads to avoid the negative implications of E2 therapy.

Myocytes and fibroblasts contain functional estrogen receptors (ER) $\alpha$ and $\beta .^{3}$ Via these receptors, E2 modulates the activity of the mitogen-activated protein kinase (MAPK) pathways in cardiac myocytes. ${ }^{8}$ The MAPK signaling pathways consist of a sequence of successively acting kinases that ultimately result in the dual phosphorylation and activationof effector kinases such as p38-MAPKs, c-Jun N-terminal kinases (JNKs), and extracellular signalregulated kinases (ERKs), which subsequently phosphorylate a large array of targets, leading to altered gene expression patterns. These signaling cascades play an important role in the initiation of cardiac hypertrophy and in the development of heart failure. ${ }^{9.12}$ E2 can inhibit p38-MAPK phosphorylation and thus p38-MAPK 
activation. ${ }^{13}$ Furthermore it is known that E2 can increase the expression of the atrial natriuretic factor (ANF), which recently has been shown to possess antihypertrophic effects. ${ }^{13-16}$

We recently reported the effects of $E_{2}$ on the development of pressure-overload hypertrophy and the activation of signalling pathways of MAPKs. ${ }^{13}$ Here we further define the role of ERs in this process. For this goal we used ERKO and BRKO mice and WT littermates of each. We found that cardioprotective effects of E2 on LVH are mediated by ER $\beta$ and not ER $\alpha$. These effects are paralleled by an increase in the expression of ANF and a decrease in the phosphorylation of 338.

\section{Material and Methods}

\section{Animals}

ERKO mice were produced as described previously. ${ }^{17}$ These mice, which have been extensively studied, do not express ER proteins in any tissue. ${ }^{17-20}$ BERKO mice were generated and provided by Organon (Oss, the Netherlands). The mouse ER $\beta$ gene was isolated from an 129 Sv genomic BAC library(Genome Systems) by screening with a full length human ER $\beta$ cDNA probe. Two BAC clones were obtained and restriction enzyme mapping was performed using a panel of restriction enzymes and degenerated probes deduced from exon 1-4. Two fragments were identified: a $2.7 \mathrm{~kb}$ HindIII-EcoRV fagment located 5' of exon 1 and a $1.6 \mathrm{~kb}$ HindIII fragment located 3' of exon 2. Both fragments were cloned into the pKO gene targeting vector (Lexicon Genetics, Woodlands, USA) containing the pgk-neo gene for positive selection and the CMV-Tk gene for negative selection. ES cells were transfected with NotI linearized targeting vector using a BioRad Gene Pulser(230V). Targeted ES cells were identified by nested PCR analysis. PCR conditions used were 100 ng each of primer 5'-GGAGTGGCAGACAAGGGCA-3' and primer 5'GATTCGCAGCGCATCGCC-3', 10 ng genomic DNA, DNA Taq polymerase(1U, Gibco BRL), a dATP, dCTP, dGTP, dTTP mixture $(10 \mathrm{mM})$, Taq buffer (Gibco BRL) for 20 cycles Nested PCR was performed using the nested primers 5'-ACCCAACACCCTCTCTGGCC-3 and 5'GGGCTCTATGGCTTCTGAGG-3' for 24 cycles. PCR products were analyzed on an $1 \%$ agarose gel and vizualised with ethidium bromide. Positive clones obtained were analyzed by Southern blot analysis. Targeted clones were expanded and injected into blastocysts from $\mathrm{C} 57 \mathrm{Bl} / 6$ mothers (Genome Systems), and were returned to pseudopregnant C57Bl/6 hosts to complete their development. Germ line transmission of the mutant allele was tested by PCR analysis of genomic tail DNA.

\section{Experimental procedures}

Ten-week-old female wild type (WT), ERKO, and BERKO, were housed under standard conditions. Animals were anesthetized with ketamine $(100 \mathrm{mg} / \mathrm{kg}$ body weight $(\mathrm{BW})$ intraperitoneal $)$ and xylazine $(10 \mathrm{mg} / \mathrm{kg}$ BW intraperitoneal ) for ovariectomy, pellet placement, and transverse aortic constriction (TAC). The study was approved by the animal ethics committee of the University of Maastricht.

\section{Estrogen Replacement}

Two weeks after ovariectomy, a 60 -day-release pellet containing $0.18 \mathrm{mg} \mathrm{E}_{2}$ or placebo was implanted subcutaneously. $\mathrm{E}_{2}$ serum levels were measured with a radioimmunoassay (DPC Biermann, Bad Nauheim, Germany) in a subset of animals. All pellets were purchased from Innovative Research of America (Sarasota, USA)

\section{Surgical Procedures and Haemodynamics}

Two weeks after the pharmacological intervertion, TAC was performed, as described previously. ${ }^{13}$ Sham-operated animals underwent an identical operation without placement of the constricting 
suture. Assessment of LV function was performed as previously described. ${ }^{21,22}$ Conductance and pressure input were digitized with a Conduct-PC data acquisition system (CDLeycom BV, Zoetermeer, The Netherlands). Average values for mean arterial pressure (MAP), heart rate (HR), systolic and diastolic left ventricular pressure (LVP), and LV end-diastolic pressure (LVEDP) were determined.

\section{Tissue Preparation and Histology}

Hearts were arrested in diastole with $\mathrm{CdCl}(0.1 \mathrm{~mol} / \mathrm{L} \mathrm{IV})$. For morphometric analysis, hearts were fixed in $10 \%$ formalin and embedded in paraffin as described previously. ${ }^{23}$ For protein extraction, hearts were excised, washed in ice-cold PBS. All external fluid was completely removed before the organs were weighed and frozen. Transverse sections of the heart were stained with hematoxylin and eosin, sirius red, or modified Azan. The analysis of the collagen content was performed with a computerized morphometry system as described previously. ${ }^{23}$

\section{Immunoblot Analysis}

Total heart lysates $(40 \mu \mathrm{g} / \mathrm{lane})$ were analyzed by standard immunoblotting procedures as described previously. ${ }^{24}$ Equal loading was checked by stripping and reprobing the membrane with troponin $\mathrm{C}$. The following primary antibodies were used: Atrial natriuretic factor (ANF) (Phoenix Pharmaceuticals Inc); p38-mitogen-activated protein kinase (p38-MAPK), (Santa Cruz Biotechnology Inc) and phospho-p-38 MAPK (Thr180/Tyr182) (New England Biolabs). Detection was performed with the enhanced chemiluminescence technique after incubation with a suitable secondary antibody coupled to horseradish peroxidase (ECL; Amersham Pharmacia Biotech). A computerized image acquisitionsystem (Alpha Innotech Corp) was used for densitometric analysis.

\section{Real time-PCR analysis}

Details of the realtime RT-PCR have been described previously. ${ }^{25}$ The primer sequences used for real time PCR are: ANF 5' primer (5'-CCT GTG TAC AGT GCG GTG TC), ANF 3' primer (5'TCC TCC AGG TGG TCT AGC A), cyclophillin 5' primer (5'-CAA ATG CTG GAC CAA ACA CAA), cyclophillin 3' primer (5'-TTC ACC TTC CCA AAG ACC ACA T). The CT measurement is defined at the fractional cycle number at which the amount of amplified target reaches a fixed threshold above background Sybr Green fluorescence. The amount of target in the cDNA sample relative to cyclophiline was calculated.

\section{Statistical Analysis}

Data are shown as mean \pm SEM. Means were compared by ANOVA, followed by Bonferroni's test for multiple comparisons. Differences were considered significant at $P<0.05$. $^{26}$ 
Sham

placebo

7

$24.00 \pm 0.61$

$114.56 \pm 4$

4. $77 \pm 0.19$

$6.24 \pm 0.24$

$0.63+0.09$

$0.18+0.06$

7

$24.17 \pm 1.56$

$112.83 \pm 10$

4. $68+0.46$

$6.55+0.66$

$0.73 \div 0.15$

$0.16+0.02$

UW/BW, mg/g

Lung weight, $g$

WT $(n=)$

BW.g

WW,mg

WW/BW, $\mathrm{mg} / \mathrm{g}$

$\mathrm{WW} / \mathrm{TL}, \mathrm{mg} / \mathrm{mm}$

UW/BW, $\mathrm{mg} / \mathrm{g}$

UW/TL, $\mathrm{mg} / \mathrm{mm}$

Lung weight, $g$
7

$23.71 \pm 2.33$

$119.14 \pm 16$

$5.01 \pm 0.28$

$6.81 \pm 0.84$

$1.33 \pm 0.22$

$1.72 \pm 0.27$

$0.17 \pm 0.02$ $119.88 \pm 12$

4.94*0.35

$6.93 \div 0.61$

$14.38 \pm 1.82 \uparrow$

$0.18+0.02$

7

$26+2.78$

$119.20 \pm 7$

$4.61 \pm 0.20$

$6.96+0.42$

$3.26 \pm 0.194$

$0.15+0.01$

7

$24.00 \pm 1$

$114.17 \pm 7$

$4.75 \pm 0.23$

$6.75 \pm 0.42$

$12.39 \pm 1.22 \dagger$

$18.29 \pm 1.78 \dagger$

$0.14 \pm 0.02$

7

$\operatorname{BERKO}(n=)$

BW.g

WW.mg

WW/BW, mg/g

$\mathrm{WW} / \mathrm{TL}, \mathrm{mg} / \mathrm{mm}$

UW/BW, mg/g

Lung weight, $g$
$24.30 \pm 1.90$

$111.30 \pm 6$

$4.60 \pm 0.28$

$6.42 \pm 0.33$

$1.16 \pm 0.16$

$0.16+0.02$

$25.86 \pm 1.27$
$122.29 \pm 6$
$4.73 \pm 0.21$
$7.14 \pm 0.39$
$13.28 \pm 3.19 t$
$0.16 \pm 00.01$

TAC

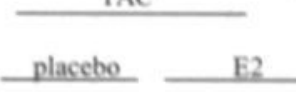

10

10

$23.55 \pm 1.14$ $161.91 \pm 26^{*}$

$6.89 \pm 1.16$

$9.21 \pm 1.59$

$1.39 \pm 0.21$

$0.17 \pm 0.01$

$23.25 \pm 0.67$

$131.75 \pm 13^{*} \uparrow$

$5.68 \pm 0.75^{\circ} \dagger$

$7.63 \pm 0.74^{\circ} t$

$11.89 \pm 2.1 t$

$0.17 \pm .04$

10

10

$22.71 \pm 2$

$164.57 \pm 29^{\circ}$

$7.34 \pm 1.70^{\circ}$

$9.93 \pm 0.61$

$0.71 \pm 0.13$

$0.20 \pm 0.09$

$24.08 \pm 0.78$

$135.92 \pm 16^{\circ} \dagger$

$5.65 \pm 0.72^{*} \dagger$

$7.99 \pm 0.98^{\circ} \dagger$

$3.42+0.35$ tt

$0.16 \pm 0.02$

10

10

$22.66 \pm 1.88$

$170.71 \pm 29$

$7.66 \pm 1.95$

$9.79 \pm 1.77$

$1.05 \pm 0.07$

$1.38 \pm 0.12$

$0.18 \pm 0.03$

$25.25 \pm 1.56$

$131.50 \pm 12^{*} \uparrow$

$5.29 \pm 0.81^{*} \dagger$

$7.45 \pm 0.89+$

$14.85 \pm 1.96 \dagger$

$20.93 \pm 1.44 \dagger$

$0.16 \pm 0.00$

10

10

$26.14 \pm 1.06$

$157.43 \pm 13^{\circ}$

$6.03 \pm 0.53^{\circ}$

$8.78 \pm 0.79^{\circ}$

$24.71 \pm 0.69$

$169.29 \pm 32^{*}$

$6.86 \pm 1.25^{\circ}$

$9.76 \pm 1.79^{\circ}$

$15.77 \pm 1.77 \dagger$

$0.16 \pm 0.01$

BW, body weight; VW, ventricular weight; TL, Tibial lengtht; and UW, Uterus weight. All values are Mean \pm SEM. ${ }^{*} \mathrm{P}<0.05$ for TAC vs sham, $\dagger \mathrm{P}<0.05$ for $\mathrm{E} 2$ vs placebo, and $\ddagger \mathrm{P}<0.05$ for $\mathrm{KO}$ vs WT

Table 5.1. Effects of TAC and E2-treatment on body and organ weights. 


\section{Results}

E2 replacement led to a reconstitution of physiological estrogen levels $(122 \mathrm{pg} / \mathrm{ml}$ in E2 treated versus $<5 \mathrm{pg} / \mathrm{ml}$ in placebo treated). All measured $\mathrm{E}_{2}$ levels in animals receiving placebo were under the detection level. Uterus weight was measured to demonstrate the effectiveness of ovariectomy and E2 substitution in all animals. In all groups ( 8 conditions with TAC or sham and placebo or E2 treatment for ERKO as well as BERKO) the uterus weight/body weight (UW/BW) and UW/tibia length (TL) ratios showed a significant difference between placebo and E2-treated mice (Table 5.1 and Figure 5.1). In E2-treated WT and BERKO the UW/BW ratios are significantly higher than that of E2-treated ERKO mice (Table 5.1, and Figure 5.1). There were no significant differences in BW between the groups (Table 5.1).

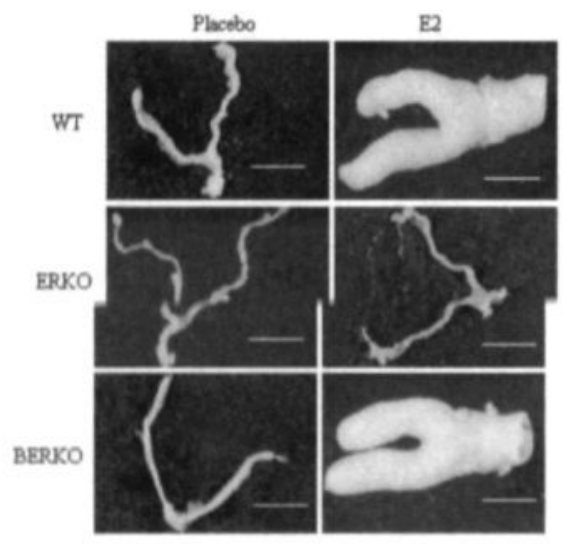

Figure 5.1. E2 and ER $\alpha$ determine the size of the uterus. Macroscopic images of uteri after treatment of 10 weeks old WT, ERKO and BERKO with E2 or vehicle for $4-6$ weeks (bars $=5 \mathrm{~mm}$ )

In ERKO as well as WT, TAC led to a significant increase in ventricular mass 4 weeks after the intervention. E2 treatment led to a significant reduction of the increase of ventricular weight (VW), the VW/BW ratio, and the VW/TL ratio in WT and ERKO (Table 5.1 and Figure 5.2A and B). No differences were observed sham-operated mice (Table 5.1 and Figure 5.2A and B). Also in BERKO and their WT littermates, TAC led to significant increase in ventricular mass 4 weeks after the intervention. In WT the degree of ventricular hypertrophy was significantly lower in E2-treated compared with placebo-treated mice.

Paradoxically, E2 treatment in BERKO mice resulted in a higher but not significant level of hypertrophy as compared with WT. No significant differences were observed in sham operated and placebo treated TAC mice (Table 5.1 and Figure 5.3A and B). 
A

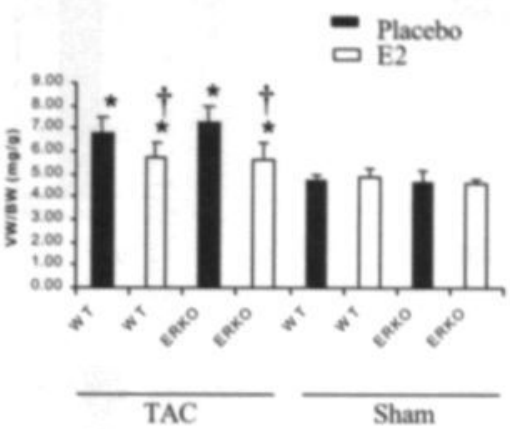

B

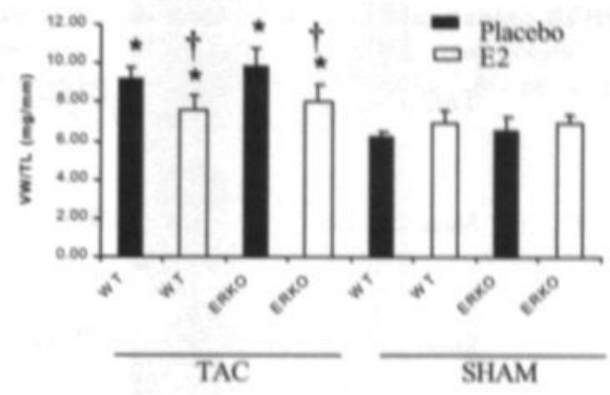

Figure 5.2. The degree of ventricular hypertrophy was significantly lower in $\mathrm{E}_{2}$-treated than placebo-treated WT and ERKO mice with pressure overload. Ventricular weight (VW)/BW ratios from animais with pressure overload (TAC) or without (Sham) that were treated with E2 or placebo 4 weeks after intervention (A). VW/TL ratios from animals with TAC or Sham that were treated with E2 or placebo 4 weeks after intervention (B). All values are mean \pm SEM, $n=7$ for sham and 10 for TAC per group. "Indicates $P<0.05$ for TAC vs sham, tindicates $\mathrm{P}<0.05$ for $\mathrm{E} 2$ vs placebo.
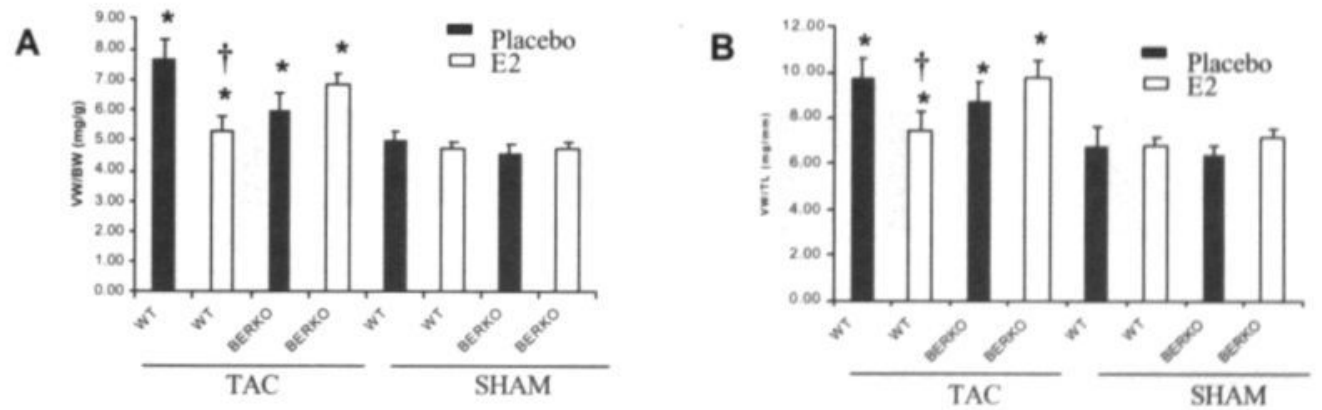

Figure 5.3. $E_{2}$ treatment led to a significant reduction in the degree of hypertrophy in WT but not in BERKO mice. The VW/BW ratios from animals with TAC or Sham that were treated with E2 or placebo 4 weeks after intervention (A). VW/TL ratios from animals with TAC or Sham that were treated with E2 or placebo 4 weeks after intervention (B). All values are mean \pm SEM, $n=7$ for sham and 10 for TAC per group." Indicates $P<0.05$ for TAC vs sham, tindicates $P<0.05$ for $E 2$ vs placebo.

Thus in TAC WT mice E2 treatment led to a significant reduction of the VW and related parameters. No differences were observed in sham operated WT and BERKO mice (Table 5.1 and Figure 5.3A and B). Weight analysis is in line with morphometric analysis (Figure 5.4A, B, C, D, E and $\mathrm{F}$ ). 

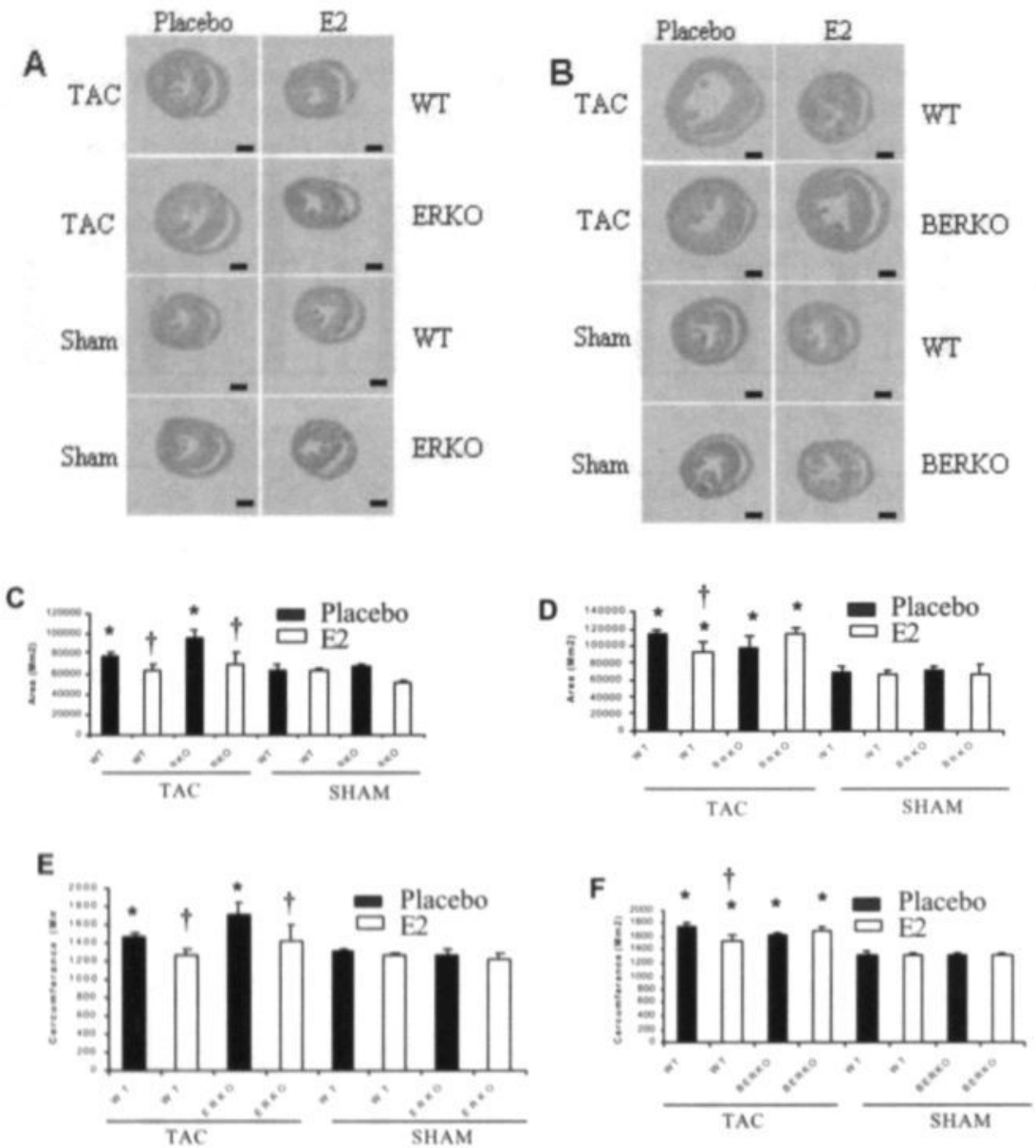

Figure 5.4. Transverse sections of hearts stained with Hematoxylin-eosin from WT and ERKO animals with TAC and without (sham) that where treated with either E2 or placebo 4 weeks after intervention (bar $=1 \mathrm{~mm}$ ) $($ bar $=1 \mathrm{~mm})(\mathrm{A})$. Transverse sections of hearts stained with Hematoxylin-eosin from WT and BERKO animals with TAC and without (sham) that where treated with either E2 or placebo 4 weeks after intervention (bar $=1 \mathrm{~mm}$ ) (B). LV area for WT and ERKO (C). LV area for WT and BERKO (D). LV circumference for WT and ERKO (E). LV circumference for WT and BERKO (F): All values are mean \pm SEM, $n=7$ for sham and 10 for TAC per group "Indicates $\mathrm{P}<0.05$ for placebo vs E2 treatments.

In this study, ventricular contraction and relaxation did not alter either between genotypes or substitution therapies following TAC. Maximal derivative of left ventricular pressure $\left(\mathrm{dP} / \mathrm{dt}_{\max }\right)$ increased and minimal drivative $\left(\mathrm{dP} / \mathrm{dt}_{\min }\right)$ decreased, although no significant differences were found between groups (Figure 5.5D and E). The pressure volume loops showed the absence of differences in cardiac performance between placebo and E2-treated BERKO (Figure 5.5F), except for the TAC-induced systolic pressure rises. No significant differences in LV end-systolic pressure, end-diastolic pressure, or heart rate were observed between the groups. Data in ERKO are comparable (not shown). 
A
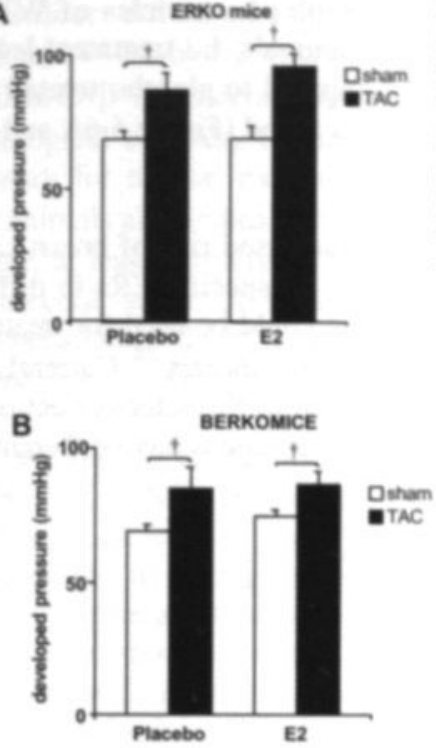

$\mathbf{E}$

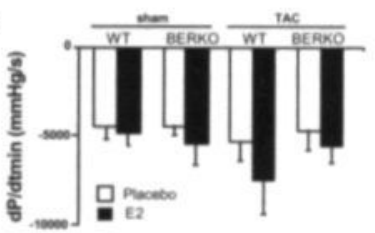

Figure 5.5 Cardiac function measured h BERKO and WT mice. Representation of left ventricular developed pressure as an indication of cardiac afterload in TAC and sham mice (A and B). Cardiac output (CO) (C). dP/dt $\max (D)$. dP/dt $\min (E)$. Left ventricular in vivo pressure-volume loops in sham placebo-treated WT mice (BERKO littermates) (black loops), TAC placebo-treated BERKO mice (blue loops) and TAC E2-treated BERKO (red loops). All values are mean \pm SEM, $n=7$ for sham and 10 for TAC per group. tindicates $P<0.05$ TAC vs sham.
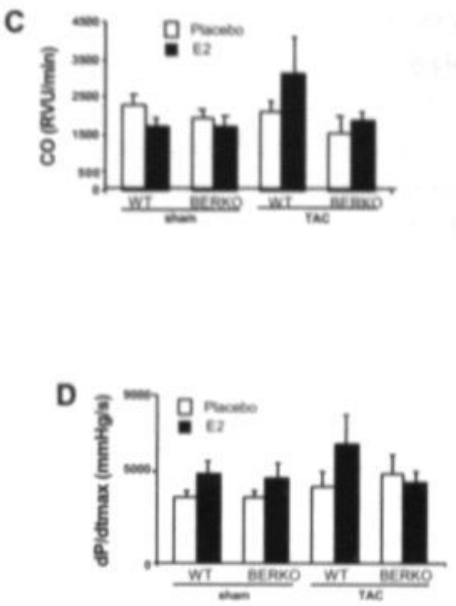

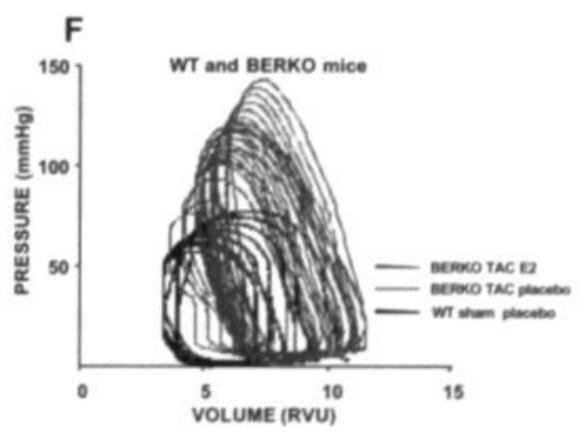

To analyse the mechanisms involved in the observed antihypertrophic effect of E2, we investigated a few selected genes involved in development and progression of cardiac hypertrophy. In previous reports these genes have been shown to be regulated by E2. Immunoblot analysis revealed that $\mathrm{E}_{2}$ blocked the increased phosphorylation of p38-MAPK in ovariectomized WT and ERKO mice with pressure-overload hypertrophy, whereas it exerted no effect in sham-operated animals and BERKO (Data not shown). 
TAC led to a significant increase in ANF expression in the hypertrophied ventricles of WT and ERKO mice 4 weeks after intervention compared with sham treated animals. E2 treatment led to a significant increase in the expression of ANF in WT and ERKO compared to placebo treated mice and BERKO ( $\mathrm{P}< \pm 0.05)$ however in BERKO mice no such effect was found (Figure 5.6A and B).

\section{Discussion}

The use of E2 as a therapy is associated with side-effects including increased risk of breast cancer and deep venous thrombosis. ${ }^{27} \mathrm{~A}$ better understanding of the function of specific ERs in different tissues is important in the development or selection of new agents that could be used for treatment. The expression of ER $\alpha$ and ER $\beta$ varies in different tissues and between species. ${ }^{28}$ Currently, the biological roles of these two different ERs is not clear. It may be related to the selective actions of E2 in various target tissues. Also it is known that different estrogenic compounds have different

A

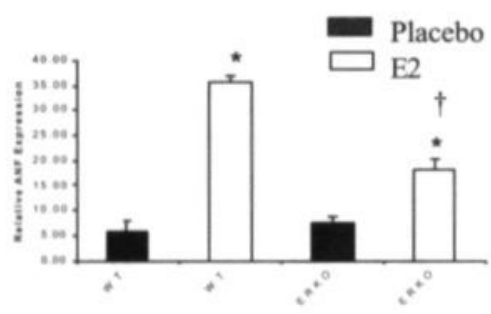

B

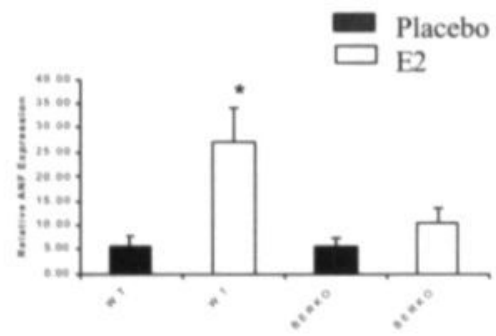

Figure 5.6. RT-PCR analysis showing ventricular expression of ANF gene which has been shown to be regulated by E2 ANF expression in TAC WT and ERKO animals treated with E2 or placebo (A). ANF expression in TAC WT and BERKO animals treated with E2 or placebo (B). All values are mean \pm SEM. "Indicates $P<0.05$ for placebo vs E2 treatments $\dagger$ indicates $P<0.05$ for ERKO vs BERKO. The values are corrected by subtracting cyclophillin values and presented as a relative values to control.

relative binding affinities for ER $\alpha$ versus ER $\beta .{ }^{29.30}$. When coexpressed, ER $\beta$ exhibits an inhibitory action on ER $\alpha$-mediated gene expression and thus opposes the actions of ER $\alpha .{ }^{31}$ For instance recent studies suggest that ER $\beta$ may inhibit the stimulatory effects of ER $\alpha$ on cellular proliferation. ${ }^{32}$ In the case of E2 signaling, cellular selectivity for one or the other ER appears to be regulated by the cellular expression pattern of the ERs and interacting coactivator and corepressor proteins. ${ }^{33}$

The ER $\alpha$ appears to be more involved in regulation of uterine growth than the ER $\beta$, as an be deduced from both the uterine wet weight and the uterine dry weight in ERKO. This is in line with previous studies regarding the importance of $E R \alpha$ for the uterine response. ${ }^{17.34}$ On the other hand the ER $\beta$, as we proved in this study, mediates the attenuation of pressure-overload hypertrophy by E2. Whereas in ERKO, ventricular weight is significanly reduced (comparable to WT) after addition of E2, no such effect is seen in BERKO. Therefore, our study supports the hypothesis that 
E2 has direct effects on cardiac myocytes and the heart. ER $\beta$ mediates transcriptional activation of eNOS and iNOS by E2 in cardiac myocytes. ${ }^{35}$ Although ER $\beta$ appears to be of major importance in the ER $\alpha / E R \beta$-dependent responses studied in this investigation, ER $\beta$ also plays an role in other physiological contexts. Recently it was demonstrated, using the same animal model, that ER $\beta$ is necessary for normal morphology in several regions of the central nervous system. ${ }^{36}$ Studies on these animals also indicate that ER $\beta$ has an antiproliferative effect in the immature uterus and in the prostate, at least partially by balancing the proliferative activity of $E R \alpha{ }^{37} \mathrm{ER} \beta$, not ER $\alpha$, mediates the anorectic action of E2 in the CNS. ${ }^{38}$ To further elucidate the mechanisms involved in E2's antihypertrophic effects, it will be necessary to identify the additional signaling molecules involved in these protective effects, the time course of their activation, and the cross talk between them.

In a previous study we showed that no differences occur in the expression levels of ERK1/2, JNK, $\mathrm{AT}_{1} \mathrm{R}$ or $\mathrm{ACE} .{ }^{13}$ To further elucidate possible mechanisms involved, we studied the activation of MAPK, and ANF. These have been shown to play important roles in the development and progression of cardiac hypertrophy. " It has been reported that the activation of p38-MAPK maintains the hypertrophic response over a longer period of time. ${ }^{39}$ E2 can inhibit p38-MAPK phosphorylation and thus p38-MAPK activation. Our results are in line with those of van Eickels et al., ${ }^{13}$ who demonstrated that inhibition of p38-MAPK phosphorylation by E2 treatment may represent one of the mechanisms by which $E_{2}$ exerts its antihypertrophic effect in the TAC model of pressure overload.

Antihypertrophic properties of ANF were shown in several studies. ${ }^{13-15.39}$ Furthermore, it has been previously shown that $E_{2}$ increases the expression of ANF. ${ }^{13,15}$ In line withthese results, $E_{2}$ led to a significant increase in ANF expression in the ventricles of WT and ERKO animals, as compared with placebo-treated WT and E2-treated BERKO mice with pressure overload. These findings confirm that ANF is part of another pathway by which E2 exerts its antihypertrophic effects.

Our results show that the antihypertrophic effects of E2 are receptor specific. This may stimulate research for ligands that only bind ER $\beta$. Such a development may circumvent the negative effects reported in the HERS and WHI studies, and provide for precisely targeted anti-hypertrophic approach.

\section{Conclusion}

Our results showed that ER $\beta$ plays a role in the control of $\mathrm{LVH}$. Protective effects of E2 in murine heart via ER $\beta$ appear to increase expression of ANF and decreased $\mathrm{p} 38$ phosphorylation. The fact that cardiovascular action of E2 relies largely on ER $\beta$ provides opportunities to develop more specific interventional strategies to treat hypertrophy, avo iding side effects.

\section{Acknowledgments}

This work was supported by grants from the Netherlands Heart Foundation (NHS 99-114 and NHS 2000-160) and the Interuniversity Cardiology Institute Netherlands, Bekalis Foundation and Wynand Pon foundation to P.A.D., the Netherlands Heart Foundation (D98.015) to M. V. B. and by the Deutsche Forschungsgemeinschaft and BONFOR to C. G and M v. E.. Additional support from the RESCAR foundation was greatly appreciated. We thank Organon, Oss, the Netherlands for providing the animals. 


\section{Refferences}

1. Liao Y, Cooper RS, Mensah GA, et al. Left ventricular hypertrophy has a greater impact on survival in women than in men. Circulation. 1995;92:805-10.

2. Gardin JM, Wagenknecht LE, Anton-Culver H, et al. Relationship of cardiovascular risk factors to echocardiographic left ventricular mass in healthy young black and white adult men and women. The CARDIA study. Coronary Artery Risk Development in Young Adults. Circulation. 1995;92:380-7.

3. Grohe C, Kahlert S, Lobbert K, et al. Cardiac myocytes and fibroblasts contain functional estrogen receptors. FEBS Lett. 1997;416:107-12.

4. Kuroski de Bold ML. Estrogen, natriuretic peptides and the renin-angiotensin system. Cardiovasc Res. 1999;41:524-31.

5. Babiker FA, De Windt LJ, van Eickels M, et al. Estrogenic hormone action in the heart: regulatory network and function. Cardiovasc Res. 2002;53:709-19.

6. Hulley S, Grady D, Bush T, et al. Randomized trial of estrogen plus progestin for secondary prevention of coronary heart disease in postmenopausal women. Heart and Estrogen/progestin Replacement Study (HERS) Research Group. Jama. 1998;280:605-13.

7. Rossouw JE, Anderson GL, Prentice RL, et al. Risks and benefits of estrogen plus progestin in healthy postmenopausal women: principal results From the Women's Health Initiative randomized controlled trial. Jama. 2002;288:321-33.

8. Nuedling S, Kahlert S, Loebbert K, et al. Differential effects of 17beta-estradiol on mitogenactivated protein kinase pathways in rat cardiomyocytes. FEBS Lett. 1999;454:271-6.

9. Sugden PH, Clerk A. "Stress-responsive" mitogen-activated protein kinases (c-Jun Nterminal kinases and p38 mitogen-activated protein kinases) in the myocardium. Circ Res. 1998;83:345-52.

10. Bueno OF, De Windt LJ, Lim HW, et al. The dua-specificity phosphatase MKP-1 limits the cardiac hypertrophic response In vitro and In vivo [In Process Citation]. Circ Res. 2001;88:88-96.

11. Bueno OF, De Windt LJ, Tymitz KM, et al. The MEK1-ERK1/2 signaling pathway promotes compensated cardiac hypertrophy in transgenic mice. Embo J. 2000;19:6341-50.

12. Haq S, Choukroun G, Lim H, et al. Differential activation of signal transduction pathways in human hearts with hypertrophy versus advanced heart failure. Circulation. 2001;103:670-7.

13. van Eickels M, Grohe C, Cleutjens JP, et al. 17beta-estradiol attenuates the development of pressure-overload hypertrophy. Circulation. 2001;104:1419-23.

14. Horio T, Nishikimi T, Yoshihara F, et al. Inhibitory regulation of hypertrophy by endogenous atrial natriuretic peptide in cultured cardiac myocytes. Hypertension. 2000;35:19-24.

15. Babiker FA, De Windt LJ, van Eickels M, et al. 17beta-estradiol antagonizes cardiomyocyte hypertrophy by autocrine/paracrine stimulation of a guanylyl cyclase A receptor-cyclic guanosine monophosphate-dependent protein kinase pathway. Circulation. 2004;109:26976.

16. Deng Y, Kaufman S. The influence of reproductive hormones on ANF release by rat atria. Life Sci. 1993;53:689-96.

17. Lubahn DB, Moyer JS, Golding TS, et al. Alteration of reproductive function but not prenatal sexual development after insertional disruption of the mouse estrogen receptor gene. Proc Natl Acad Sci U S A. 1993;90:11162-6.

18. Krege JH, Hodgin JB, Couse JF, et al. Generation and reproductive phenotypes of mice lacking estrogen receptor beta. Proc Natl Acad Sci US A. 1998;95:15677-82.

19. Couse JF, Hewitt SC, Bunch DO, et al. Postnatal sex reversal of the ovaries in mice lacking estrogen receptors alpha and beta. Science. 1999;286:2328-31. 
20. Ogawa S, Chester AE, Hewitt SC, et al. Abolition of male sexual behaviors in mice lacking estrogen receptors alpha and beta (alpha beta ERKO). Proc Natl Acad Sci $U S A$. 2000;97:14737-41.

21. Lips DJ, van der Nagel T, De Windt LJ. Left ventricular pressure-volume measurements in mice: closed-chest versus open-chest. Basic Res Cardiol (in press). 2004.

22. Lips DJ, Bueno OF, Wilkins BJ, et al. MEK1-ERK2 signaling pathway protects myocardium from ischemic injury in vivo. Circulation. 2004;109:1938-41.

23. Lutgens E, Daemen MJ, de Muinck ED, et al. Chronic myocardial infarction in the mouse: cardiac structural and functional changes. Cardiovasc Res. 1999;41:586-93.

24. Rubattu S, Lee-Kirsch MA, DePaolis P, et al. Altered structure, regulation, and function of the gene encoding the atrial natriuretic peptide in the stroke-prone spontaneously hypertensive rat. Circ Res. 1999;85:900-5.

25. Monroe DG, Johnsen SA, Subramaniam M, et al. Mutual antagonism of estrogen receptors alpha and beta and their preferred interactions with steroid receptor coactivators in human osteoblastic cell lines. J Endocrinol. 2003;176:349-57.

26. Wallenstein S, Zucker CL, Fleiss JL. Some statistical methods useful in circulation research. Circ Res. 1980;47:1-9.

27. Daly E, Vessey MP, Hawkins MM, et al. Risk of venous thromboembolism in users of hormone replacement therapy. Lancet. 1996;348:977-80.

28. Kuiper GG, Enmark E, Pelto-Huikko M, et al. Cloning of a novel receptor expressed in rat prostate and ovary. Proc Natl Acad Sci US A. 1996;93:5925-30.

29. Kuiper GG, Carlsson B, Grandien K, et al. Comparison of the ligand binding specificity and transcript tissue distribution of estrogen receptors alpha and beta. Endocrinology. 1997; 138:863-70.

30. Katzenellenbogen JA, Katzenellenbogen BS. Nuclear hormone receptors: ligand-activated regulators of transcription and diverse cell responses. Chem Biol. 1996;3:529-36.

31. Matthews J, Gustafsson JA. Estrogen Signaling: A Subtle Balance Between ER \{alpha\} and ER \{beta\}. Mol Intervent. 2003;3:281-292.

32. Barkhem T, Nilsson S, Gustafsson JA. Molecular mechanisms, physiological consequences and pharmacological implications of estrogen receptor action. Am J Pharmacogenomics. 2004;4:19-28.

33. Nilsson S, Makela S, Treuter E, et al. Mechanisms of estrogen action. Physiol Rev. 2001;81:1535-65.

34. Lindberg MK, Weihua Z, Andersson N, et al. Estrogen receptor specificity for the effects of estrogen in ovariectomized mice. J Endocrinol. 2002;174:167-78.

35. Nuedling S, Karas RH, Mendelsohn ME, et al. Activation of estrogen receptor beta is a prerequisite for estrogen-dependent upregulation of nitric oxide synthases in neonatal rat cardiac myocytes. FEBS Lett. 2001;502:103-8.

36. Wang L, Andersson S, Warner M, et al. Estrogen receptor (ER)beta knockout mice reveal a role for ERbeta in migration of cortical neurons in the developing brain. Proc Natl Acad Sci US A. 2003;100:703-8.

37. Weihua Z, Makela S, Andersson LC, et al. A role for estrogen receptor beta in the regulation of growth of the ventral prostate. Proc Natl Acad Sci U S A. 2001;98:6330-5.

38. Liang YQ, Akishita M, Kim S, et al. Estrogen receptor beta is involved in the anorectic action of estrogen. Int J Obes Relat Metab Disord. 2002;26:1103-9.

39. Clerk A, Michael A, Sugden PH. Stimulation of the p38 mitogen-activated protein kinase pathway in neonatal rat ventricular myocytes by the $\mathrm{G}$ protein-coupled receptor agonists, endothelin-1 and phenylephrine: a role in cardiac myocyte hypertrophy? $J$ Cell Biol. 1998;142:523-35. 


\section{6}

\section{Estrogen Modulates Infaret Size Through Estrogen Receptor Specific}

Mechanisms

Fawzi A. Babiker, Daniel J. Lips, Els Delvaux, Pieter Zandberg, Guillaume van Eys, Martin van Eickels, Christian Grohé, Ben Janssen, Pieter A. Doevendans. 


\begin{abstract}
Introduction: Observational and clinical studies suggest different responses upon hormone replacement therapy in ischemic heart disease between sexes. Few studies have examined the impact of estrogen receptor (ER) dependent mechanisms on the extent of injury by myocardial infarction (MI). Therefore, we set out to evaluate the effect of estrogen (E2) replacement on infarct size and the respective role of the estrogen receptors (ER)- $\alpha$ and $-\beta$ in this process, using ER $\alpha$ and $\mathrm{ER} \beta$ deficient mice.

Methods and results: Wildtype (WT), ER $\alpha$ knockout (ERKO) and ER $\beta$ knockout (BERKO) mice were ovariectomized and subsequently supplemented with E2 or placebo using subcutaneous 60 day release pellets. MI was induced by left coronary artery ligation. Two weeks following MI hemodynamic function was assessed and infarct size determined. There was no significant difference in infarct size in WT mice between E2 or placebo substituted mice. Surprisingly, E2 treatment did result in smaller infarct sizes in ERKO mice. Left ventricular mass increase was significantly larger in the E2-treated animals compared to placebo treated animals. E2 treatment also significantly increased mortality in WT and ERKO animals.

Conclusions: E2 decreased the infarct size in ERKO mice. However, in these mice E2 also increased mortality possibly because of unfavorable post-MI ventricular remodeling. Deletion of the respective ERs has a specific effect on the infarct size in presence of E2. Further studies will be necessary to uncover the mechanisms underlying the observed effects of E2 reported in this study.
\end{abstract}

\title{
Introduction
}

The outcome of ischemic heart disease reveals gender-based differences, which can partially be attributed to the varying sex hormone levels between males and females.' Many observational studies suggest that estrogen replacement therapy (ERT) has cardioprotective effects in postmenopausal women. ${ }^{2}$ Premenopausal women appear to be protected from the development of coronary artery disease. Furthermore, ERT reduces the incidence of coronary artery disease and the progression of coronary artery lesions after the menopause. ${ }^{3}$ However, recent clinical trials have failed to show a cardiovascular benefit of ERT in women with established coronary artery disease. ${ }^{4}$ The recently published Heart and Estrogen/Progestin Replacement Studies (HERS) I and II $^{5}$, and Women's Health Initiative (WHI) report ${ }^{6}$ failed to demonstrate that conjugated E2 plus progestin reduce the overall incidence of cardiac events in patients with established coronary artery disease (secondary prevention) or the risk of cardiovascular disease in healthy postmenopausal women (primary prevention). Earlier studies ${ }^{7,8}$ have demonstrated the presence of ERs $\alpha$ and $\beta$ in cardiomyocytes and fibroblasts. These ERs are functional and have been shown to regulate the expression of specific cardiac genes, such as the progesterone receptor and the gap junction protein connexin 43 gene. $^{8}$ These findings suggest that gender-based and pre- versus postmenopausal differences in cardiac pathophysiology may in part be due to direct effects of E2 on cardiac cells such as myocytes and fibroblasts. These cells are also involved in the remodeling process post-MI. Estrogens may act in a gender-specific way to protect against cardiovascular dieases. ${ }^{9}$ Additional analyses examining the complex association between estrogens, lipoprotein serum levels, and cardiovascular disease suggested that the protective effect of E2 is substantially mediated through increased high-density lipoprotein levels. ${ }^{10}$

E2 has recently been shown to attenuate the development of cardiac hypertrophy in response to pressure-overload. ${ }^{11,12}$ Cardiac ischemia studies investigating the effects of estrogens in myocardial infarction (MI) have revealed conflicting results. Various studies report a protective effect of estrogens in myocardial ischemia leading to reduced infarct sizes, prevention of adverse post-MI remodeling and cardiac function deterioration. ${ }^{13.14}$ Other studies report no effect of E2 supplementation. ${ }^{15.16}$ Several studies observed increased infaret sizes and mortality following E2 supplementation in cardiac ischemia studies. ${ }^{17} \mathrm{E} 2$ is detrimental at the time of MI or early post-MI 
period, resulting in an increased size of infarct or infarct expansion. ${ }^{18}$ Major limitations in comparing these studies are the various forms of E2 supplementation, time-points of treatment and investigated species. Due to the inconsistency in results no conclusive consensus about E2 treatment in cardiac ischemia could be reached. The role of ERs in post-MI adaptation is unknown. To date, no studies have examined the effects of estrogen supplementation on infaret size or post-MI remodeling and survival in ER deficient models. In the current study, we compared the effects of E2 replacement on infarct size, mortality, and cardiac remodeling after MI in ERKO and BERKO mice. In these mouse models we demonstrate that E2-treatment affects infarct size, influences left ventricular (LV) remodeling and increases death rates following MI depending on the type of ERdeficiency.

\section{Materials and methods}

\section{Study plan}

We used WT (WT ERKO and WT BERKO littermates), ERKO and BERKO mice. Ten weeks old mice were ovariectomized and randomized for placebo or 17-beta-estradiol

\begin{tabular}{|c|c|c|c|c|}
\hline & \multicolumn{2}{|c|}{ Sham } & \multicolumn{2}{|l|}{ MI } \\
\hline & placetoo & $\mathrm{F}_{2}$ & placsto & $\mathrm{H} 2$ \\
\hline WT $(n=)$ & 7 & 7 & 10 & 10 \\
\hline $\mathrm{BW}_{\boldsymbol{g}}$ & $22.57 \pm 0.78$ & $24.67 \div 0.83$ & $23.33 \pm 1.36$ & $26.33+1.75$ \\
\hline WW/EW, molg & $5.02 \div 0.22$ & $4.99+0.33$ & $5.95 \pm 1.61^{\circ}$ & $6.36 \times 0.96^{\circ}$ \\
\hline UW/BW, molg & $1.46 \div 0.32$ & $1412 \pm 1781$ & $1.29 \div 0.07$ & $1172 a 184 t$ \\
\hline Lung weight, g & $0.15 \pm 0.03$ & $0.19+0.04$ & $0.17 \approx 0.01$ & 0.1890 .01 \\
\hline ERKO $(n=)$ & 7 & 7 & 10 & 10 \\
\hline$B W_{g}$ & $2171 \pm 1.10$ & $24.83 \pm 1.63$ & $23.00 \pm 1.75$ & $24.06+1.22$ \\
\hline Wriw, molg & $4.79 \div 0.24$ & $4.70+0.31$ & $5.53 \div 0.39^{\circ}$ & $6.20 * 0.40^{\circ} \mathrm{t}$ \\
\hline UW/EW, mog & $0.74 \div 0.05$ & $3.30 t 0.34 t$ & $0.74 \div 0.04$ & $3.24 \div 0.41 \mathrm{it}$ \\
\hline Lung weight g & $0.15 \div 0.01$ & $0.18+0.02$ & $0.15 \div 0.01$ & $0.16 * 01$ \\
\hline WT $N=$ ) & 7 & 7 & 10 & 10 \\
\hline $\mathrm{BW}_{\mathrm{g}}$ & $22.70 \pm 2.44$ & $25.44 \pm 2.15$ & $26.33 \pm 1.44$ & $27.00 \pm 3.11$ \\
\hline WWBW, molg & $4.95 \div 0.30$ & $4.77 \pm 0.27$ & $5.85 \div 0.33^{*}$ & $606 \times 0.78^{\circ}$ \\
\hline UW/BW, ma/g & $1.35+0.37$ & $14.76+2.07 \uparrow$ & $1.31 \div 0.13$ & $1437 \pm 1.63 t$ \\
\hline Lung weight, g & $0.15 \neq 0.01$ & $0.16+0.01$ & $0.18=0.01$ & $0.19 * 0.04$ \\
\hline BERKO $(n=)$ & 7 & 7 & 10 & 10 \\
\hline$B W_{g}$ & $25.27+1.80$ & $2475 \div 1.25$ & $2436 \times 1.28$ & $2600 t 2$ \\
\hline W/BW, molg & $4.68 \div 0.42$ & $4.60+0.20$ & $569 \div 0.46^{\circ}$ & $6.1121 .15^{\circ}$ \\
\hline UW/BW, mgla & $1.07=0.30$ & $14.08 \div 0.95 t$ & $1.16=0.22$ & $15.7821 .76 t$ \\
\hline Lung weight. g & $0.16 \pm 0.01$ & $0.14+0.01$ & $0.17 \div 0.01$ & $0.21=0.06$ \\
\hline
\end{tabular}

Table 6.1. Effects of MI and E2-treatment on body and organ weights two weeks following MI.

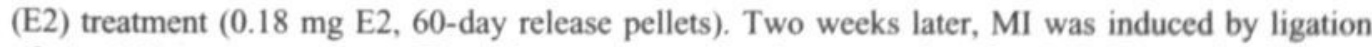
of the left coronary artery. The mice were sacrificed two weeks after MI. The animals were randomized to 8 different subgroups for ERKO and BERKO mice (Table 6.1).

\section{Animals}

The ERKO mice were described previously. ${ }^{19}$ BERKO mice were generated and provided by Organon NV (Oss, Netherlands) for details see chapter 5. Mice were housed under standard conditions. Animals were anesthetized with ketamine $(100 \mathrm{mg} / \mathrm{kg}$, intraperitoneal) and xylazine (10 $\mathrm{mg} / \mathrm{kg}$, intraperitoneal ) for ovariectomy, pellet placement, and MI. The study was approved by the animal ethics committee of the University of Maastricht. 


\section{Estrogen Replacement}

Two weeks following ovariectomy, 60-day-release pellets containing $0.18 \mathrm{mg} \mathrm{E}$ or placebo were implanted subcutaneously (Innovative Research Sarasota, FL, USA). E 2 serum levels were measured with a radioimmunoassay (DPC Biermann, Bad Nauheim, Germany) in a subset of animals.

\section{Surgical Procedures and LV Function Measurements}

Two weeks following the pharmacological intervention, MI was performed, as described previously $^{20}$ Sham-operated animals underwent a thoracotomy, but no suture was placed on the coronary artery. Assessment of LV function was performed as previously described. ${ }^{21,22}$ Conductance and pressure input was digitized with a Conduct-PC data acquisition system (CDLeycom BV, Zoetermeer, The Netherlands). Average values for mean arterial pressure (MAP), heart rate (HR), systolic and diastolic left ventricular pressure (LVP), and LV end-diastolic pressure (LVEDP) were determined.

\section{Tissue Preparation and Histology}

Hearts were arrested in diastole with $\mathrm{CdCb}(0.1 \mathrm{~mol} / \mathrm{L} \mathrm{IV})$ and subsequently harvested. For morphometric analysis, the left ventricle (LV) was separated from atria, great vessels and the right ventricular free wall, and weighed. All external fluids were completely removed before the organs were weighed. The left ventricles were fixed in $10 \%$ formalin and embedded in paraffin as described previously. For protein extraction, hearts were excised, washed in ice-cold PBS, and frozen.

\section{Determination of infarct size}

Infaret size was measured by compressing the LV between two glass slides and capturing images of both sides using a computerized image analysis system Image-Pro Plus (Image Processing Solutions, Inc., North Reading, USA). The infarct area was distinguishable from noninfarcted myocardium by the bleached color of the infarct area. Infarct size was determined by calculating the relative surface area of the infarct as a percentage of the total LV surface area.

\section{Statistical Analysis}

Data are shown as mean \pm SEM. Means were compared by ANOVA, followed by Bonferroni's test for multiple comparisons. Differences were considered significant at $P<0.05$.

\section{Results}

Ovariectomized animals treated with placebo had undetectable E2 serum levels $(<5 \mathrm{pg} / \mathrm{ml})$, while E2 serum levels were normalized in E2 treated mice $(122 \mathrm{pg} / \mathrm{ml})$. Uterus weight (UW) was measured to demonstrate the effectiveness of ovariectomy and $E_{2}$ substitution in all animals. $\mathrm{UW} / \mathrm{BW}$ ratios were significantly lower and uteri atrophied in placebo treated mice compared to E2 treated mice (Table 6.1 and Figure 6.1). Interestingly, UW/BW ratios were significantly larger in BERKO compared to ERKO mice.

To examine the long-term effects of E2 on LV remodeling and survival following ischemia, mice were randomized to either placebo or E2 supplementation, and subsequently underwent $\mathrm{MI}$ or sham operation with a two week follow up period. Left ventricular weight (VW) was indexed to BW and tibia length (TL) to detect hypertrophic growth. MI led to significant higher VW/BW ratios compared with sham animals in WT, ERKO and BERKO mice (Table 6.1, Figure 6.2A, B and C and Figure 6.3A, B and C). Surprisingly, $\mathrm{E}_{2}$ treatment in mice which underwent $\mathrm{MI}$ led to higher increase in VW/BW and VW/TL ratios compared to placebo treatment. In contrast, no differences 


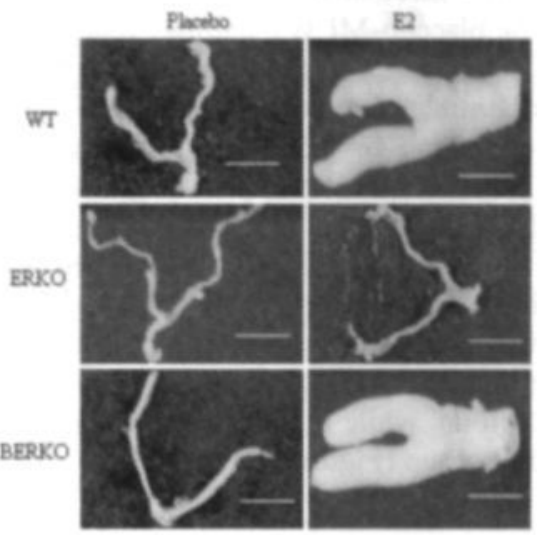

Figure 6.1. E2 and ER $\alpha$ determine the size of the uterus. Macroscopic images of uteri after treatment of 10 weeks old WT, ERKO and BERKO with E2 or vehicle for 4 weeks (bars $=5 \mathrm{~mm}$ ).

were observed between the $\mathrm{E}_{2}$ - and the placebo-treatment in sham groups (Table 6.1, Figure 6.2A, $\mathrm{B}$ and $\mathrm{C}$ and Figure 6.3A, B and C). The prohypertrophic effect of E2 treatment, therefore, was only observed subsequent to MI surgery, both in ERKO and BERKO studygroups.

A
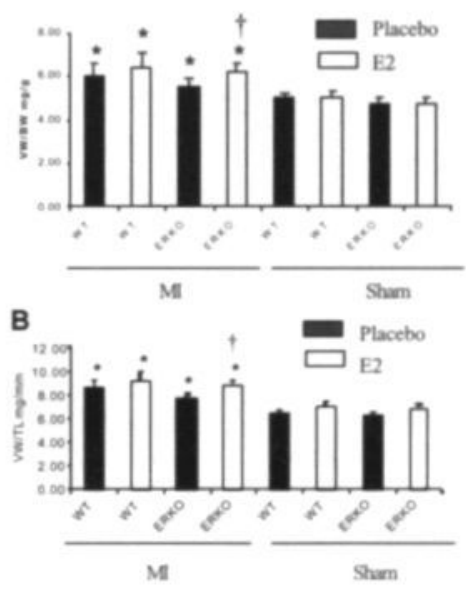

C

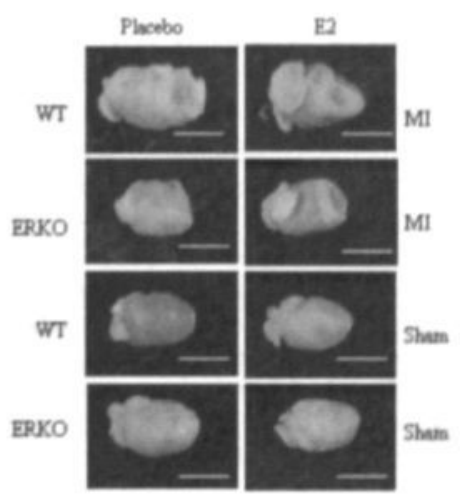

Figure 6.2. The degree of ventricular hypertrophy was significantly higher in $E_{2}$-treated than placebo-treated WT and ERKO mice with MI. VW/BW ratios from animals with MI or without (sham) that were treated with E2 or placebo two weeks after intervention (A). VW/TL ratios from animals with MI or sham that were treated with E2 or placebo two weeks after intervention (B). Intact hearts from animals with MI or sham that were treated with E2 or placebo two weeks after intervention (bars $=5 \mathrm{~mm})(C)$ : All values are mean $\pm S E M, n=7$ for sham and $10 \mathrm{Ml}$ per group. "Indicates $\mathrm{P}<0.05$ for $\mathrm{MI}$ vs sham, tindicates $\mathrm{P}<0.05$ for E2 vs placebo. 
In the sham-operated animals, $1-3$ animals died in each treatment group $(n=10)$. Mortality increased significantly in the E2-treated WT mice after MI compared to placebo treated and sham operated mice $(\mathrm{P}<0.05)$. Mortality in the placebo-MI WT animals was $28 \%(\mathrm{n}=21)$, while it was $68 \%$ in E2-treated WT $(\mathrm{n}=28)$. In the KO mice E2-treatment increased mortality rate significantly in ERKO compared to placebo-treated and sham mice $(\mathrm{P}<0.05)$. Mortality in the placebo-MI ERKO animals was $14 \%(n=14)$ compared to $52 \%$ in E2-treated ERKO mice $(n=23)$. Interestingly, mortality in the BERKO mice was higher in placebo treated compared to E2 treated and sham mice. Mortality in placebo-MI BERKO animals was $30 \%(\mathrm{n}=10)$ higher than in the infarcted, E2-treated BERKO where it was $23 \%(n=13)$. In the infarcted WT and ERKO animals, E2 treatment was associated with a higher risk for death (Figure 6.4A and B). The mean infarct size assessed two weeks after infarction was not significantly different in the E2-MI WT groups compared with the placebo-MI WT groups. It was found to be significantly smaller in E2-MI ERKO compared to placebo-MI ERKO group, while it was significantly bigger in E2-MI BERKO group compared with placebo-MI BERKO group (Figure 6.5).
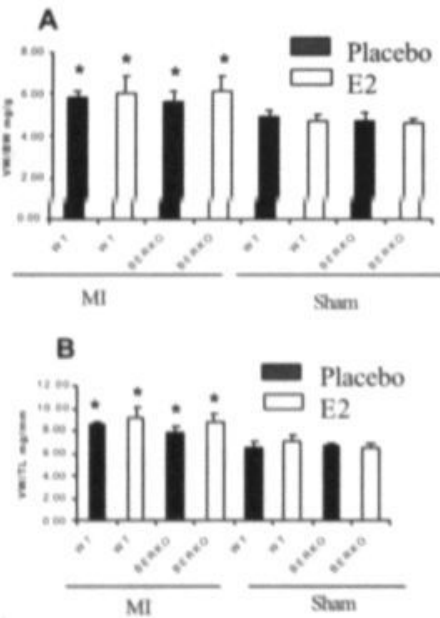

C

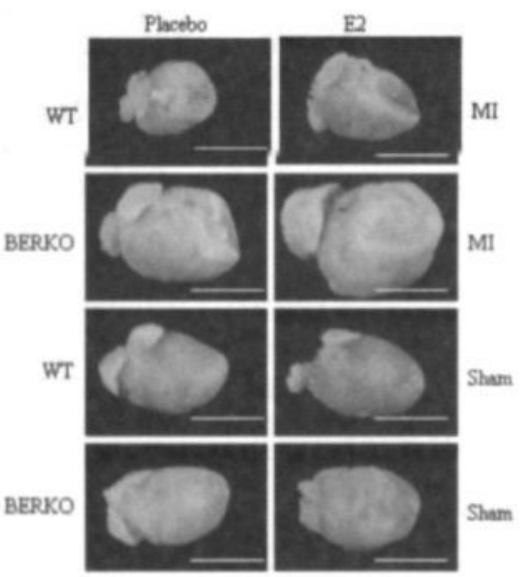

Figure 6.3. $E_{2}$ treatment led to an increase in the degree of hypertrophy in WT and in BERKO mice. The VW/BW ratios from animals with $\mathrm{MI}$ or sham that were treated with E2 or placebo two weeks after intervention (A). VW/TL ratios from animals with MI or sham that were treated with E2 or placebo two weeks after intervention (B). Intact hearts from animals with MI or Sham that were treated with E2 or placebo two weeks after intervention (bars $=5 \mathrm{~mm})(\mathrm{C})$ All values are mean \pm SEM, $n=7$ for sham and 10 for MI per group. "Indicates $P<0.05$ for $\mathrm{Ml}$ vs sham, tindicates $\mathrm{P}<0.05$ for $\mathrm{E} 2$ vs placebo. 


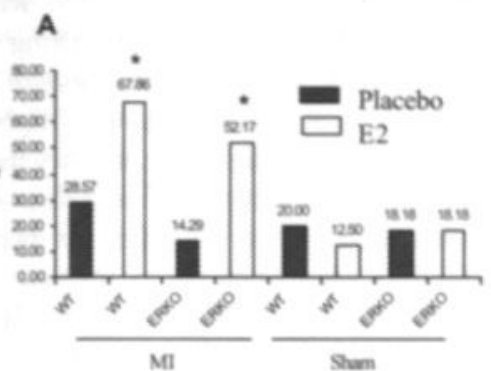

Figure 6.4. Mortality percentage in WT and ERKO mice with MI and without (sham) that where treated with either E2 or placebo two weeks after intervention (A). Mortality percentage in WT and BERKO animals with MI and without (sham) that where treated with either E2 or placebo two weeks after intervention (B). "Indicates $\mathrm{P}<0.05$ for E2 vs placebo.

\section{B}

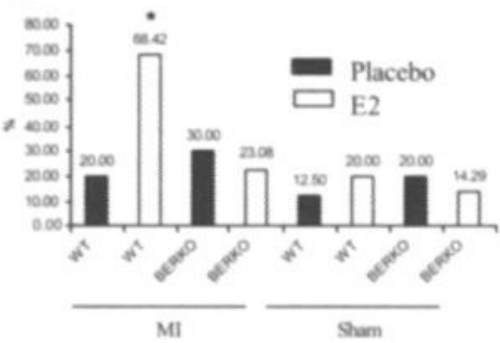

In ERKO groups, E2 treatment significantly decreased $\mathrm{dP} / \mathrm{dt}_{\max }$ and $\mathrm{dP} / \mathrm{dt}_{\min }$ in WT and ERKO sham studygroups compared to placebo-shams. This cardiodepressive effect was not seen in MI studygroups. MI alone, however, significantly decreased $\mathrm{dP} / \mathrm{dt}_{\max }$ and $\mathrm{dP} / \mathrm{dt}_{\min }$ in WT MI-placebo, ERKO MI-placebo and ERKO MI-E2 compared to WT sham-placebo, ERKO sham-placebo and ERKO sham-E2 respectively. No significant differences in LV end-systolic pressure, end-diastolic pressure, or heart rate were observed between ERKO groups (Table 6.2A). In BERKO studygroups, E2 treatment decreased $\mathrm{dP} / \mathrm{dt}_{\max }$ and $\mathrm{dP} / \mathrm{dt}_{\min }$ in BERKO sham animals compared to placebo treated BERKO mice. MI significantly increased $\mathrm{dP} / \mathrm{dt}_{\max }$ and $\mathrm{dP} / \mathrm{dt}_{\min }$ in BERKO MI compared to BERKO sham animals irrespective of supplementation therapy. No significant differences in LV end-systolic pressure, end-diastolic pressure, or heart rate were observed between the groups (Table $6.2 \mathrm{~B})$.

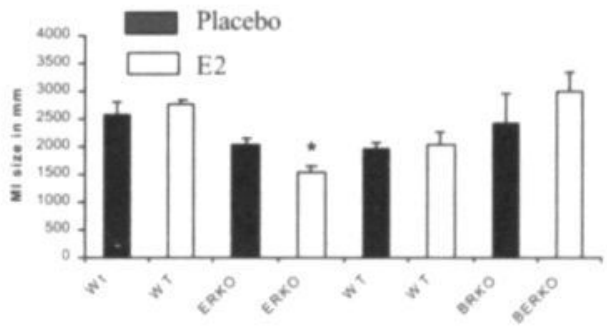

Figure 6.5. Infarct size increase in presence of E2 in WT and BERKO while there is a significant decrease in the infarct size in ERKO mice treated with either E2 or placebo two weeks after intervention. All values are mean \pm SEM, $n=7$ for sham and 10 for $\mathrm{MI}$ per group *Indicates $\mathrm{P}<0.05$ for E2 treatments vs placebo.

\section{Discussion}

There was a reduction in both uterine wet weight ERKO, but not in BERKO mice, confirming previous studies by our group and others regarding the importance of ER $\alpha$ for the uterine response. ${ }^{12,19,23} \mathrm{ER} \alpha$ appears to play a major role in the regulation of reproductive events. ERKO female mice are completely infertile, whereas BERKO females display severe but incomplete infertility. ${ }^{24,25}$ 
In this study, mortality after MI increased in all mice with an intact ER $\beta$ if they were treated with E2. However, if the ER $\beta$ is mutated mortality decreases. Thus ER $\beta$ mediates processes resulting in death. Previous study by Van Eickels et al. ${ }^{26}$ reported a similar effect in WT mice. Our results in mice also corroborate with clinical studies, ${ }^{27-30}$ which have shown that women have a higher mortality after MI compared with men. Clinical studies examining sex differences in morbidity and mortality following MI reveal an apparently poorer prognosis in females during hospitalization or during the first 30 days after infarction. ${ }^{31}$ Recent data suggest that an elevated risk of early death among women relative to men gradually decreases with age and is seen only up to the age of approximately $75 .^{32}$ Vaccarino et $\mathrm{aP}^{33}$ reported that among patients aged $<50$ years, the mortality rate during hospitalizationafter MI was more than twice as high in women than in men. In the longterm, however, women appear to have an improved survival compared with men. ${ }^{30,34}$ As both ERs $\alpha$ and $\beta$ are present in the women's hearts, ${ }^{8,35}$ distinguishing the role of each receptor would be of vital importance in the treatment of MI.
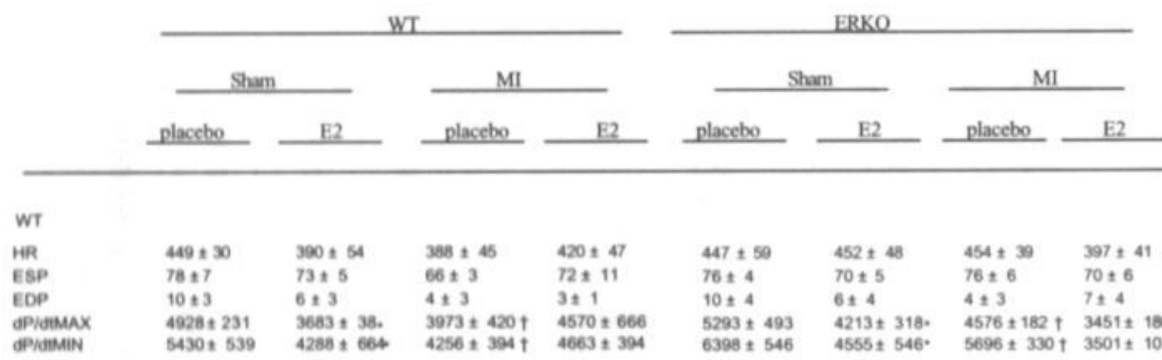

\begin{tabular}{|c|c|c|c|}
\hline $447+59$ & $452+48$ & $454+39$ & $397+41$ \\
\hline $76 \pm 4$ & $70 \div 5$ & $76 \div 6$ & $70 \div 6$ \\
\hline $10 \div 4$ & $6 \pm 4$ & $4+3$ & $7+4$ \\
\hline $5293 \div 493$ & $4213+318$. & $4576+182 t$ & $3451 \geq 186 t$ \\
\hline $6398 \div 546$ & $4555 \div 546^{*}$ & $5696 \geq 330 t$ & $3501 \pm 107 t$ \\
\hline
\end{tabular}

HR, hear rate; ESP, end systolic pressure, and EDP, end diastolic pressure. All values are mean $\pm \mathrm{SEM}$. $* \mathrm{P}<0.05 \mathrm{E} 2$ vs placebo and $+\mathrm{P}<0.05 \mathrm{MI}$ vs sham.

Table 6.2A. Invasive hemodynamic measurements in WT and ERKO mice two weeks following MI.
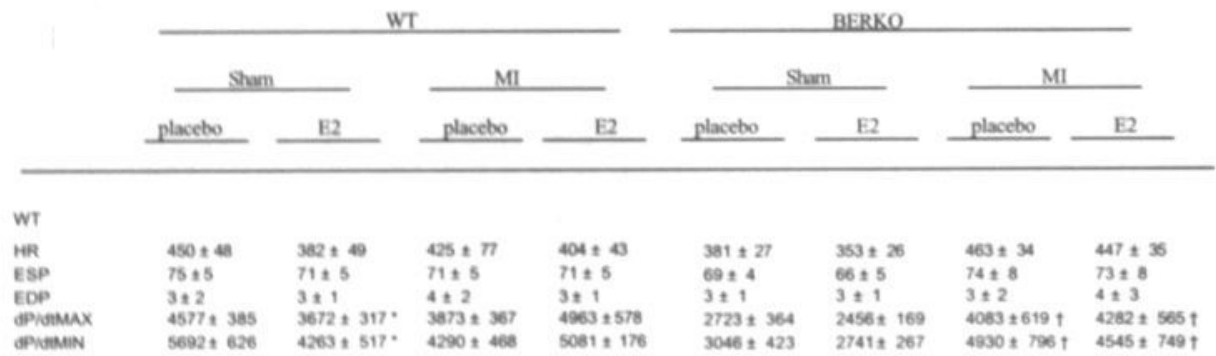

HR, heart rate; ESP, end systolic pressure, and EDP, end diastolic pressure. All values are mean \pm SFM. $* P<0.05$ E2 vs placebo and $+\mathrm{P}<0.05 \mathrm{Ml}$ v s sham

Table 6.2B. Invasive hemodynamic measurements in WT and BERKO mice two weeks following MI.

We examined the effects of E2 substitution on MI in ovariectomized female WT, ERKO and BERKO mice, and found that E2 treatment did not affect the infarct size in WT mice. E2 treatment did however decrease the infarct size in ERKO, while it was associated with increased infarct size in BERKO mice. Thus, opposite effects are mediated by the two ERs. In WT these effects appear to neutralize each other. However, absence of one of the receptors affects infarct size as well as 
mortality. The paradox in the KO animals could be due to the nature of the ER receptors. For instance, ER $\alpha$ and ER $\beta$ act differently at AP-1 sites $^{36}$, which may be due to differences in their activation domains. ${ }^{37}$ The difference in infarct size between ER $\alpha$ and ER $\beta$ knockouts points towards differences in remodeling of the affected region. The presence of ER $\beta$ may result in extensive remodeling which decreased the infarct size but on the other hand increased the risk for arrhythmia. Ventricular arrhythmias are the primary acute cause of mortality after MI. On the other hand E2 is considered to have antiarrhythmic properties. ${ }^{38}$ These finding are of potential clinical relevance, as cardiac hypertrophy and remodeling are important negative predictors of morbidity and mortality in patients with heart failure. ${ }^{39}$ In our model an increased risk of sudden death may occur as a consequence of infarct- or hypertrophy-associated increases in electrical inhomogeneity. Also E2-induced alterations in circulating neurohumoral factors also could contribute to an increase in sudden death. Estrogen-induced increases in thrombosis could also be hypothesized to explain the increased mortality, perhaps because of an increased risk of thromboembolism, though so far no specific evidence has been observed to support this. ${ }^{26}$

Though the role of the ERs is not clear E2 hs been shown to inhibit the formation of collagen in noncardiac cells. ${ }^{40}$ Furthermore, E2 can inhibit the growth of cardiac fibroblasts. ${ }^{41}$ The suppression of fibroblast growth and collagen synthesis may be in part responsible for the increased scar size found in the E2-treated rats. The reduction in infarct size observed in the ERKO E2-treated mice could be caused by apoptosis. In vitro, E2 inhibits apoptosis in cultured cardiomyocytes ${ }^{42}$, and the extent to which apoptosis participates in infarct-induced cell death. ${ }^{43} \mathrm{E} 2$ inhibits apoptosis in LVs of E2-treated infarcted mice. ${ }^{26}$ It also inhibits apoptosis in nonmyocyte cell types. ${ }^{44}$ Estrogens are known to activate ERK1/2. ${ }^{21}$ Lips et al. ${ }^{21}$ showed that ERK1/2 overexpression limits ischemiainduced apoptosis, while ERK1/2 knockout augments ischemia-induced apoptosis rates. E2 could also inhibit NF- $\mathrm{KB}$ activity, ${ }^{42}$ which represents a potential mechanism to reduce infarct size by E2 treatment. The cardioprotective effect of E2 is probably mediated by ER $\beta{ }^{45}$ Since E2 could enhance antiapoptotic activity through ER $\beta$ during oxidative damage in hepatocytes, ${ }^{46}$ in our animals presence of ER $\beta$ could be responsible for this anti-apoptotic process leading to a small infarct size in these animals.

MI led to LV remodeling which was not decreased by E2 treatment in infracted WT, ERKO and BERKO mice. This is in line with previous findings. ${ }^{26}$ Experiments analyzing the effect of E2 treatment on infarct size have revealed conflicting results. ${ }^{15,26}$ Hugel et al. ${ }^{15}$ found that neither ovariectomy nor E2 replacement had any effect on geometry or function in either sham-operated or infarcted rat hearts. Rupture rate was not altered by ovariectomy in females, while supplemental E2 tended to reduce it in males although not to a significant degree. Physiological concentrations of $E_{2}$ do not have major effects on the remodeling process post-MI. ${ }^{15}$ E2 deficiency occurring after ovariectomy does not have a major adverse effect on the remodeling process post-MI in ovariectomized rats. ${ }^{15}$ These observations challenge the assumption that E2 is cardioprotective. ${ }^{13}$ Our results indicate that such confusion may be the result of differences in the gene induction pattern, induced by the two receptors. Further studies applying receptor-specific ligands will be required to analyse the in vivo functions of the receptors.

In conclusion, the current studies demonstrate that E2 treatment slightly reduces infarct size via ER $\beta$. Despite this protective effect, E2 in presence of ER $\beta$ significantly increases post-MI hypertrophic growth and mortality in mice (Figure 6.7). The two ERs play different roles in the heart. 


\section{Acknowledgments}

This work was supported by grants from the Netherlands Heart Foundation (NHS 99-114 and NHS 2000-160) and the Interuniversity Cardiology Institute Netherlands and Wynand Pon foundation to P.A.D., the Netherlands Heart Foundation (D98.015) to M. V. B. and by the Deutsche Forschungsgemeinschaft and BONFOR to $\mathrm{C}$. $\mathrm{G}$ and $\mathrm{M}$ v. E.. Additional support from the RESCAR foundation was greatly appreciated. We thank Organon, Oss, the Netherlands for providing the animals.

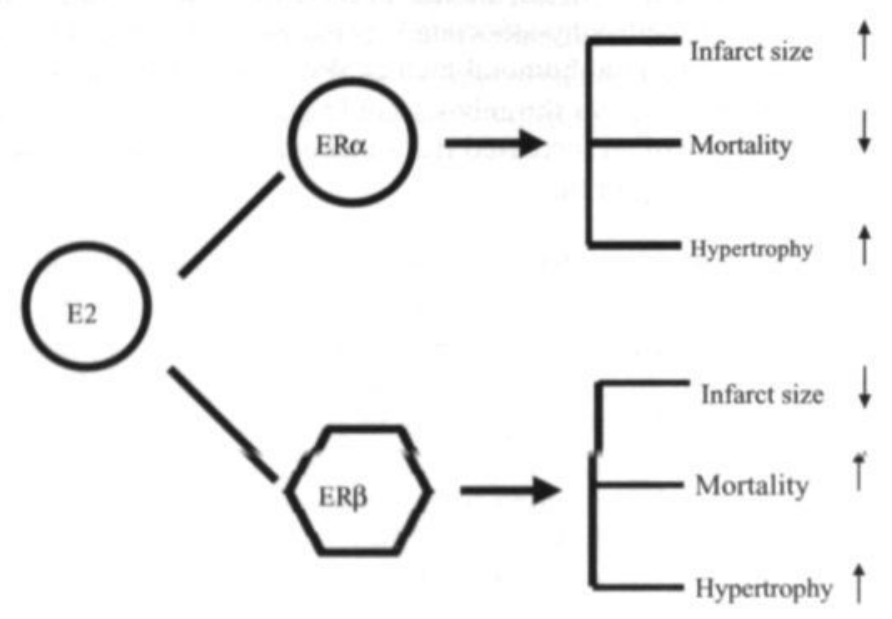

Figure 6.7. Schematic representation showing the effects of ERs on infracted hearts in presence of E2. Up and downwards arrows indicate increase or decrease in the effect. 


\section{References}

1. Blum A, Koh K, Cannon RO, 3rd. CME Paper: Hormone Replacement Therapy for Prevention or Treatment of Atherosclerosis in Postmenopausal Women: Promises, Controversies, and Clinical Trials. Am J Geriatr Cardiol. 2000;9:81-88.

2. Grady D, Rubin SM, Petitti DB, et al. Hormone therapy to prevent disease and prolong life in postmenopausal women. Ann Intern Med. 1992;117:1016-37.

3. Sullivan JL. Estrogen and coronary heart disease in women. Jama. 1991;266:1358.

4. Mendelsohn ME, Karas RH. The time has come to stop letting the HERS tale wag the dogma. Circulation. 2001;104:2256-9.

5. Hulley S, Furberg C, Barrett-Connor E, et al. Noncardiovascular disease outcomes during 6.8 years of hormone therapy: Heart and Estrogen/progestin Replacement Study follow-up (HERS II). Jama. 2002;288:58-66.

6. Rossouw JE, Anderson GL, Prentice RL, et al. Risks and benefits of estrogen plus progestin in healthy postmenopausal women: principal results From the Women's Health Initiative randomized controlled trial. Jama. 2002;288:321-33.

7. Saunders PT, Maguire SM, Gaughan J, et al. Expression of oestrogen receptor beta (ER beta) in multiple rat tissues visualised by immunohistochemistry. $J$ Endocrinol. 1997; 154:R13-6.

8. Grohe C, Kahlert S, Lobbert K, et al. Cardiac myocytes and fibroblasts contain functional estrogen receptors. FEBS Lett. 1997;416:107-12.

9. Pines A, Mijatovic V, van der Mooren MJ, et al. Hormone replacement therapy and cardioprotection: basic concepts and clinical considerations. Eur J Obstet Gynecol Reprod Biol. 1997;71:193-7.

10. Bush TL, Barrett-Connor E, Cowan LD, et al. Cardiovascular mortality and noncontraceptive use of estrogen in women: results from the Lipid Research Clinics Program Follow-up Study. Circulation. 1987;75:1102-9.

11. van Eickels M, Grohe C, Cleutjens JP, et al. 17beta-estradiol attenuates the development of pressure-overload hypertrophy. Circulation. 2001;104:1419-23.

12. Babiker FA, De Windt LJ, van Eickels M, et al. 17beta-estradiol antagonizes cardiomyocyte hypertrophy by autocrine/paracrine stimulation of a guanylyl cyclase A receptor-cyclic guanosine monophosphate-dependent protein kinase pathway. Circulation. 2004;109:26976.

13. Cavasin MA, Sankey SS, Yu AL, et al. Estrogen and testosterone have opposing effects on chronic cardiac remodeling and function in mice with myocardial infarction. Am J Physiol Heart Circ Physiol. 2003;284:H1560-9.

14. Node K, Kitakaze M, Kosaka H, et al. Amelioration of ischemia- and reperfusion-induced myocardial injury by 17 beta-estradiol: role of nitric oxide and calcium-activated potassium channels. Circulation. 1997;96:1953-63.

15. Hugel $\mathrm{S}$, Reincke $\mathrm{M}$, Stromer $\mathrm{H}$, et al. Evidence against a role of physiological concentrations of estrogen in post-myocardial infarction remodeling. $\mathrm{J} \mathrm{Am}$ Coll Cardiol. 1999;34:1427-34.

16. McNulty PH, Jagasia D, Whiting JM, et al. Effect of 6-wk estrogen withdrawal or replacement on myocardial ischemic tolerance in rats. Am J Physiol Heart Circ Physiol. 2000;278:H1030-4.

17. McHugh NA, Merrill GF, Powell SR. Estrogen diminishes postischemic hydroxyl radical production. Am J Physiol. 1998;274:H1950-4.

18. Smith PJ, Ornatsky O, Stewart DJ, et al. Effects of estrogen replacement on infarct size, cardiac remodeling, and the endothelin system after myocardial infarction in ovariectomized rats. Circulation. 2000;102:2983-9. 
19. Lubahn DB, Moyer JS, Golding TS, et al. Alteration of reproductive function but not prenatal sexual development after insertional disruption of the mouse estrogen receptor gene. Proc Natl Acad Sci US A. 1993;90:11162-6.

20. Patten RD, Aronovitz MJ, Deras-Mejia L, et al. Ventricular remodeling in a mouse model of myocardial infarction. Am J Physiol. 1998;274:H1812-20.

21. Lips DJ, Bueno OF, Wilkins BJ, et al. MEK1-ERK2 signaling pathway protects myocardium from ischemic injury in vivo. Circulation. 2004;109:1938-41.

22. Lips DJ, van der Nagel T, De Windt LJ. Left ventricular pressure-volume measurements in mice: closed-chest versus open-chest. Basic Res Cardiol (in press). 2004.

23. Lindberg MK, Weihua Z, Andersson N, et al. Estrogen receptor specificity for the effects of estrogen in ovariectomized mice. J Endocrinol. 2002;174:167-78.

24. Warner M, Nilsson S, Gustafsson JA. The estrogen receptor family. Curr Opin Obstet Gynecol. 1999;11:249-54.

25. Ogawa S, Chan J, Chester AE, et al. Survival of reproductive behaviors in estrogen receptor beta gene-deficient (betaERKO) male and female mice. Proc Natl Acad Sci US A. 1999;96:12887-92.

26. van Eickels M, Patten RD, Aronovitz MJ, et al. 17-beta-estradiol increases cardiac remodeling and mortality in mice with myocardial infarction. $\mathrm{J} \mathrm{Am}$ Coll Cardiol. 2003;41:2084-92.

27. Karlson BW, Herlitz J, Hartford M. Prognosis in myocardial infarction in relation to gender. Am Heart J. 1994;128:477-83.

28. Demirovic J, Blackburn H, McGovern PG, et al. Sex differences in early mortality after acute myocardial infarction (the Minnesota Heart Survey). Am J Cardiol. 1995;75:1096101.

29. Marrugat J, Anto JM, Sala J, et al. Influence of gender in acute and long-term cardiac mortality after a first myocardial infarction. REGICOR Investigators. J Clin Epidemiol. 1994;47:111-8.

30. Vaccarino V, Krumholz HM, Berkman LF, et al. Sex differences in mortality after myocardial infarction. Is there evidence for an increased risk for women? Circulation. 1995;91:1861-71.

31. Greenland P, Reicher-Reiss H, Goldbourt U, et al. In-hospital and 1-year mortality in 1,524 women after myocardial infarction. Comparison with 4,315 men. Circulation. 1991;83:48491.

32. Vaccarino V, Horwitz RI, Meehan TP, et al. Sex differences in mortality after myocardial infarction: evidence for a sex-age interaction. Arch Intern Med. 1998;158:2054-62.

33. Vaccarino V, Parsons L, Every NR, et al. Sex-based differences in early mortality after myocardial infarction. National Registry of Myocardial Infarction 2 Participants. $N$ Engl J Med. 1999:341:217-25.

34. Martin CA, Thompson PL, Armstrong BK, et al. Long-term prognosis after recovery from myocardial infarction: a nine year follow-up of the Perth Coronary Register. Circulation. 1983;68:961-9.

35. Taylor AH, At-Azzawi F. Immunolocalisation of oestrogen receptor beta in human tissues. $J$ Mol Endocrinol. 2000;24:145-55.

36. Paech K, Webb P, Kuiper GG, et al. Differential ligand activation of estrogen receptors ERalpha and ERbeta at API sites. Science. 1997;277:1508-10.

37. Hall JM, McDonnell DP. The estrogen receptor beta-isoform (ERbeta) of the human estrogen receptor modulates ERalpha transcriptional activity and is a key regulator of the cellular response to estrogens and antiestrogens. Endocrinology. 1999;140:5566-78. 
38. McHugh NA, Cook SM, Schairer JL, et al. Ischemia- and reperfusion-induced ventricular arrhythmias in dogs: effects of estrogen. Am J Physiol. 1995;268:H2569-73.

39. Liao Y, Cooper RS, Mensah GA, et al. Left ventricular hypertrophy has a greater impact on survival in women than in men. Circulation. 1995;92:805-10.

40. Kwan G, Neugarten J, Sherman M, et al. Effects of sex hormones on mesangial cell proliferation and collagen synthesis. Kidney Int. 1996;50:1173-9.

41. Dubey RK, Gillespie DG, Jackson EK, et al. 17Beta-estradiol, its metabolites, and progesterone inhibit cardiac fibroblast growth. Hypertension. 1998;31:522-8.

42. Pelzer T, Schumann M, Neumann M, et al. 17beta-estradiol prevents programmed cell death in cardiac myocytes. Biochem Biophys Res Commun. 2000;268:192-200.

43. Bialik S, Geenen DL, Sasson IE, et al. Myocyte apoptosis during acute myocardial infarction in the mouse localizes to hypoxic regions but occurs independently of p53.J Clin Invest. 1997;100:1363-72.

44. Wang TT, Phang JM. Effects of estrogen on apoptotic pathways in human breast cancer cell line MCF-7. Cancer Res. 1995;55:2487-9.

45. Hale SL, Bimbaum Y, Kloner RA. beta-Estradiol, but not alpha-estradiol, reduced myocardial necrosis in rabbits after ischemia and reperfusion. Am Heart J. 1996;132:258-62.

46. Inoue H, Shimizu I, Lu G, et al. Idoxifene and estradiol enhance antiapoptotic activity through estrogen receptor-beta in cultured rat hepatocytes. Dig Dis Sci. 2003;48:570-80. 


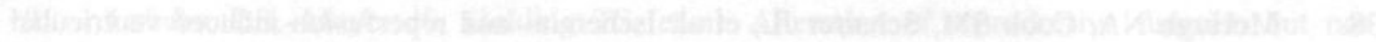

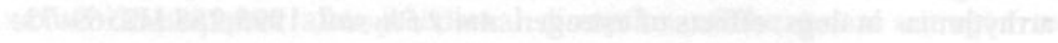

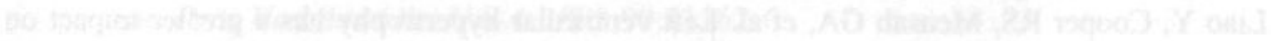

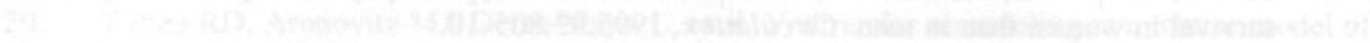

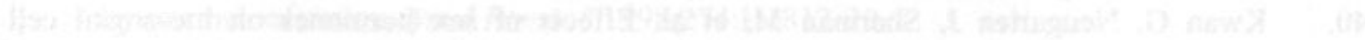

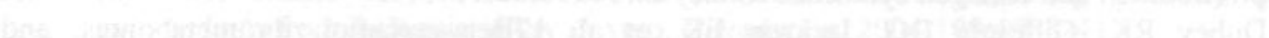

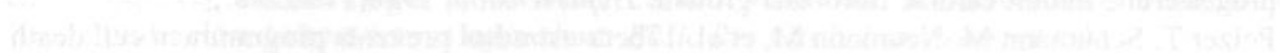

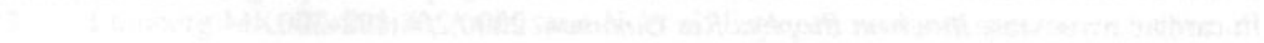

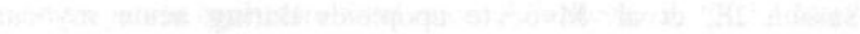




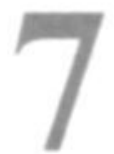

General Discussion 


\section{General discussion}

\section{Introduction}

In mice, cardiac myocytes rapidly proliferate during fetal development but typically cease to divide soon after birth. ${ }^{1}$ Adult murine cardiac myocytes have lost the ability to proliferate, but in many pathological situations they are subjected to increased hemodynamic stress, necessitating them to increase mass by compensatory strategies. This increase in mass, called hypertrophy, is directed by proteins linked to cytoplasmic signaling cascades and proteins that induce gene expression. ${ }^{2-5}$ Increase in left ventricular mass represents a mechanism of structural adaptation of the heart in response to pressure overload. The resulting left ventricular hypertrophy is an important negative predictor of cardiac morbidity and mortality and displays significant sex-based differences. ${ }^{6-9}$

Despite improved medical treatment and intense investigation, heart failure is a leading cause of morbidity and mortality in industrialized countries. ${ }^{8-10} \mathrm{~A}$ fundamental shift in the underlying etiology of heart failure is becoming evident, in which the most common cause of chronic heart failure is no longer hypertension or valvular disease, but rather coronary artery disease (CAD) and long-term survival after myocardial infarction (MI). ${ }^{8} \mathrm{E} 2$ is known to have multiple protective effects on the cardiovascular system. " The role of E2 in the development of left ventricular hypertrophy $(\mathrm{LVH})$, however, is poorly understood. Many observational studies suggest that estrogen replacement therapy (ERT) has cardioprotective effects in postmenopausal women. ${ }^{12,13}$ However, recent clinical trials have failed to show a cardiovascular benefit of ERT in women with established coronary artery disease. ${ }^{14}$ In this thesis, we investigated the effects of E2 on cardiomyocyte gene expression in vitro and in vivo. In vitro we used neonatal rat ventricular myocytes NRVMs and the hypertrophic agonists endothelin-1 (ET-1) and phenyephrine (PE). These hypertrophied cardiomyocytes were treated with E2 to investigate the counteracting effects of E2. In vivo we used two mouse models, E2 receptor alpha $(\mathrm{ER} \alpha)$ knockout (ERKO) and E2 receptor beta (ER $\beta$ ) knockout (BERKO) subjected to either pressure overload or MI. The main hypothesis tested was that $\mathrm{E} 2$ reduces $\mathrm{LVH}$ and regulates ventricular remodeling in hypertensive heart disease and MI. To study the effect and pathology of E2 treatment, changes in morphology and performance were related to changes in gene expression profiles in particular of fetal and stress proteins.

\section{Estrogen and estrogen receptors}

Previous studies demonstrate that the heart is a target organ for E2. ${ }^{15}$ Steroid hormones regulate target cell expression upon binding to intracellular and membrane receptors. ${ }^{16,17}$ Gender-based differences found in cardiovascular disease raise the possibility that E2 may have direct effects on cardiac tissue. E2 inhibits vascular smooth muscle cell growth and migration, protects against atherosclerosis and vascular injury and regulates gene expression in vascular cells. ${ }^{18,19}$ It promotes vasodilation via increased endothelial nitric oxide $(\mathrm{NO})$ release, and causes favorable changes in the blood lipid profile. Rat models of pulmonary hypertension demonstrate that ovariectomy potentiates the induction of ventricular hypertrophy while E2 replacement attenuates this response. ${ }^{20}$ Gender differences in clinical studies of LVH and heart failure are also supported by findings from animal models. In response to pressure increases (by aortic banding), male rats develop ventricular dysfunction at an earlier stage than female rats. ${ }^{21}$ Even at similar pressure loads, female rats have greater LVH and maintained chamber function. ${ }^{22}$ In spontaneously hypertensive rats, heart failure is delayed in female compared to male rats. ${ }^{23}$ E2 has been shown to attenuate the hypertrophic response to pressure overload in mice. ${ }^{3,4,24}$ Also, E2 has been proposed to play an important role in cardiac hypertrophy and remodeling after myocardial infarction. ${ }^{25}$

ERs have been found in myocardial cells, mediating, for example, the antiproliferative effects of E2. Treatment of ovariectomized rats with E2 induces nitric oxide synthase in cardiac myocytes ${ }^{26}$ and reduces heart contractility by inhibition of L-type calcium channel activity. ${ }^{27}$ E2 also increased 
$\mathrm{ER} \alpha$ as well as ER $\beta$ transcripts in cultured cardiomyocytes. ${ }^{26}$ Recent studies have shown that ovariectomy increases and E2 decreases L-type calcium channel density in rabbit ventricular myocytes. ${ }^{28}$ These effects may be mediated by the NO/cGMP pathway. E2 increases NO production which in turn stimulates cGMP production. Fraser et al. ${ }^{29}$ reported that chronic administration of E2 to ovariectomized rats increases NO synthase activity, restores impaired cGMP production, and improves post ischemic left ventricular work in hearts isolated from these animals.

The ER $\alpha$ mediates a number of E2-induced events during development, reproduction and normal physiology in E2 responsive target tissues. ${ }^{30}$ It has been shown that bone in vivo undergoes an adaptive response to loading that is less effective in the absence of the $E R \alpha$ and that osteoblast-like cells require $\mathrm{ER} \alpha$ to proliferate in response to mechanical strain in vitro. As ER $\alpha$ expression in osteoblasts and osteocytes depends on E2 concentration, ${ }^{31-44}$ failure to maintain bone strength after the menopause might be due to a reduction in the activity of ER $\alpha$ in bone cells. ${ }^{35}$ Recent studies on ERá function and modulation suggest that ERá is important in normal mammary gland development and neoplasia. ${ }^{30,36,37}$ E2 replacement increased the expression of ER $\beta .{ }^{38}$ Nuedling et $\mathrm{aP}^{39}$ showed that axtivation of ER $\beta$ is a prerequisite for E2-dependent upregulation of nitric oxide synthases in NRVM. Recent in vitro studies in ER $\beta$ transfected cells have demonstrated that ER $\beta$ activation by E2 facilitates transcription of the oxytocin gene. ${ }^{40}$ Disruption of ER $\beta$ therefore leads to loss of the E2 effect to attenuate vasoconstriction ${ }^{41}$ In intact BERKO animals and their WT littermates. Animals had normal BP until 5 to 6 months of age, when BP increased in approximately half of a cohort of 20 BERKO mice. ${ }^{41}$

Interestingly, both sexes of the ERKO mice are infertile, whereas only the BERKO female has shown impaired fertility. ${ }^{42,43}$ ERKO sperm was functional but does not function because of the immature in testes of ERKO mice. ${ }^{44}$ The testes of the BERKO mice produce sufficient and functional sperm for production of offspring. ${ }^{45}$ Therefore, ER $\alpha$ appears to be more critical than ER $\beta$ in mediation of the E2 actions necessary for successful sperm maturation. The infertility of the female ERKO mouse is due in part to the insensitivity of the uterus to the mitogenic and differentiating actions of E2. ${ }^{46,47}$ All expected tissues of the ERKO uterus are present but appear immature, as illustrated by a reduced number of glands in the endometrium. ${ }^{45} E R \alpha$ is thus not necessary for development of the uterus, but is necessary for complete maturation and function of the tissue. In contrast, BERKO uteri are indistinguishable from wild-type, and show normal organization and development of the stromal, myometrial and epithelial layers, as well as glandular structures. ${ }^{45}$ ER $\beta$ is thus not required for normal development of the female reproductive tract. ${ }^{45}$ When challenged with estrogenic compounds, the wild-type and BERKO uteri respond with increased weight and epithelial development, while the ERKO uterus is nonresponsive. We have used this response to demonstrate the effect of E2 or lack of it in BERKO and ERKO mice.

\section{Gene expression profile}

While it has been well established that estrogens have a specific, direct and physiologically relevant effect for the vasculature, the situation in the myocardium is less clear. ${ }^{11}$ To analyze gene expression changes during LVH and estrogen (E2) treatment we used microarrays. This enabled us to show an upregulation of fetal, stress and structural genes with hypertrophy, such as ANF, HSP, $\beta \mathrm{MHC}, \mathrm{MLC}-2$, and $\alpha$-sk-actin. This increase in gene expression could be inhibited by E2treatment. ${ }^{48} \mathrm{~A}$ similar increase in cardiac mRNA of fetal, stress and structural genes was demonstrated in cardiac biopsies from patients with mitral valve disease, indicating that such activation of gene expression correlated with the induction of hypertrophy. ${ }^{49}$ The upregulation of fetal genes is mediated through specific signal transduction pathways. ${ }^{50}$ In mice an increase in ANF mRNA is found in the ventricle that is stressed by aortic banding, ${ }^{51}$ by genetic hypertension ${ }^{52}$, and in viable ventricular myocardium following experimental infarction. ${ }^{53}$ Even though ventricular ANF 
expression has been considered to be a specific molecular marker of hypertrophy, its role in hypertrophy is unclear. Changes in cardiomyocyte morphology in response to hypertrophic signals are reflected at the molecular level by the induction of important sarcomeric proteins, including the $\beta$ MHC, MLC-2V, MLC-2 and $\alpha$-sk-actin. ${ }^{54-57}$ Re-expression of fetal genes such as $\beta$ MHC, $\alpha$-skactin and $\alpha$-mooth muscle (sm) actin and ANF may occur after 6-20 h. Despite its name ANF is coexpressed in the embryonic atrium and ventricle but is transcriptionally silent in the normal adult ventricle. An upregulation of constitutively expressed contractile proteins such as ventricular myosin light chain (MLC) $2^{58}$ appears to be delayed. Although ANF is not found on the affymetrix chips but we could show the increase in its expression by RT-PCR. HSPs expression is known to be important for the heart protection (Plumer ross 1995, Marber Mestri 1995 and Radford, Fina 1996). Gender differences in expression of HSPs have not previously been reported in heart diseases. ${ }^{59}$. In our study we found that there is a decrease in the expression of HSPs in absence of TAC. The relation of HSPs and E2 treatment in TAC mice is not clear. This could be because of the transient nature of the expression of HSPs. Transcription of some HSPs genes was induced at an early stage of cardiac hypertrophy caused by pressure overload. Accumulation of these HSPs mRNA was observed at 4 hour and then gradually disappeared. ${ }^{60}$ The role of these stress genes in cardiac remodeling deserve more attention.

TGF $\beta$ is present in both cardiomyocytes and myocardial fibroblasts ${ }^{61,62}$ In the heart, TGF $\beta$ has been shown to be expressed at high levels during cardiac development ${ }^{63,64}$ and pathology. ${ }^{62,65-67}$ In fact, growth factors such as TGF $\beta$ have been implicated in cardiomyocyte growth. ${ }^{5,68}$ TGF $\beta$ mRNA levels were increased under pressure but not volume overioad. ${ }^{60}$ Clinical evidence revealed that patients with idiopathic hypertrophic obstructive cardiomyopathy have elevated TGF $\beta$ mRNA and protein levels localized to cardiomyocytes and TGF $\beta$ receptor levels found on both cardiomyocytes and fibroblasts. ${ }^{62,66} \mathrm{~A}$ number of studies have demonstrated that mRNA levels of TGF $\beta$ are markedly increased upon pressure overload or pharmacological manipulation and correlated these mRNA changes with hypertrophic growth. ${ }^{68}$ Decrease or absence of TGF $\beta$ leads to decrease of LVH. Echocardiographic analysis revealed that TGF $\beta$-deficient mice subjected to hypertrophy had no significant change in LV mass. ${ }^{70}$

\section{Hypertrophy}

In vitro hypertrophy can be induced by ET-1 and PE as in NRVMs. ET-1, a potent vasoconstrictor peptide from vascular endothelial cells, ${ }^{71}$ has been shown to be synthesized and secreted by cardiomyocytes $^{71}$ and to induce hypertrophy of cardiomyocytes. ${ }^{71,72}$ Upregulation of preproET-1 $^{-1}$ mRNA expression is induced by several stimuli that activate protein kinase $\mathrm{C}$, such as angiotensin II, ET-1 itself, phorbol ester, and stretch. ${ }^{73}$ The ET-1 gene has AP-1 binding sites in the promoter region, and these factors are known to upregulate AP-1, suggesting that the ET-1 gene is partly induced through AP-1 binding. ${ }^{71} \mathrm{PE}$ was found to induce hypertrophic growth response in adult rat ventricular cardiomyocytes, similar to that of ET-1. This effect is due to á-adrenoceptor stimulation, because the growth effect can be antagonized by the $\alpha$-adrenoceptor blocker, but not by inhibition of $\beta$-adrenoceptors ${ }^{74,75}$ (Figure 7.1). 


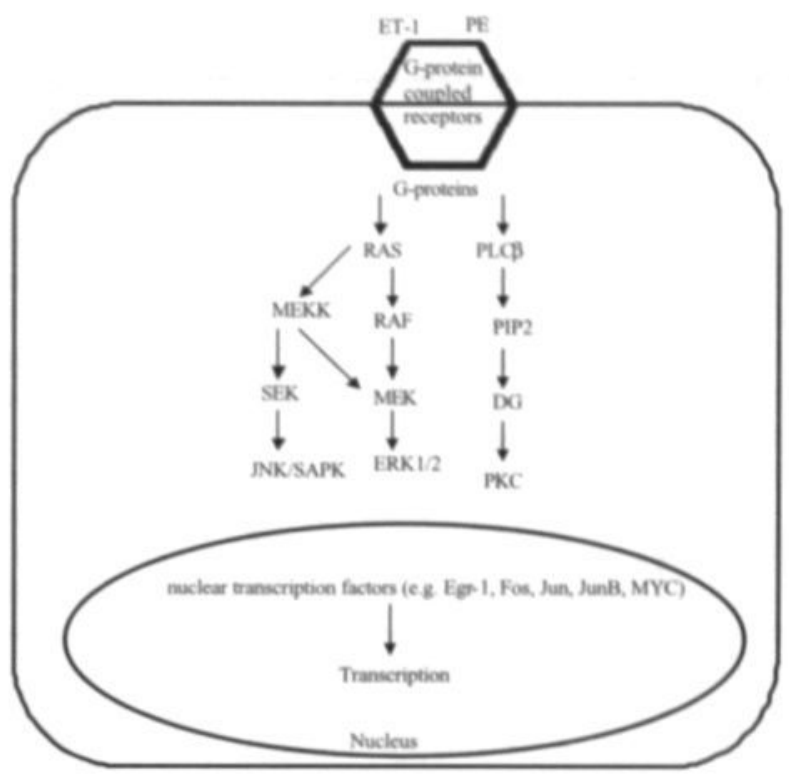

Figure 7.1. Multiple interacting signal transduction pathways are initiated by mediators of hypertrophic phenotypes in cultured cardiomyocytes. The specific effect of a given hypertrophic stimulus may well be the result of a complex combinatorial activation of individual pathways depending on abundance of relevant proteins in the cell in question. Evidences suggest a central role for the Ras-Raf-MEK-ERK pathway in transmitting these stimuli to the nucleus.

PE and ET-1 stimulate cell growth and expression of several genes (e.g. ANF) associated with cardiac hypertrophy. ${ }^{76} \mathrm{PE}$ increases rates of ANF production from 24-72h. ET-1 stimulates ANF production equal to the PE response at $24 \mathrm{~h}$, but subsides after $72 \mathrm{~h} .{ }^{76}$ Thus, although the effect of both stimuli is the same, the dynamics differ. ${ }^{54}$ Associated with this hypertrophic response is the induction of a variety of genes, including several immediate early genes ${ }^{54}$, embryonic genes ${ }^{77}$, $\mathrm{ANF}^{4}$ and MLC-2. ${ }^{78}$

\section{Estrogen and hypertrophy in NRVMs}

We used NRVMs to further elucidate the pathways and the elements required for hypertrophy (Figure 7.2). NRVM were trated with hypertrophic agonists ET-1 or PE to induce hypertrophy (Chapter 3). E2-treatment counteracted morphological and biochemical parameters of myocyte hypertrophy. A marked upregulation of ANF mRNA and protein levels accompanied the morphological observations mediated through an ER mediated pathway. Isolated cardiac myocyte preparations respond to a variety of hormones and growth factors by recapitulating many of the characteristics of hypertrophy in vivo, including increased myocyte size, enhanced RNA and protein synthesis and the re-expression of certain fetal genes such as ANF. ${ }^{54,73,79,80}$ Indeed, in hypertrophied and failing hearts production of ANF and BNP in cardiomyocytes is markedly augmented and is a prognostic indicator of clinical severity. ${ }^{81}$ ANF induces inhibition of L-type calcium channels in the myocardium. $^{82}$ ANF has been shown to have growth-inhibitory effects in both non-myocardial cells $^{83,84}$ and cardiac myocytes. ${ }^{85}$ These effects are recognized as being protective to the cardiovascular system and are also induced by $\mathrm{E} 2 .^{11}$ 


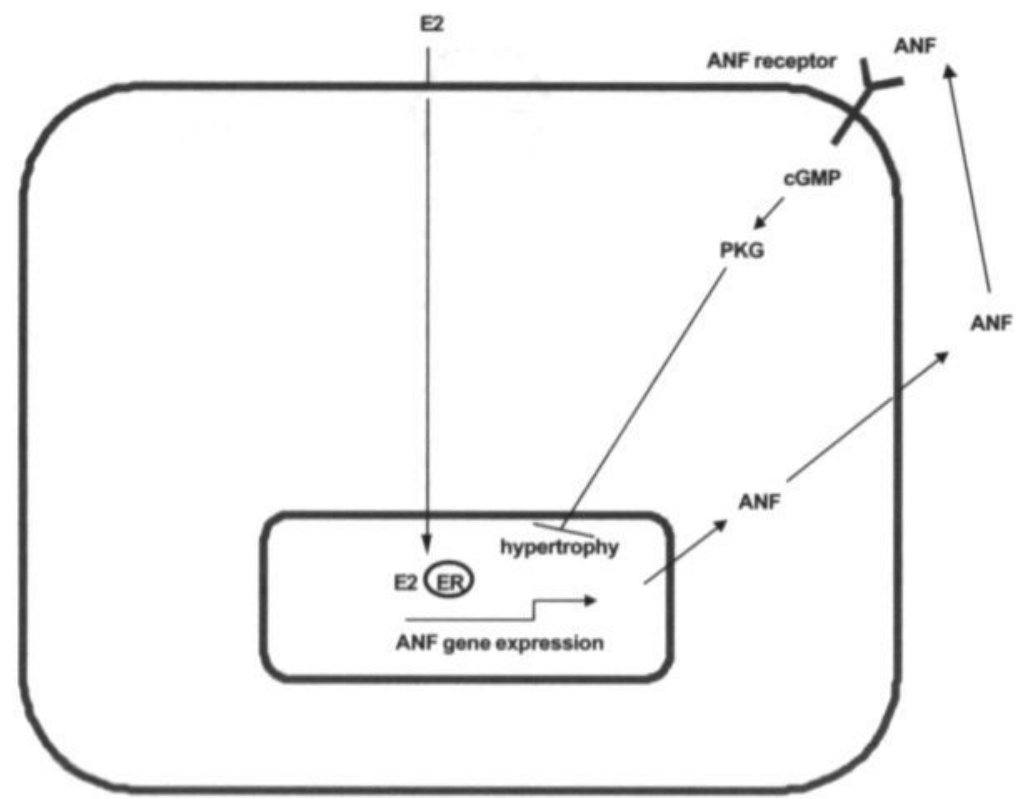

Figure 7.2. Estrogen protect the heart against LVH by increasing the expression of ANF. Treatment of NRVM with E2 increase the expression of ANF. ANF affect the cells by autocrine/paracrine process, through its stimulation of the ANF receptor. This stimulation increase the cGMP which increase the expression of PKG and antagonizes hypertrophy. Blockade of PKG result in hypertrophy even in presence of E2, ANF and cGMP.

In ventricular myocytes ANF activates particular guanylyl cyclase, leading to increased cGMP accumulation. ANF can counteract hypertrophic stimuli by direct growth-inhibiting effects on cardiac myocytes ${ }^{86}$, and indirectly by reducing the extracellular fluid volume and inhibiting the rennin-angiotensin-aldosterone system. Signaling via guanylyl cyclase-A is a potent inhibitor of $\mathrm{LVH}^{87}$ It is interesting to note that inactivation of guanylyl cyclase-A has been found to result in hypertension, cardiac hypertrophy and increased mortality. ${ }^{88}$ The observation that both $\mathrm{E} 2{ }^{27.89}$ and $\mathrm{ANF}^{82}$ inhibit calcium channels in cardiomyocytes is consistent with linkage to cGMP elevation. Diffusible cGMP acts as a second messenger primarily by stimulating PKG ${ }^{90}$ PKG is the major mediator of cGMP-induced smooth muscle relaxation. ${ }^{91}$ Furthermore, there is recent evidence that the membrane-bound guanylyl cyclase, type A natriuretic peptide receptor (NPRA), has potent effects on plasma membrane control of the calcium ATPase pump, ${ }^{92}$ suggesting that NO- and natriuretic peptides (NP)- mediated effects are compartmentalized in cells.

These data suggest that the cGMP/PKG system plays a potentially important and direct role in transcriptional regulation. Receptor-generated cGMP binds to PKG. cGMP-dependent nuclear localization of PKG causes transactivation of the Fos promoter. ${ }^{93}$ We and others have recently reported that ANF inhibits cardiac hypertrophy through cGMP/PKG signaling. ${ }^{94}$ (Chapter 4) Our data suggest that PKG membrane recruitment is an effect of NPRA activation and not a general consequence of rising cGMP levels. It is well established that both NO and NPs signal through cGMP, generated by membrane-bound guanylyl cyclases. Most of the downstream actions of cGMP $^{95}$ occur through its binding and subsequent activation of PKG, but cGMP also directly regulates ion channels. ${ }^{96.9}$ Downstream signalling events involve the generation of cGMP, since 
many of the ligand-induced effects can be mimicked by the administration of cGMP analogues. Intravenously administered synthetic or native ANF was shown to increase cGMP concentrations in the urine of treated animals. ${ }^{100}$ In these animals, the hypertrophic phenotype is rescued ${ }^{101}$ and that enhanced expression of ANF protects the animal from cardiac hypertrophy and systemic hypertension. ${ }^{102}$ Thus, there is apparently an important counterbalancing relationship between ANF gene expression and cardiac hypertrophy.

\section{Hypertrophy in vivo}

LVH caused by essential hypertension is one of the major causes of impaired cardiac function followed by heart failure. ${ }^{103,104}$ Although the increase in left ventricular mass may represent adaptation of the heart in response to pressure overload, left ventricular hypertrophy is associated with an increased risk of cardiovascular complications and mortality/morbidity. ${ }^{109-167}$ Hypertrophy can be induced by many different physiological and molecular stimuli ${ }^{108}$, as illustrated by a variety of experimental models in mice ${ }^{109.110}$, such as genetic modification ${ }^{111}$, pressure overload ${ }^{112}$, drug treatment ${ }^{113}$ and strain-dependent genetic modifiers ${ }^{114,115}$ (For details see chapter 2). Despite the variety of methods used for induction, hypertrophic hearts share a common feature: re-expression of a fetal-like and stress gene program. This program shift includes changes in secreted and contractile proteins, ion channels, and energy metabolism. Hypertrophy is characterized by cardiomyocyte growth , myofibrillar disarray, fibrosis, apoptosis, arrhythmias, elevated filling and end-diastolic pressure, decline in systolic function, cellular and mitochondrial energy inefficiency, alteration in calcium handling and eventually transition towards heart failure. ${ }^{116}$ The single most powerful predictor for development of heart failure is the presence of left ventricular hypertrophy. ${ }^{119}$ For this reason there is much effort to study the mechanism of LVH and the best treatment modes. In this study we used TAC in ERKO and BERKO mice models to induce LVH, and to study the effect of E2-treatment on this pressure challenge.

\section{Estrogen and LVH}

E2 was proven to be cardiac protective for hypertrophic agonist stimulated NRVMs and animal models (Chapter 3, Chapter 4). ${ }^{24}$ Despite presence of several studies supporting this finding, other researchers were unable to confirm the results. In this study we used animal models to dissect the role of the ERs in LVH in order to define new targets for treatment of hypertrophy. We showed for the first time that $E 2$ protects the murine heart from $L V H$ via ER $\beta$ and not $E R \alpha$. TAC increased the $\mathrm{LVH}$ in all treatment groups, while E2 decreased this hypertrophy in the presence of ER $\beta$. This protective effect includes increased expression of ANF and decreased p38 phosphorylation. E2treatment blocked the increased phosphorylation of p38-MAPK and increased the expression of ANF in presence of ER $\beta$. The protective effects of E2 together with the blockade of p38 phosphorylation and increased ANF expression disappeared completely in absence of ER $\beta$, despite the presence of ER $\alpha$. These findings indicated that E2 protects the murine heart via the ER $\beta$ and not $\mathrm{ER} \alpha$.

E2 has been reported to prevent the development of cardiac hypertrophy in the aortic-banded mouse model. ${ }^{24}$ In an isolated working rat heart, E2 was found to restore ventricular function following gonadectomy. ${ }^{118}$ In rats increased arterial pressure is known to be associated with significant increases in LV mass. Pretreatment with E2 has been shown to abolish this increase in ventricular remodeling. ${ }^{119}$ In postmenopausal women, left ventricular hypertrophy is commonand likely to be a strong cardiovascular risk factor compared with men, suggesting that E2 has potential protective effects in the cardiovascular system. ${ }^{104}$ In fact, hormone replacement therapy in hypertensive postmenopausal women contributes to reducing left ventricular mass, improving cardiac function, and decreasing future cardiovascular events. ${ }^{33.120,121}$ Investigations into hypertrophic signaling pathways have implicated the activation of mitogen-activated protein (MAP) kinases ${ }^{122}$ 
Specifically, PKA and/or PKC may stimulate raf-1 independent of ras, with subsequent activation of 338 and ERK1/2 MAP kinases which finally results in hypertrophy. ${ }^{123-125}$

Inactivation of MAPK is mediated, in part, by dephosphorylation of MAPK by dualspecificity phosphatases called MAPK phosphatases (MKP). ${ }^{126}$ Since MKP is principally regulated at the transcription level, the cardiac MKP gene expression in response to E2 was studied. Transgenic overexpression of MKP was associated with a suppressed p38 activation and hypertrophic response to either pressure overload or prolonged $\alpha$-agonist infusion. ${ }^{127}$ Furthermore, MKP expression was inhibited by ICI 182,780 . Therefore, control of MAPK activity by E2 is exercised not only by protein phosphorylation, but also through phosphatases such as MKP by dephosphorylation. Taken together, these data demonstrate that E2 influences both phosphorylation and deactivation of these protein kinases and that this process is also mediated through the ERs. ${ }^{128}$ Interestingly, a recent study $^{129}$ indicated that E2 my mediate p38-kinase inactivation via MKP induction, suggesting a protective effect of E2. Therefore, the inhibition of the p38-MAPK phosphorylation by E2 treatment may represent one of the mechanisms by which $\mathrm{E}_{2}$ exerts its antihypertrophic effect in pressure overload. $^{24,130,131}$

E2 has been shown to increase the cardiac expression and secretion of ANF. ${ }^{132,133}$ The ANF gene is strongly activated in response to hypertrophic stimuli in the heart and prevents hypertrophy by inhibition of protein synthesis in cardiac myocytes via a cGMP-dependent process. ${ }^{4,86}$ Mice lacking ANF or its guanylyl cyclase A receptor exhibit marked cardiac hypertrophy that is disproportionately large for the very modest blood pressure increases found in these animals because of the loss of the vasodilating action of cGMP. ${ }^{134,135}$

Interestingly, the hearts from ANF receptor knockout male mice are considerably larger than those of female mice ${ }^{134,135}$ suggesting a parallel role of E2 and ANF in the prevention of cardiac hypertrophy. The colocalization of ERs and ANF in cardiac myocytes ${ }^{136}$ and stimulation of ANF secretion from the isolated, perfused rat right atrium by E2 ${ }^{137}$ provide arguments for the hypothesis that ANF acts as a mediator of E2 action. ANF has an inhibitory action on cardiomyocyte hypertrophy. ${ }^{87,94,138,139}$ ANF inhibits collagen synthesis in cardiac fibroblasts ${ }^{140}$ and both attenuate the growth response to adrenergic stimuli in cultured $\mathrm{NRVM}^{86}$ and induce apoptosis. ${ }^{141}$ This raises the possibility that, in addition to protecting the heart by reducing workload, ANF and brain natriuretic peptide (BNP) act directly on the myocardium to inhibit myocyte hypertrophy and fibrosis. $^{142}$ We have shown that E2 increases the expression of ANF and decreases the phosphorylation of $\mathrm{p} 38$ via ER $\beta$.

\section{Myocardial infarction}

Myocardial infarction (MI) induces scar formation and changes in surviving myocardium, called post-Ml ventricular remodeling. This process consists of initial wall thinning of the infarcted area, ventricular chamber dilation with side-to-side slippage, and eccentric myocyte hypertrophy of the individual myofibers in the noninfarcted portion of the myocardium. ${ }^{143}$ In spite of clinical evidence that the postinfarcted heart often progressively dilates and displays accelerated deterioration of left ventricular function, the early hypertrophic remodeling of the viable portion of the $\mathrm{LV}$ after ischemic damage is considered an adaptive response to compensate for the acute loss of functional myocardium and to preserve cardiac performance ${ }^{144-146}$ (For more details see Chapters 1 and 2). To induce $\mathrm{MI}$ in this study we used a surgical method previously described. ${ }^{147}$

\section{E2 and MI}

Although E2-treatment slightly reduced infarct size in ERKO is also increased LV remodeling and post-infaret mortality in these animals. BERKO animals showed an increase in MI size and a decrease in mortality. These esults support the finding of van Eickels, ${ }^{148}$ who showed that E2 
treatment decreases infarct size and increases mortality. The ER $\beta$ was found to be important for the modulation effect of E2 in the infarcted hearts (Chapter 4).

Currently, it is not clear which biological roles the two different ER subtypes have in MI. The role of the ERs could provide an explanation for the selective actions of E2 in various target tissues and it is known that different estrogenic compounds have different relative binding affinities for ER $\alpha$ versus ER $\beta .{ }^{149,150}$ The expression of $\operatorname{ER} \alpha$ and ER $\beta$ varies in different tissues and also between species. ${ }^{151}$ When coexpressed, ER $\beta$ exhibits an inhibitory action on ER $\alpha$-mediated gene expression. ${ }^{152}$ In the case of E2 signaling, cellular selectivity for one or the other ER appears to be regulated by the cellular expression pattern of the ERs and coactivator and corepressor proteins. ${ }^{153,134}$ Recent studies have begun to define receptor-specific differences in ligand binding affinity ${ }^{151,155,156}$ and receptor interacting proteins. ${ }^{157,158}$ These findings suggest the potential for differences in the physiological effects of these two receptors.

\section{Suggestions for further research}

Our results showed that E2-treatment protects the heart against LVH. The protective effects are mediated via ER $\beta$, which increases the expression of ANF and inactivates p38. The role of HSP in hypertrophy and E2-treatment as shown by the array analysis is not completely clear. Further research will be required to clarify the involvement of these proteins in E2-treatment.

These findings could open the way for further research in the field of HRT. The diminished interest in E2 research due to the recently reported results of long term HRT could be reactivated by these findings. Future work could further elucidate the function of ERs using selective estrogen receptor modulators (SERMs). SERMs comprise a group of structurally diverse compounds, which are distinguished from E2 by their ability to selectively interact with one ER, and the y can act as E2 agonist or antagonist depending on the target tissue and hormonal milieu. The tissue-specific activity of SERMs suggests that they may be clinically useful as, for example, potential substitutes for long term female HRT. However no studies have yet been initiated to evaluate the effect of SERMs on LVH or cardiac remodeling after MI. ${ }^{159-164}$ Further research on the downstream effectors like ANF and cGMP could also provide new strategies for therapies.

\section{Conclusions}

Using microarrays we were able to show that pressure overload increased the expression of fetal and structural genes and E2-treatment decreases the expression of these genes. E2-treatment antagonizes hypertrophy, in NRVM and animal models. E2 acts by increasing the expression of ANF and decreasing the phosphorylation of p38 to block hypertrophy. The protective effects of E2 use the ER $\beta$ pathway rather than $E R \alpha$ pathway. 


\section{References}

1. Soonpaa MH, Kim KK, Pajak L, et al. Cardiomyocyte DNA synthesis and binucleation during murine development. Am J Physiol. 1996;271:H2183-9.

2. Parker TG, Schneider MD. Growth factors, proto-oncogenes, and plasticity of the cardiac phenotype. Annu Rev Physiol. 1991;53:179-200.

3. Babiker FA, De Windt LJ, van Eickels M, et al. Estrogenic hormone action in the heart: regulatory network and function. Cardiovasc Res. 2002;53:709-19.

4. Babiker FA, De Windt LJ, van Eickels M, et al. 17beta-estradiol antagonizes cardiomyocyte hypertrophy by autocrine/paracrine stimulation of a guanylyl cyclase A receptor-cyclic guanosine monophosphate-dependent protein kinase pathway. Circulation. 2004;109:26976.

5. Bueno OF, van Rooij E, Molkentin JD, et al. Calcineurin and hypertrophic heart disease: novel insights and remaining questions. Cardiovasc Res. 2002;53:806-21.

6. Krumholz HM, Larson M, Levy D. Sex differences in cardiac adaptation to isolated systolic hypertension. Am J Cardiol. 1993;72:310-3.

7. Liao Y, Cooper RS, Mensah GA, et al. Left ventricular hypertrophy has a greater impact on survival in women than in men. Circulation. 1995;92:805-10.

8. Gheorghiade M, Bonow RO. Chronic heart failure in the United States: a manifestation of coronary artery disease. Circulation. 1998;97:282-9.

9. Cleland JG, Khand A, Clark A. The heart failure epidemic: exactly how big is it? Eur Heart J. 2001;22:623-6.

10. Bueno OF, Lips DJ, Kaiser RA, et al. Calcineurin Abeta gene targeting predisposes the myocardium to acute ischemia-induced apoptosis and dysfunction. Circ Res. 2004;94:91-9.

11. Mendelsohn ME, Karas RH. The protective effects of estrogen on the cardiovascular system. N Engl J Med. 1999;340:1801-11.

12. Stampfer MJ, Colditz GA, Willett WC, et al. Postmenopausal estrogen therapy and cardiovascular disease. Ten-year follow-up from the nurses' health study. $N$ Engl J Med. 1991;325:756-62.

13. Grady D, Rubin SM, Petitti DB, et al. Hormone therapy to prevent disease and prolong life in postmenopausal women. Ann Intern Med. 1992;117:1016-37.

14. Mendelsohn ME, Karas RH. The time has come to stop letting the HERS tale wag the dogma. Circulation. 2001;104:2256-9.

15. Grohe C, Kahlert S, Lobbert K, et al. Modulation of hypertensive heart disease by estrogen. Steroids. 1996;61:201-4.

16. Katzenellenbogen BS, Montano MM, Ediger TR, et al. Estrogen receptors: selective ligands, partners, and distinctive pharmacology. Recent Prog Horm Res. 2000;55:163-93; discussion 194-5.

17. Grohe C, van Eickels M, Wenzel S, et al. Sex-specific differences in ventricular expression and function of parathyroid hormone-related peptide. Cardiovasc Res. 2004;61:307-16.

18. Mendelsohn ME, Karas RH. Estrogen and the blood vessel wall. Curr Opin Cardiol. 1994;9:619-26.

19. Farhat MY, Lavigne MC, Ramwell PW. The vascular protective effects of estrogen. Faseb J. 1996;10:615-24.

20. Farhat MY, Chen MF, Bhatti T, et al. Protection by oestradiol against the development of cardiovascular changes associated with monocrotaline pulmonary hypertension in rats. $\mathrm{Br} J$ Pharmacol. 1993;110:719-23.

21. Pfeffer JM, Pfeffer MA, Fletcher P, et al. Favorable effects of therapy on cardiac performance in spontaneously hypertensive rats. Am J Physiol. 1982;242:H776-84. 
22. Douglas PS, Katz SE, Weinberg EO, et al. Hypertrophic remodeling: gender differences in the early response to left ventricular pressure overload. J Am Coll Cardiol. 1998;32:111825 .

23. Tamura T, Said S, Gerdes AM. Gender-related differences in myocyte remodeling in progression to heart failure. Hypertension. 1999;33:676-80.

24. van Eickels M, Grohe C, Cleutjens JP, et al. 17beta-estradiol attenuates the development of pressure-overload hypertrophy. Circulation. 2001;104:1419-23.

25. Pelzer T, Shamim A, Wolfges S, et al. Modulation of cardiac hypertrophy by estrogens. Adv Exp Med Biol. 1997;432:83-9.

26. Grohe C, Kahlert S, Lobbert K, et al. Expression of oestrogen receptor alpha and beta in rat heart: role of local oestrogen synthesis. J Endocrinol. 1998;156:R1-7.

27. Johnson BD, Zheng W, Korach KS, et al. Increased expression of the cardiac L-type calcium channel in estrogen receptor-deficient mice. J Gen Physiol. 1997;110:135-40.

28. Patterson E, Ma L, Szabo B, et al. Ovariectomy and estrogen-induced alterations in myocardial contractility in female rabbits: role of the L-type calcium channel. J Pharmacol Exp Ther. 1998;284:586-91.

29. Fraser H, Davidge ST, Clanachan AS. Activation of $\mathrm{Ca}(2+)$-independent nitric oxide synthase by 17beta-estradiol in post-ischemic rat heart. Cardiovasc Res. 2000;46:111-8.

30. Korach KS, Couse JF, Curtis SW, et al. Estrogen receptor gene disruption: molecular characterization and experimental and clinical phenotypes. Recent Prog Horm Res. 1996;51:159-86; discussion 186-8.

31. Sutherland MK, Hui DU, Rao LG, et al. Immunohistochemical localization of the estrogen receptor in human osteoblastic SaOS-2 cells: association of receptor levels with alkaline phosphatase activity. Bone. 1996;18:361-9.

32. Hoyland JA, Baris C, Wood L, et al. Effect of ovarian steroid deficiency on oestrogen receptor alpha expression in bone. J Pathol. 1999;188:294-303.

33. Lim SK, Won YJ, Lee HC, et al. A PCR analysis of ERalpha and ERbeta mRNA abundance in rats and the effect of ovariectomy. J Bone Miner Res. 1999;14:1189-96.

34. Ankrom MA, Patterson JA, d'Avis PY, et al. Age-related changes in human oestrogen receptor alpha function and levels in osteoblasts. Biochem J. 1998;333 ( Pt 3):787-94.

35. Lee K, Jessop H, Suswillo R, et al. Endocrinology: bone adaptation requires oestrogen receptor-alpha. Nature. 2003;424:389.

36. Grunt TW, Saceda M, Martin MB, et al. Bidirectional interactions between the estrogen receptor and the cerbB-2 signaling pathways: heregulin inhibits estrogenic effects in breast cancer cells. Int J Cancer. 1995;63:560-7.

37. Suo Z, Berner HS, Risberg B, et al. Estrogen receptor-alpha and C-ERBB-4 expression in breast carcinomas. Virchows Arch. 2001;439:62-9.

38. Xu Y, Arenas IA, Armstrong SJ, et al. Estrogen modulation of left ventricular remodeling in the aged heart. Cardiovasc Res. 2003;57:388-94.

39. Nuedling S, Karas RH, Mendelsohn ME, et al. Activation of estrogen receptor beta is a prerequisite for estrogen-dependent upregulation of nitric oxide synthases in neonatal rat cardiac myocytes. FEBS Lett. 2001;502:103-8.

40. Loven MA, Wood JR, Nardulli AM. Interaction of estrogen receptors alpha and beta with estrogen response elements. Mol Cell Endocrinol. 2001;181:151-63.

41. Zhu Y, Bian Z, Lu P, et al. Abnormal vascular function and hypertension in mice deficient in estrogen receptor beta. Science. 2002;295:505-8.

42. Eddy EM, Washburn TF, Bunch DO, et al. Targeted disruption of the estrogen receptor gene in male mice causes alteration of spermatogenesis and infertility. Endocrinology.

1996;137:4796-805. 
43. Hess RA, Bunick D, Lee $\mathrm{KH}$, et al. A role for oestrogens in the male reproductive system. Nature. 1997;390:509-12.

44. Mahato D, Goulding EH, Korach KS, et al. Spermatogenic cells do not require estrogen receptor-alpha for development or function. Endocrinology. 2000;141:1273-6.

45. Curtis Hewitt S, Couse JF, Korach KS. Estrogen receptor transcription and transactivation: Estrogen receptor knockout mice: what their phenotypes reveal about mechanisms of estrogen action. Breast Cancer Res. 2000;2:345-52.

46. Lubahn DB, Moyer JS, Golding TS, et al. Alteration of reproductive function but not prenatal sexual development after insertional disruption of the mouse estrogen receptor gene. Proc Natl Acad Sci US A. 1993;90:11162-6.

47. Couse JF, Korach KS. Reproductive phenotypes in the estrogen receptor-alpha knockout mouse. Ann Endocrinol (Paris). 1999;60:143-8.

48. Nuedling S, van Eickels M, Allera A, et al. 17 Beta-estradiol regulates the expression of endothelin receptor type B in the heart. Br J Pharmacol. 2003;140:195-201.

49. Zahringer J, Pritzl N, Stab G, et al. Quantitation of cardiac messenger RNA in heart-muscle biopsies. Adv Myocardiol. 1985;6:285-95.

50. Neyses L, Vetter H. Molecular biology of oncogenes and cardiovascular hypertrophy. $J$ Hypertens. 1992;10:1447-52.

51. Knowlton KU, Rockman HA, Itani M, et al. Divergent pathways mediate the induction of ANF transgenes in neonatal and hypertrophic ventricular myocardium. J Clin Invest. 1995;96:1311-8.

52. Ohta K, Kim S, Iwao H. Role of angiotensin-converting enzyme, adrenergic receptors, and blood pressure in cardiac gene expression of spontaneously hypertensive rats during development. Hypertension. 1996;28:627-34.

53. Larsen TH, Saetersdal T. Regional appearance of atrial natriuretic peptide in the ventricles of infarcted rat hearts. Virchows Arch B Cell Pathol Incl Mol Pathol. 1993;64:309-14.

54. Chien KR, Knowlton KU, Zhu H, et al. Regulation of cardiac gene expression during myocardial growth and hypertrophy: molecular studies of an adaptive physiologic response. Faseb J. 1991;5:3037-46.

55. Kumar C, Saidapet C, Delaney P, et al. Expression of ventricular-type myosin light chain messenger RNA in spontaneously hypertensive rat atria. Circ Res. 1988;62:1093-7.

56. Doevendans PA, Bronsaer R, Ruiz-lozano P, et al Ventricular expression of the atrial regulatory myosin light chain gene. in: cardiovscular Specific Gene expression. Doevendans PA, Reneman R, van Bilsen M, eds. 1999. Kluwer Academic Publishers, Dordrecht, Maastricht.

57. Doevendans PA, Bronsaer R, Loza no PR, et al. The murine atrial myosin light chain-2 gene: a member of an evolutionarily conserved family of contractile proteins. Cytogenet Cell Genet. 2000;90:248-52.

58. Lee HR, Henderson SA, Reynolds R, et al. Alpha 1-adrenergic stimulation of cardiac gene transcription in neonatal rat myocardial cells. Effects on myosin light chain-2 gene expression. J Biol Chem. 1988;263:7352-8.

59. Pockley AG, Shepherd J, Corton JM. Detection of heat shock protein 70 (Hsp 70) and antiHsp70 antibodies in the serum of normal individuals. Immunol Invest. 1998;27:367-77.

60. Huang $\mathrm{SN}$, Yang $\mathrm{H}$, Zhang $\mathrm{CH}$, et al. [Transcription of HSP 70 gene induced by pressure overload in left ventricule of rats]. Sheng Li Xue Bao. 1994;46:333-7.

61. Thompson NL, Bazoberry F, Speir EH, et al. Transforming growth factor beta-1 in acute myocardial infarction in rats. Growth Factors. 1988;1:91-9. 
62. Li G, Li RK, Mickle DA, et al. Elevated insulin-like growth factor-l and transforming growth factor-beta 1 and their receptors in patients with idiopathic hypertrophic obstructive cardiomyopathy. A possible mechanism. Circulation. 1998;98:II144-9; discussion II149-50.

63. Millan FA, Denhez F, Kondaiah P, et al. Embryonic gene expression patterns of TGF beta 1, beta 2 and beta 3 suggest different developmental functions in vivo. Development.

1991:111:131-43.

64. Pelton RW, Saxena B, Jones M, et al. Immunohistochemical localization of TGF beta I, TGF beta 2, and TGF beta 3 in the mouse embryo: expression patterns suggest multiple roles during embryonic development. J Cell Biol. 1991;115:1091-105.

65. Brand T, Schneider MD. The TGF beta superfamily in myocardium: ligands, receptors, transduction, and function. J Mol Cell Cardiol. 1995;27:5-18.

66. Li RK, Li G, Mickle DA, et al. Overexpression of transforming growth factor-betal and insulin-like growth factor-I in patients with idiopathic hypertrophic cardiomyopathy. Circulation. 1997:96:874-81.

67. MacLellan WR, Brand T, Schneider MD. Transforming growth factor-beta in cardiac ontogeny and adaptation. Circ Res. 1993;73:783-91.

68. Takahashi N, Calderone A, Izzo NJ, Jr., et al. Hypertrophic stimuli induce transforming growth factor-beta 1 expression in rat ventricular myocytes. J Clin Invest. 1994;94:1470-6.

69. Tsutsui H, Tagawa H, Kent RL, et al. Role of microtubules in contractile dysfunction of hypertrophied cardiocytes. Circulation. 1994;90:533-55.

70. Schultz Jel J, Witt SA, Glascock BJ, et al. TGF-betal mediates the hypertrophic cardiomyocyte growth induced by angiotensin II. J Clin Invest. 2002;109:787-96.

71. Miyauchi T, Masaki T. Pathophysiology of endothelin in the cardiovascular system. Annu Rev Physiol. 1999;61:391-415.

72. Suzuki T, Hoshi H, Mitsui Y. Endothelin stimulates hypertrophy and contractility of neonatal rat cardiac myocytes in a serum-free medium. FEBS Lett. 1990;268:149-51.

73. Sugden PH. Signaling in myocardial hypertrophy: life after calcineurin? Circ Res. 1999;84:633-46.

74. Pinson A, Schluter KD, Zhou XJ, et al. Alpha- and beta-adrenergic stimulation of protein synthesis in cultured adult ventricular cardiomyocytes. J Mol Cell Cardiol. 1993;25:477-90.

75. Taimor G, Schluter KD, Best P, et al. Transcription activator protein 1 mediates alpha- but not beta-adrenergic hypertrophic growth responses in adult cardiomyocytes. Am J Physiol Heart Circ Physiol. 2004;286:H2369-75.

76. McDonough PM, Brown JH, Glembotski CC. Phenylephrine and endothelin differentially stimulate cardiac PI hydrolysis and ANF expression. Am J Physiol. 1993;264:H625-30.

77. Bishopric NH, Simpson PC, Ordahl CP. Induction of the skeletal alpha-actin gene in alpha 1-adrenoceptor-mediated hypertrophy of rat cardiac myocytes. J Clin Invest. 1987;80:11949.

78. Knowlton KU, Baracchini E, Ross RS, et al. Co-regulation of the atrial natriuretic factor and cardiac myosin light chain-2 genes during alpha-adrenergic stimulation of neonatal rat ventricular cells. Identification of cis sequences within an embryonic and a constitutive contractile protein gene which mediate inducible expression. J Biol Chem. 1991;266:775968.

79. Hefti MA, Harder BA, Eppenberger HM, et al. Signaling pathways in cardiac myocyte hypertrophy. J Mol Cell Cardiol. 1997;29:2873-92.

80. Bird SD, Doevendans PA, van Rooijen MA, et al. The human adult cardiomyocyte phenotype. Cardiovasc Res. 2003;58:423-34.

81. Kjaer A, Hesse B. Heart failure and neuroendocrine activation: diagnostic, prognostic and therapeutic perspectives. Clin Physiol. 2001;21:661-72. 
82. Tohse N, Nakaya H, Takeda Y, et al. Cyclic GMP-mediated inhibition of L-type Ca2+ channel activity by human natriuretic peptide in rabbit heart cells. Br J Pharmacol. 1995; 114:1076-82.

83. Itoh H, Pratt RE, Dzau VJ. Atrial natriuretic polypeptide inhibits hypertrophy of vascular smooth muscle cells. J Clin Invest. 1990;86:1690-7.

84. Cao L, Wu J, Gardner DG. Atrial natriuretic peptide suppresses the transcription of its guanylyl cyclase-linked receptor. J Biol Chem. 1995;270:24891-7.

85. Calderone A, Thaik CM, Takahashi N, et al. Nitric oxide, atrial natriuretic peptide, and cyclic GMP inhibit the growth-promoting effects of norepinephrine in cardiac myocytes and fibroblasts. J Clin Invest. 1998;101:812-8.

86. Horio T, Nishikimi T, Yoshihara F, et al. Inhibitory regulation of hypertrophy by endogenous atrial natriuretic peptide in cultured cardiac myocytes. Hypertension. 2000;35:19-24.

87. Kishimoto I, Rossi K, Garbers DL. A genetic model provides evidence that the receptor for atrial natriuretic peptide (guanylyl cyclase-A) inhibits cardiac ventricular myocyte hypertrophy. Proc Natl Acad Sci US A. 2001;98:2703-6.

88. Oliver PM, Fox JE, Kim R, et al. Hypertension, cardiac hypertrophy, and sudden death in mice lacking natriuretic peptide receptor A. Proc Natl Acad Sci U S A. 1997;94:14730-5.

89. Jiang C, Poole-Wilson PA, Sarrel PM, et al. Effect of 17 beta-oestradiol on contraction, $\mathrm{Ca} 2+$ current and intracellular free $\mathrm{Ca} 2+$ in guinea-pig isolated cardiac myocytes. $\mathrm{Br} \mathrm{J}$ Pharmacol. 1992;106:739-45.

90. Silberbach M, Roberts CT, Jr. Natriuretic peptide signalling: molecular and cellular pathways to growth regulation Cell Signal. 2001;13:221-31.

91. Pfeifer A, Klatt P, Massberg S, et al. Defective smooth muscle regulation in cGMP kinase Ideficient mice. Embo J. 1998;17:3045-51.

92. Zolle O, Lawrie AM, Simpson AW. Activation of the particulate and not the soluble guanylate cyclase leads to the inhibition of $\mathrm{Ca} 2+$ extrusion through localized elevation of cGMP. J Biol Chem. 2000;275:25892-9.

93. Gudi T, Lohmann SM, Pilz RB. Regulation of gene expression by cyclic GMP-dependent protein kinase requires nuclear translocation of the kinase: identification of a nuclear localization signal. Mol Cell Biol. 1997; 17:5244-54.

94. Silberbach M, Gorenc T, Hershberger RE, et al. Extracellular signal-regulated protein kinase activation is required for the anti-hypertrophic effect of atrial natriuretic factor in neonatal rat ventricular myocytes. J Biol Chem. 1999;274:24858-64.

95. Eigenthaler M, Lohmann SM, Walter U, et al. Signal transduction by cGMP-dependent protein kinases and their emerging roles in the regulation of cell adhesion and gene expression. Rev Physiol Biochem Pharmacol. 1999;135:173-209.

96. Mery PF, Lohmann SM, Walter U, et al. Ca2+ current is regulated by cyclic GMPdependent protein kinase in mammalian cardiac myocytes. Proc Natl Acad Sci US A. 1991;88:1197-201.

97. Delay RJ, Dubin AE, Dionne VE. A cyclic nucleotide-dependent chloride conductance in olfactory receptor neurons. J Membr Biol. 1997;159:53-60.

98. Anthony TL, Brooks HL, Boassa D, et al. Cloned human aquaporin-1 is a cyclic GMP-gated ion channel. Mol Pharmacol. 2000;57:576-88.

99. Hagen V, Dzeja C, Bendig J, et al. Novel caged compounds of hydrolysis-resistant 8-BrcAMP and 8-Br-cGMP: photolabile NPE esters. J Photochem Photobiol B. 1998:42:71-8.

100. Hamet P. Tremblay J, Pang SC, et al. Effect of native and synthetic atrial natriuretic factor on cyclic GMP. Biochem Biophys Res Commun. 1984;123:515-27. 
101. Tamura N, Ogawa Y, Chusho $\mathrm{H}$, et al. Cardiac fibrosis in mice lacking brain natriuretic peptide. Proc Natl Acad Sci US A. 2000;97:4239-44.

102. de Bold AJ, Bruneau BG, Kuroski de Bold ML. Mechanical and neuroendocrine regulation of the endocrine heart. Cardiovasc Res. 1996;31:7-18.

103. Wachtell K, Rokkedal J, Bella JN, et al. Effect of electrocardiographic left ventricular hypertrophy on left ventricular systolic function in systemic hypertension (The LIFE Study). Losartan Intervention For Endpoint. Am J Cardiol. 2001;87:54-60.

104. Agabiti-Rosei E, Muiesan ML. Left ventricular hypertrophy and heart failure in women. $J$ Hypertens. 2002;20 Suppl 2:\$34-8.

105. Verdecchia P, Carini G, Circo A, et al. Left ventricular mass and cardiovascular morbidity in essential hypertension: the MAVI study. J Am Coll Cardiol. 2001;38:1829-35.

106. Cipriano C, Gosse P, Bemurat L, et al. Prognostic value of left ventricular mass and its evolution during treatment in the Bordeaux cohort of hypertensive patients. Am J Hypertens. 2001;14:524-9.

107. Vakili BA, Okin PM, Devereux RB. Prognostic implications of left ventricular hypertrophy, Am Heart J. 2001;141:334-41.

108. Frey N, Obon EN. Cardiac hypertrophy: the good, the bad, and the ugly. Annu Rev Physiol. 2003;65:45-79.

109. Doevendans PA, Daemen MJ, de Muinck ED, et al. Cardiovascular phenotyping in mice. Cardiovasc Res. 1998;39:34-49.

110. Doevendans PA. Cardiovascular physiology in the genetically engineered mouse. Neth Heart J. 2002;10:488-489.

111. Takeishi Y, Walsh RA. Cardiac hypertrophy and failure: lessons learned from genetically engineered mice. Acta Physiol Scand. 2001;173:103-11.

112. Takaoka H, Esposito G, Mao L, et al. Heart size-independent analysis of myocardial function in murine pressure overload hypertrophy. Am J Physiol Heart Circ Physiol. 2002;282:H2190-7.

113. Friddle CJ, Koga T, Rubin EM, et al. Expression profiling reveals distinct sets of genes altered during induction and regression of cardiac hypertrophy. Proc Natl Acad Sci USA. 2000;97:6745-50.

114. Marian AJ. Modifier genes for hypertrophic cardiomyopathy. Curr Opin Cardiol. 2002;17:242-52.

115. Suzuki M, Carlson KM, Marchuk DA, et al. Genetic modifier loci affecting survival and cardiac function in murine dilated cardiomyopathy. Circulation. 2002;105:1824-9.

116. Lips DJ, deWindt LJ, van Kraaij DJ, et al. Molecular determinants of myocardial hypertrophy and failure: alternative pathways for beneficial and maladaptive hypertrophy. Eur Heart J. 2003;24:883-96.

117. Maron BJ. Hypertrophic cardiomyopathy. Lancet. 1997;350:127-33.

118. Scheuer J, Malhotra A, Schaible TF, et al. Effects of gonadectomy and hormonal replacement on rat hearts. Circ Res. 1987;61:12-9.

119. Cabral AM, Vasquez EC, Moyses MR, et al. Sex hormone modulation of ventricular hypertrophy in sinoaortic denervated rats. Hypertension. 1988;11:193-7.

120. Miya Y, Sumino H, Ichikawa S, et al. Effects of hormone replacement therapy on left ventricular hypertrophy and growth-promoting factors in hypertensive postmenopausal women. Hypertens Res. 2002;25:153-9.

121. Light KC, Hinderliter AL, West SG, et al. Hormone replacement improves hemodynamic profile and left ventricular geometry in hypertensive and normotensive postmenopausal women. J Hypertens. 2001;19:269-78. 
122. Yamazaki T, Komuro I, Zou Y, et al. Norepinephrine induces the raf 1 kinase/mitogenactivated protein kinase cascade through both alpha 1- and beta-adrenoceptors. Circulation. 1997;95:1260-8.

123. Sugden PH, Clerk A. Regulation of mitogen-activated protein kinase cascades in the heart. Adv Enzyme Regul. 1998;38:87-98.

124. Clerk A, Michael A, Sugden PH. Stimulation of the p38 mitogen-activated protein kinase pathway in neonatal rat ventricular myocytes by the $\mathrm{G}$ protein-coupled receptor agonists, endothelin-1 and phenylephrine: a role in cardiac myocyte hypertrophy? J Cell Biol. 1998;142:523-35.

125. Zechner D, Thuerauf DJ, Hanford DS, et al. A role for the p38 mitogen-activated protein kinase pathway in myocardial cell growth, sarcomeric organization, and cardiac-specific gene expression. J Cell Biol. 1997;139:115-27.

126. Derijard B, Hibi M, Wu IH, et al. JNK1: a protein kinase stimulated by UV light and HaRas that binds and phosphorylates the c-Jun activation domain. Cell. 1994;76:1025-37.

127. Bueno OF, De Windt LJ, Lim HW, et al. The duakspecificity phosphatase MKP-1 limits the cardiac hypertrophic response in vitro and in vivo. Circ Res. 2001;88:88-96.

128. Nuedling S, Kahlert S, Loebbert K, et al. Differential effects of 17 beta-estradiol on mitogenactivated protein kinase pathways in rat cardiomyocytes. FEBS Lett. 1999;454:271-6.

129. Krepinsky J, Ingram AJ, James L, et al. 17beta -Estradiol modulates mechanical straininduced MAPK activation in mesangial cells. J Biol Chem. 2002;277:9387-94.

130. Kaiser RA, Bueno OF, Lips DJ, et al. Targeted inhibition of p38 mitogen-activated protein kinase antagonizes cardiac injury and cell death following ischemia-reperfusion in vivo. $J$ Biol Chem. 2004;279:15524-30.

131. Lips DJ, Bueno OF, Wilkins BJ, et al. MEK1-ERK2 signaling pathway protects myocardium from ischemic injury in vivo. Circulation. 2004;109:1938-41.

132. Olivetti G, Quaini F, Lagrasta C, et al. Cellular basis of ventricular remodeling after myocardial infarction in rats. Cardioscience. 1995;6:101-6.

133. Jankowski M, Rachelska G, Donghao W, et al. Estrogen receptors activate atrial natriuretic peptide in the rat heart. Proc Natl Acad Sci US A. 2001;98:11765-70.

134. John SW, Krege JH, Oliver PM, et al. Genetic decreases in atrial natriuretic peptide and saltsensitive hypertension. Science. 1995;267:679-81.

135. Oliver PM, John SW, Purdy KE, et al. Natriuretic peptide receptor 1 expression influences blood pressures of mice in a dose-dependent manner. Proc Natl Acad Sci U S A. 1998;95:2547-51.

136. Back H, Forssmann WG, Stumpf WE. Atrial myoendocrine cells (cardiodilatin/atrial natriuretic polypeptide-containing myocardiocytes) are target cells for estradiol. Cell Tissue Res. 1989;255:673-4.

137. Deng $\mathrm{Y}, \mathrm{Kaufman} \mathrm{S}$. The influence of reproductive hormones on ANF release by rat atria. Life Sci. 1993;53:689-96.

138. Knowles JW, Esposito G, Mao L, et al. Pressure-independent enhancement of cardiac hypertrophy in natriuretic peptide receptor A-deficient mice. J Clin Invest. 2001;107:97584.

139. Fiedler B, Lohmann SM, Smolenski A, et al. Inhibition of calcineurin-NFAT hypertrophy signaling by cGMP-dependent protein kinase type I in cardiac myocytes. Proc Natl Acad Sci US A. 2002;99:11363-8.

140. Redondo J, Bishop JE, Wilkins MR. Effect of atrial natriuretic peptide and cyclic GMP phosphodiesterase inhibition on collagen synthesis by adult cardiac fibroblasts. $\mathrm{Br} J$ Pharmacol. 1998;124:1455-62. 
141. Wu CF, Bishopric NH, Pratt RE. Atrial natriuretic peptide induces apoptosis in neonatal rat cardiac myocytes. J Biol Chem. 1997;272:14860-6.

142. King L, Wilkins MR. Natriuretic peptide receptors and the heart. Heart. 2002;87:314-5.

143. Pfeffer MA, Braunwald E, Moye LA, et al. Effect of captopril on mortality and morbidity in patients with left ventricular dysfunction after myocardial infarction. Results of the survival and ventricular enlargement trial. The SAVE Investigators. $N$ Engl J Med. 1992;327:669-77.

144. Sadoshima J, Izumo S. The cellular and molecular response of cardiac myocytes to mechanical stress. Anmu Rev Physiol. 1997;59:551-71.

145. Lips DJ, Hassink RJ, Brutel de la Riviere A, et al. The use of transgenic animals to study cardiac remodeling. In: myocardial remodeling: Mechanisms and Treatment. greenberg B, ed. 2004. Marcel Dekker.

146. Eefting F, Rensing B, Wigman J, et al. Role of apoptosis in reperfusion injury. Cardiovasc Res. 2004;61:414-26.

147. Patten RD, Aronovitz MJ, Deras-Mejia L, et al. Ventricular remodeling in a mouse model of myocardial infarction. Am J Physiol. 1998;274:H1812-20.

148. van Eickels M, Patten RD, Aronovitz MJ, et al. 17-beta-estradiol increases cardiac remodeling and mortality in mice with myocardial infarction. $J \mathrm{Am}$ Coll Cardiol. 2003;41:2084-92.

149. Kuiper GG, Carlsson B, Grandien K, et al. Comparison of the ligand binding specificity and transcript tissue distribution of estrogen receptors alpha and beta. Endocrinology. 1997;138:863-70.

150. Katzenellenbogen BS. Estrogen receptors: bioactivities and interactions with cell signaling pathways. Biol Reprod. 1996;54:287-93.

151. Kuiper GG, Enmark E, Pelto-Huikko M, et al. Cloning of a novel receptor expressed in rat prostate and ovary. Proc Natl Acad Sci US A. 1996;93:5925-30.

152. Matthews J, Gustafsson JA. Estrogen signaling: a subtle balance between ER alpha and ER beta. Mol Interv. 2003;3:281-92.

153. Nilsson S, Makela S, Treuter E, et al. Mechanisms of estrogen action. Physiol Rev. 2001;81:1535-65.

154. Doevendans PA, van Bilsen M. Transcription factors and the cardiac gene programme. Int $J$ Biochem Cell Biol. 1996;28:387-403.

155. Barkhem T, Carlsson B, Nilsson Y, et al. Differential response of estrogen receptor alpha and estrogen receptor beta to partial estrogen agonists/antagonists. Mol Pharmacol. 1998;54:105-12.

156. Paech K, Webb P, Kuiper GG, et al. Differential ligand activation of estrogen receptors ERalpha and ERbeta at AP1 sites. Science. 1997;277:1508-10.

157. Montano MM, Ekena K, Delage-Mourroux R, et al. An estrogen receptor-selective coregulator that potentiates the effectiveness of antiestrogens and represses the activity of estrogens. Proc Natl Acad Sci U S A. 1999;96:6947-52.

158. Poelzl G, Kasai Y, Mochizuki N, et al. Specific association of estrogen receptor beta with the cell cycle spindle assembly checkpoint protein, MAD2. Proc Natl Acad Sci US A. 2000;97:2836-9.

159. Baynes KC, Compston JE. Selective oestrogen receptor modulators: a new paradigm for HRT. Curr Opin Obstet Gynecol. 1998;10:189-92.

160. Bryant HU, Dere WH. Selective estrogen receptor modulators: an alternative to hormone replacement therapy. Proc Soc Exp Biol Med. 1998;217:45-52.

161. Compston JE. Selective oestrogen receptor modulators: potential therapeutic applications. Clin Endocrinol (Oxf). 1998;48:389-91. 
162. Grese TA, Pennington LD, Sluka JP, et al. Synthesis and pharmacology of conformationally restricted raloxifene analogues: highly potent selective estrogen receptor modulators. $\mathrm{JMed}$ Chem. 1998;41:1272-83.

163. Grese TA, Cho S, Finley DR, et al. Structure-activity relationships of selective estrogen receptor modulators: modifications to the 2-arylbenzothiophene core of raloxifene. $J$ Med Chem. 1997;40:146-67.

164. Hardcastle IR, Rowlands MG, Grimshaw RM, et al. Homologs of idoxifene: variation of estrogen receptor binding and calmodulin antagonism with chain length. JMed Chem. 1996;39:999-1004. 
Summary

Samenvatting

Acknowledgements

Curriculum Vitae 


\section{Summary}

Hypertrophy is in simple words the increase in the left ventricular mass (LV) due to increased load. The mammalian heart adapts to increased hemodynamic load, such as that induced by hypertension, valvular heart disease, and loss of myocytes (as after myocardial infarction or cardiomyopathy), by developing compensatory hypertrophy of the remaining cells. In response to multiple extrinsic or intrinsic stimuli the heart undergoes adaptive hypertrophy in an attempt to decrease wall tension and energy utilization. Cardiac hypertrophy is characterized by an increase in cell surface area of individual myocytes, enhanced sarcomeric organization and the re-expression of specific genes which were expressed during the fetal development (fetal genes).

It has been hypothesized that estrogens are able to attenuate hypertrophic responses. Estrogens appear to act as cardioprotective steroid hormones. Indeed, the development of cardiovascular diseases in pre-menopausal women is lower when compared to men of the same age. The effect of estrogen on the vessel wall is reasonably well understood. Recently, it has been described that estrogen and its receptors Estrogen Receptor (ER) alpha $(\boldsymbol{\alpha})$ and beta $(\beta)$ mediate the preventive effects of estrogens in the protection against the development of atherosclerosis. Studies in knockout mice lacking both ER $\alpha$ and $\operatorname{ER} \beta$ showed a higher risk for atherosclerosis than wild type littermates. In addition, it has been documented that estrogens influence the lipoprotein profile. Although the effects of estrogen on the vessel wall have been partly unravelled, its direct effects on cardiomyocytes are far less well understood. Recently, it has been reported that both male and female rat neonatal and adult cardiomyocytes express estrogen receptors. Estrogen-treatment of cultured cardiomyocytes demonstrated that estrogen regulates the expression of cardiac specific genes via activation of the ERs.

Estrogen replacement therapy is cardioprotective. However, recently the large scale estrogen supplement studies were stopped because of side effects and no positive results. The existence of different ERs may be (in part) responsible for the confusing data. Therefore, we investigated the effects of estrogen via ER $\alpha$ and ER $\beta$ respectively on cardiac performance and remodeling. This was possible because of the presence of two knockout mouse models, wherein either the ER $\alpha$ (ERKO mice) or the ER $\beta$ (BERKO mice) was removed. In these mice two experimental interventions were performed 1) myocardial infarction (MI) 2) increasing hemdynamic load by transverse aortic constriction (TAC). Changes in the LV wall were analyzed at the morphological and molecular levels by techniques ranging from microscopy to microarrays.

In chapter 1 a brief account on left ventricular hypertrophy ( $\mathrm{LVH})$ is provided, with the possible effects of estrogen and also the aim of this study is presented. A detailed literature review about cardiovascular disease and the possible role of estrogens is given in chapter 2. In chapter 3 we have listed information on the gene profile in both mouse models (ERKO and BERKO) after TAC using microarray. From a large group of genes we selected some for further analysis. Those genes code for cytoskeleton, cell adhesion/extra cellular matrix and stress proteins. Some of these genes are expressed only during fetal development. E2-treatment decreased the expression of most of these genes via ER $\beta$. In chapter 4 we used neonatal rat ventricular myocytes to study the effects of hypertrophy and estrogen treatment at the molecular level. We found that estrogen treatment counterbalanced morphological and biochemical parameters of myocyte hypertrophy following stimulation with phenylephrine (PE) or endothelin-1 (ET-1). This can be explained by a marked upregulation of ANF mRNA and protein levels that accompanied the morphological observations mediated through ERs. ANF activates cGMP/cGMP-dependent protein kinase (PKG). Activation of this cascade has a protective effect on the heart (Chapter 4). At the organ and whole animal level we used ERKO and BERKO mice to study the effect of pressure overload and to dissect the role of ERs in this process. TAC led to LVH in all mice, wild type as well as knockouts. In ERKO mice which are $\mathrm{ER} \alpha$ deficient, but with intact ER $\beta, \mathrm{E} 2$-treatment decreased hypertrophy (Chapter 5). At the molecular level E2-treatment decreased phosphorylation of p38-MAPK in ovariectomized wild type 
ERKO mice with pressure-overload hypertrophy. It also increased the expression of ANF in vivo and in these animal models, E2-treatment has no effect in BERKO mice. These findings indicated that estrogens protect the murine heart via ER $\beta$. ER $\alpha$ does not play any protective role in this process. In chapter 6 we presented the effect of estrogen treatment on Ml using these mouse models. Estrogen-treatment reduces infarct size in ERKO mice, but not in BERKO mice. Again these results prove that ER $\beta$ is the mediator of the protective effects of E2 in the heart. Surprisingly, the decrease in the infarct size is associated with increased mortality in these mice. In BERKO mice the infarct size was larger, whereas mortality decreased. These results show again the importance of ER $\beta$ in E2-treatment in the heart.

In conclusion this study showed that the heart adapts itself in response to changing conditions. After TAC the heart responds with hypertrophy of the myocytes in the left ventricle and after MI with remodeling to limit the effect of the infarct. E2-treatment interferes with this adaptation by influencing the molecular response to the stimulus. ER $\beta$ was found to be the important modulator of the protective effects of estrogen in the heart, whereas ER $\alpha$ is the modulator of less favorable effects of E2. This means that future research has to concentrate on selective estrogen receptors modulators that either block ER $\alpha$ or stimulate ER $\beta$. 


\section{Samenvatting}

In alledaagse taal is hypertrofie een toename van de massa van de linker kamer (LK) van het hart tengevolge van een vergrote werklast. Zo'n grotere belasting kan het gevolg zijn van hoge bloeddruk, problemen met de hartkleppen, of het verlies van hartspiercellen (zoals optreedt bij een hartinfarct of andere hartspierziekten). Het hart van zoogdieren reageert op een dergelijke situatie door de (resterende) hartspiercellen hypertroof (= groter) te maken teneinde voor het verlies te compenseren. Als antwoord op vele stimuli van buiten of van binnen het hart past het hart zich aan de nieuwe omstandigheden aan met als doel de spanning van de hartwand te verlagen en het energiegebruik te optimaliseren. Hypertrofie wordt gekenmerkt door een vergroting van het volume van de hartspiercellen, een verbetering van de organisatie van het sarcolemma en de re-expressie van een aantal genen, die normaal alleen tijdens de embryogenese tot expressie komen.

Men heeft geopperd dat oestrogenen in staat zijn de hypertrofie in het hart te verminderen. Oestrogenen lijken een beschermend effect op hart en bloedvaten te hebben. Uit bevolkingsonderzoek is gebleken dat cardiovasculaire ziekten in pre-menopausale vrouwen minder voorkomen dan bij mannen van dezelfde leeftijd. Studies aan de vaatwand hebben laten zien dat estrogenen en de beide oestrogen-receptoren $(\alpha$ en $\beta$ ) beschermen tegen de ontwikkeling van atherosclerose. Muizen die of de $\alpha$ - of de $\beta$-oestrogen receptor missen lopen een groter risico atherosclerose te ontwikkelen dan hun wildtype nestgenoten. Ook blijken oestrogenen invloed te hebben op het lipide-profiel van het bloed. Men begrijpt de werking van oestrogenen in bloedvaten voor een deel. De effecten op het hart zijn echter minder goed begrepen. Recent heeft men ontdekt dat hartspiercellen van zowel vrouwelijke als mannelijke ratten oestrogeen receptors tot expressie brengen. Behandeling van gekweekte cardiomyocyten met oestrogen laat zien dat via interactie met oestrogen-receptoren er veranderingen optreden in het expressie patroon van een aantal genen.

Hoewel men aanneemt dat oestrogenen het cardiovasculaire systeem beschermen is uit een tweetal grootschalige studies gebleken dat oestrogeen-suppletie in post-menopausale vrouwen meer nadelen dan voordelen heeft. Het feit dat oestrogenen via verschillende receptoren werken heeft hier waarschijnlijk invloed op. Daarom hebben we in deze studie naar de afzonderlijke werking van de oestrogeen $\alpha$-receptor $(E R \alpha)$ en $\beta$-receptor $(E R \beta)$ op remodeling en werking van het hart gekeken. Dit was mogelijk doordat er twee muizen knockout modellen zijn, waarin of de estrogeen $\alpha$ receptor (ERKO muizen) of de $\beta$-receptor (BERKO muizen) uitgeschakeld zijn. In deze muizen zijn twee klassieke experimenten uitgevoerd: 1) het doen ontstaan van een myocard infarct (MI) en 2) het vergroten van de belasting van het hart door het gedeeltelijk afbinden van de aorta (TAC). Veranderingen in de hartspier tengevolge van deze ingrepen werden met behulp van morfologische, functionele en moleculair biobgische technieken geanalyseerd.

In hoofdstuk 1 is een overzicht gegeven van ventriculaire hypertrofie en myocard infarct, en mogelijke effecten van oestrogenen in relatie tot het doel van dit proefschrift. De bestaande literatuur van deze ziektebeelden $\dot{s}$ in meer detail in hoofdstuk twee behandeld. In de daarop volgende hoofdstukken komt het experimentele werk aan bod. In hoofdstuk 3 is beschreven hoe met behulp van array technologie een analyse is gemaakt van de genexpressie profielen die ontstaan in beide muizenmodellen na Ml en TAC. Uit de grote aantallen op- en neergereguleerd genen hebben we enkele groepen genen genomen voor nadere studie. Deze groepen genen codeerden voor cytoskelet, celadhesie of extra-cellulaire matrix en stress eiwitten. Een aantal van deze eiwitten komen normaal alleen tijdens de embryogenese tot expressie. Voor de meeste van deze genen geldt dat oestrogenen de veranderingen in genexpressie tegengaan en dat dit effect via de ER $\beta$ maar niet via de ER $\alpha$ bewerkstelligd wordt. Als aanzet voor in vivo experimenten werd in vitro in rat hartspiercellen gekeken naar effecten van hypertrofie en oestrogenen op moleculair niveau. Hartspiercellen kunnen in kweek met behulp van phenylephrine (PE) of endothelin-1 (ET-1) 
aangezet worden tot hypertrofie. Oestrogeen blijkt de stimulatie door PE of ET-1 grotendeels te niet te doen. Voor een deel kan dit verklaart worden door een opmerkelijke op-regulatie van het ANF gen. Oestrogeen blijkt de expressie van ANF te stimuleren, hetgeen resulteert in een activatie van het cGMP / cGMP-afhankelijke protein kinase. Activering van deze cascades heeft een beschermend effect op het hart hoewel de manier waarop nog niet geheel duidelijk is.

Met behulp van de ERKO en BERKO muis modellen werd het onderzoek op organ en organisme niveau voortgezet door TAC en MI toe te passen. TAC leidt tot hypertrofie van de linker kamer van het hart in, zowel wild-type als ook knockout muizen. In ERKO muizen, waarin de ER $\alpha$ uitgeschakeld is maar de ER $\beta$ intact, resulteerde toediening van oestrogeen in een verminderde hypertrofie (hoofdstuk 5). Oestrogeen bleek de toename van de massa van de linker kamerwand tegen te gaan. Op moleculair niveau bleek oestrogeen de toegenomen fosforylatie van p38-MAPK te blokkeren en ook in vivo de synthese van ANF te bevorderen. In BERKO muizen had oestrogeen toediening geen effect. Deze resultaten geven aan dat oestrogenen de remodellering van het muizenhart tegengaan en op deze manier het muizenhart beschermen via activatie van ER $\beta$. De ER $\alpha$ blijkt bij deze bescherming geen rol te spelen.

In hoofdstuk 6 worden de resultaten besproken die in deze muismodellen met MI bereikt zijn. Oestrogenen bleken de grootte van het infarctgebied te beperken in ERKO muizen maar niet in BERKO muizen, hetgeen opnieuw aangeeft dat de ER $\beta$ de receptor is die de gunstige effecten van oestrogenen op het hart bepaal. De verminderde grootte van het myocardinfaret bleek echter samen te gaan met een verhoogde sterfte in deze muizen. In BERKO muizen werden tegengestelde effecten gevonden. In deze muizen was het infarctgebied vergroot maar bleek de sterfte onder de dieren verminderd. Deze resultaten wijzen er wederom op dat ER $\beta$ de gunstige receptor is, die belangrijk is voor de effecten van oestrogenen op het hart.

Concluderend kan gesteld worden dat deze studie laat zien dat het hart op veranderende omstandigheden reageert door adaptatie. Voor TAC is dat een vergroting van de hartspier in linkerkamerwand en voor MI een begrenzing van infarct gebied gevolgd door remodelering. Oestrogenen gaan deze structurele aanpassingen tegen door te interfereren met de moleculaire mechanismen die deze aanpassingen in gang zetten. De werking van oestrogenen verloopt via de ERâ, terwijl een aantal van de nevenwerkingen toegeschreven kunnen worden aan ER $\alpha$. Dit betekent dat in de toekomst mogelijkheden ontstaan om binnen de cardiologie het gebruik van oestrogenen meer gericht aan te wenden, door bv modificatie van deze steroiden waardoor ze specifiek een interactie aangaan met ER $\beta$. 


\section{Acknowledgements}

After four years of hard work I finalized my thesis. Not all the work of four years is reported in this book. Some experiments were not successful and some others were not reproducible. During the study period I encountered many complicated situations and life crises. With help of many colleagues and friends I was able to find my way. Many individuals contributed to the successful end of this project through their direct or indirect efforts. I would like to thank all the people who helped me during the entire project period till the final step of my work and writing my thesis. With the risk of forgetting some people I would like to mention some people by name.

I am indebted to my promoter, prof. Dr. Pieter A. Doevendans, who first selected ne as a PhD student after four years of suffering, looking for financial support for my career. He has influenced my whole life by helping me to settle safely in the Netherlands, solving all my problems including even the personal ones and bring peace to my soul again. When I came to Maastricht University my knowledge of cardiology and molecular biology was rather limited. He taught and guided me step by step till I gained confidence to do my research. He has given me an unlimited support despite his time constraints, combining clinical and research work. I benefited a lot from his ideas, suggestions, comments, and high confidence. I will never forget his encouragements, suggestions and criticism.

Dr. Guillaume van Eys, my co-promoter, who assigned me a place in his lab to finish my study, when the rest of the molecular cardiology group moved to the University of Utrecht. I thank him for his honest guidance and encouragement. I benefited greatly from his knowledge and enjoyed a lot the scientific discussions which we used to have in our weekly meetings at his room. He has shown a lot of patience and dedication despite his overloaded schedule. I will never forget his kindness, helpful suggestions as well as his humor.

Dr. Christian Grohe, my co-promoter, who used to be very inventive but also critical. He taught me many things including the patience and positive thinking. I would like to pass my deep gratitude to my colleagues Dr. Daniel Joseph Lips, Els Delvaux and Rutger. Hassink who did a great job during the animal sugery. Dr. Leon de Windt and Dr. Martin van Eickels contributions are really appreciated. Special thanks to Prof. Wellens for sparing some of his very valuable time for correcting and evaluating this work.

Prof. Dr. Harry Crijns the head of the Department of Cardiology, University of Maastricht for his invaluable help. Thanks Prof. for being very honest to me and give me encouraging remarks and advice. Thanks are also extended to Dr. Martin Smit, Dr. Jan A. Gossen and Dr. Pieter Zandberg from Organon NV. Through them I would like to thank Organon for providing the animals for this study. They have been also so kind to make a place for us in their laboratory and they were available at any time for help and assistance.

I would like to thank my colleagues at different departments of Maastricht University. In Physiology Department I would like to thank Peter Willemsen for being very kind to me and for his continuous help and assistance. Theo van der Nagel for his help and support, andries Gilde, Martijn Lindhout, Henny Schulten for being very friendly and helpfull. In addition to these colleagues I would like to pass my thanks to the whole Department of Physiology. At the Department of Cardiology, Chiel de Thije, Denny Sonnemans, Bianca Schrans, Alexandra Buehler, Blanche Schroen, Rik van Leeuwen, Sarah Pokharel, Mark Schelling and Ruddy Duisters for their cooperation.

At the Department of Molecular Genetics, Sander Rensen, Bianca van den Bosch, Petra Niessen, Erika Timmer, Rob Janssen, Patrick van Gorp and Monique Vergouwe for their technical help. At the Department of Pharmacology, Jacques Debets, Tijl de Celle, Agniska Brouns, Pieter Leenders and Nicole Bitsch for their help and guidance in the animal surgery.

I would like to convey my gratitude to my friends who never stop giving their moral support till I finish writing this thesis, Saad Eddin Abdaghani and his wife Hana Hashim, Amir and his wife Rihab, Rashid Abusin and his wife Somia Abdulrahim, Dr. Mohamed Mukhaier and his wife Dr. 
Aziza Mukhaier. Mohammed Alhafiz Almukashfi and his wife Hagir, Mutasim Mekki Medani and his wife Manal, Khalid Muhyeddin and his wife Hanan, Mohamed Ali Almelik AND his wife Intisar, Osman Gailani and his wife Awatif, Abdelkadir Awad (Gudura), Bashir Ali Mahdi and his wife Huda, Rasha Ali Mahdi and abudurahim Ali Mahdi. I would like to pass my thanks to Dr. Bashir Rezk Dr. Khalid Habani and Dr. Rayed for their moral help.

Last but not least I would like to pass my sincere gratitude and love to my wife Hala Mohamed Alamin. In her I don't have only a wife, she is my best friend, my sister and in most cases my mother. Thanks a lot for your patience and sacrifice. Forgive me for the pain I caused to you leaving you several days and nights suffering with our kids needs. Our children Mohamed and Ahmed, thanks a lot in making me laugh even at the very darkest moments. Thanks for being my key to the social relations and forcing me to visit our friends, neighbors and land mates. My mother Alhaga Bint Eltyeb, thanks for your patience and prayers. Thanks for your continuous encourage, pushing and efforts that make me feel my presence as Fawzi. Thanks to my uncles Prof. Abdelgabar Eltyeb and Dr. Abdelrhman Eltyeb who I took as my example in life. Thanks for asking about me and giving their advice and encouragement. 


\section{Curriculum Vitae}

The author of this thesis, Fawzi Abdalla Babiker, was born January $1^{\text {st }}$, 1964, Elzaidab, Sudan. He had his primary and secondary school education at Elzaidab and high school education at Eddamer and Wad Medani. Subsequently he started his academic career at the Faculty of Science, University of Khartoum. He obtained the University of Khartoum prize and graduated with BSc (Honours) from the Department of Zoology, University of Khartoum, Khartoum, Sudan 1987. 1987-1989 he worked as crops protection officer at the Central Trading Company, Wad Medani. 1989 he was appointed as teaching assistant at the Department of Zoology, College of Natural Resources and Environmental Engineering, University of Juba, Sudan. He obtained post graduate diploma in Environmental Science and Technology from the International Institute for Infra Structural Hydraulics and Environmental Engineering, Delft, the Netherlands 1991. 1993 he was appointed as registrar, Faculty of Science, University of Alneelain, Khartoum, Sudan. 1996 he obtained his MSc in Environmental Science and Technology from the International Institute for Infra Structural Hydraulics and Environmental Engineering, Delft, the Netherlands. After obtaining his master he developed an interest in the field of molecular biology. From 2000 he filled a position as $\mathrm{PhD}$ student in the group of Prof P. A. Doevendans working in molecular cardiology at the Department of Cardiology, Cardiovascular Research Institute (CARIM), University of Maastricht, Maastricht, the Netherlands.

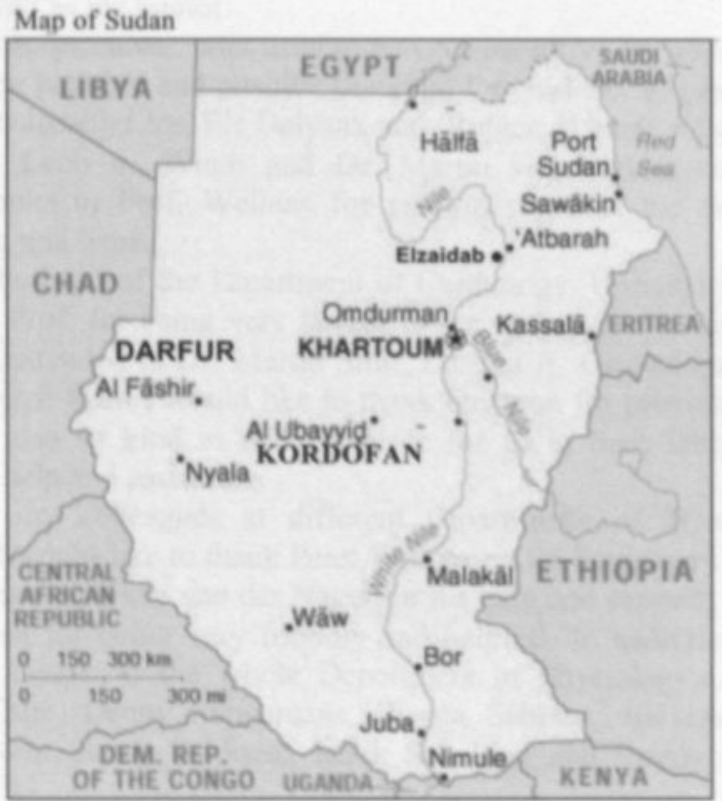



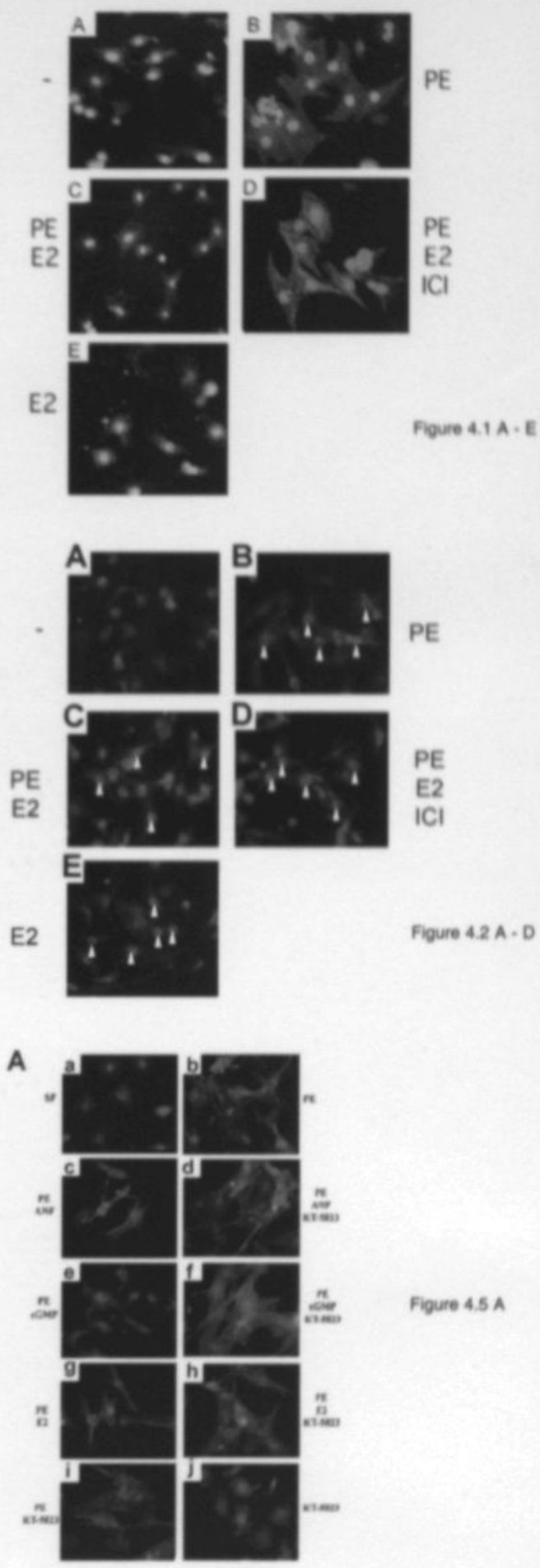

Figure $4.5 \mathrm{~A}$

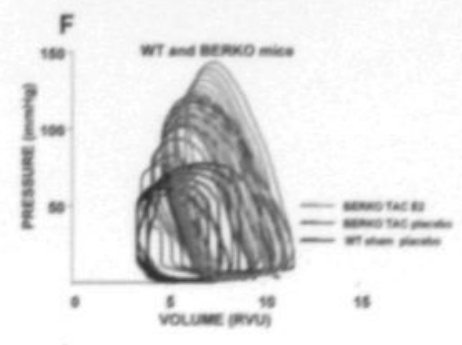




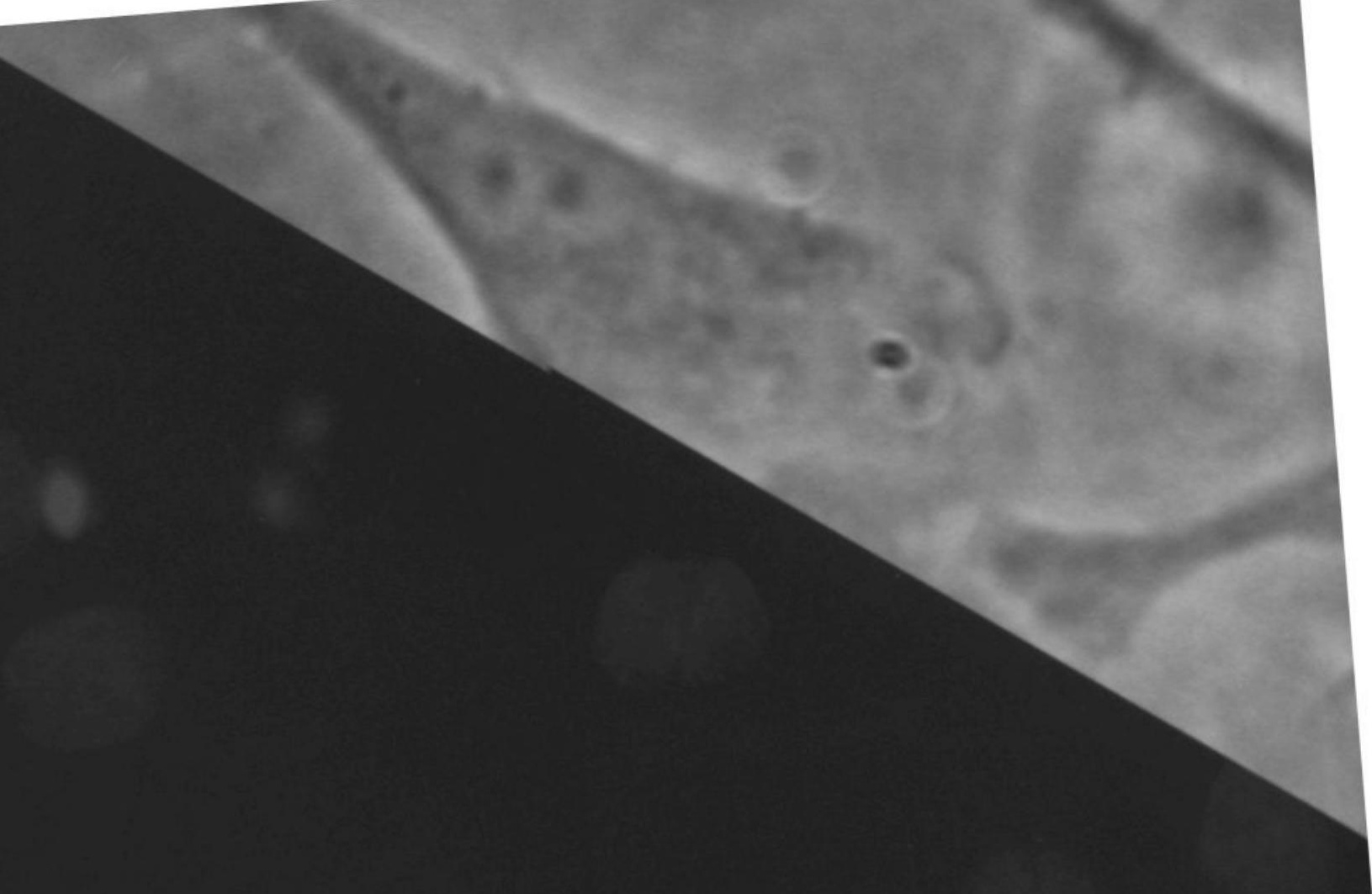

